\author{
UNIVERSITY OF BELGRADE \\ FACULTHY OF PHYSICS \\ INSTITUTE OF METEOROLOGY
}

M.Sc. Abdulla A.Y. Al Mandoos

\title{
ANALYSIS OF THE CUMULONIMBUS CLOUDS CHARACTERISTICS AND THE EFFICIENCY OF THE PRECIPITATION ENHANCEMENT OVER THE EASTERN AREA OF THE UAE
}

Doctoral Dissertation

Belgrade, 2012 


\author{
UNIVERZITET U BEOGRADU \\ FIZIČKI FAKULTET \\ INSTITUT ZA METEOROLOGIJU
}

\author{
Mr Abdulla A.Y. Al Mandoos
}

\title{
ANALIZA KARAKTERISTIKA KUMULONIMBUSNIH OBLAKA I EFIKASNOSTI STIMULISANJA PADAVINA IZNAD ISTOČNIH OBLASTI UAE
}

Doktorska disertacija

Beograd, 2012 
Mentor

Dr. Mladjen Ćurić, full prof. University of Belgrade,

Faculty of Physics, Belgrade

\section{Commission:}

1. Dr. Mladjen Ćurić, full prof. University of Belgrade, Faculty of Physics, Belgrade

2. Dr. Dejan Janc, assoc. prof. University of Belgrade, Faculty of Physics, Belgrade

3. Dr. Nevena Petrović, assoc. prof. University of Belgrade, Agricultural Faculty, Belgrade

Date of defence: 


\section{Mentor}

dr Mlađen Ćurić, red. prof.

Univerzitet u Beogradu,

Fizički fakultet, Beograd

\section{Članovi komisije:}

1. dr Mlađen Ćurić, red. prof. Univerzitet u Beogradu,

Fizički fakultet, Beograd

2. dr Dejan Janc, van. prof. Univerzitet u Beogradu, Fizički fakultet, Beograd

3. dr Nevena Petrović, van. prof.

Univerzitet u Beogradu,

Poljoprivredni fakultet, Beograd

\section{Datum odbrane:}




\title{
Analysis of the cumulonimbus clouds characteristics and the efficiency of the precipitation enhancement over the eastern area of the UAE
}

\begin{abstract}
The water resource community in the United Arab Emirates (UAE) has had a growing concern about the sustainability of its fresh groundwater resources over longer than the last two decades. In order to enhance precipitation the concept of cloud-seeding is to seed with appropriate cloud condensation nuclei $(\mathrm{CCN})$ or ice nuclei $(\mathrm{IN})$ to either make precipitation develop or more efficiently. A major effort during realization of this research was the development of an infrastructure: a networks of radars and automatic weather stations, an instrumented aircraft with trace gas, aerosol and cloud microphysical instrumentation to determine the background aerosol characteristics of the region and their influence on cloud and precipitation processes. A significant part was intensive collection of observational data including aircraft, radar, surface measurements and satellite.

Measurements of $\mathrm{CCN}$ showed that background levels were enhanced due to local pollution sources in the region, which resulted in higher cloud droplet concentrations in clouds, making them more continental in nature. The polluted background particles generally work to suppress precipitation development. When desert dust exists in conjunction with sulfates, the dust particles become coated with sulfate, making them more active as cloud condensation nuclei. When the general weather conditions where not favorable for development of strong convection the convective clouds are developed, mainly inland, along the coast line and some on the western slopes of Oman mountain. The most favorable local conditions for cloud development occur on the sunlight side of Oman mountain. Cb clouds also develop on the front side of the sea-breeze circulation. The sea-breeze circulation was the trigger mechanism for many $\mathrm{Cb}$ clouds.

The accumulated precipitation of convective clouds are obtained by using two methods of measurements, with rain gauges and by radars. The high discrepancies in the precipitation amount are found because the precipitation data taken from rain gauge network is poorly depicted due to the limited resolution and that the radar measurements highly overestimate the rain gauge data due to evaporation of precipitation from the level of radar measurement to the ground. The results of analysis of precipitation from two methodology of measurement give sufficient confidence to conclude that both, rain gauge and radar data are needed for better reproduction of the areal accumulated convective precipitation over a small area during convective precipitation events
\end{abstract}

Keywords: Storms; Cloud condensation nuclei; Accumulated convective precipitation; Microphysical instrumentation; Radar measurement; Cloud lifetime, Cloud displacement.

Research field: Meteorology

Subfield: Cloud Physics

UDC:551.576.1(043.3) 


\section{Analiza karakteristika kumulonimbusnih oblaka i efikasnosti stimulisanja padavina iznad istočnih oblasti UAE}

\section{Rezime}

Snadbevanje vodom u Ujedinjenim Arapskim Emiratima postaje vrlo veliki problem duže od dve decenije. Da bi se delimično ublažila nestašica preduzete su mere da se izuči da li postoje prirodni uslovi da se povećavaju padavine zasejavanjem oblaka sa kondenzacionim i ledenim jezgrima. Tokom realizacije ovog istraživanja posebna pažnja je posvećena razvoju infrastrukture, naročito mreže radara, mreže automatskih meteoroloških stanica, opremanju aviona sa instrumentima za merenje gasova, aerosola i mikrofizičkih karakteristika oblaka i padavina. Značajan deo posla je bilo intenzivno prikupljanje podataka dobijenih letilicama, radarima, površinskim merenjima i i satelitima.

Merenja kondenzacionih čestica su pokazala da je osnovni nivo sadržaja povećan zbog lokalnih izvora zagađenja u regionu, što je rezultiralo većim koncentracijama oblačnih kapljica, što ih čini više kontinentalninim. Kada postoji pustinjska prašina (koja je neaktivna za kondenzaciju) i sulfati iz izvora zagađenja, tada se čestice peska oblažu sa slojem sulfata, tako da postaju aktivne čestice kondenzacije. Ovo je posebno važno u regionu UAE u kojem postoje oba izvora, koji imaju uticaj na procese stvaranja oblaka i padavina. Kada opšti vremenski uslovi nisu povoljni za razvoj jake konvekcije, konvektivni oblaci se razvijaju uglavnom u unutrašnjosti, duž obale, a neki na zapadnim padinama Omanskih planina. Najpovoljniji uslovi za lokalni razvoj oblaka su na zapadnoj strani Omanskih planina. Cb oblaci se takođe razvijaju na prednjoj strani fronta cirkulacije more-kopno. Ova cirkulacija je bila okidač za razvoj mnogih $\mathrm{Cb}$ oblaka. Ove oluje se premeštaju u unutrašnjost u pravcu u kome se proširuje cirkulacija more-kopno.

Akumulirane padavina iz konvektivnih oblaka su dobijene korišćenjem dva metoda merenja, sa kišomerima i radarima. Uočavaju se velike razlike u količini padavina. One nastaju zbog toga što padavine uzete iz mreže kišomernih stanica daju lošu sliku zbog ograničenog broja mernih mesta, i što radarska merenja mnogo precenjuju količine padavina usled isparavanja padavina od nivoa radarskog merenja do tla. Rezultati analize padavina dobijenih sa dve metodologije merenja omogućili su da se zaključi da su obe vrste podataka potrebne za što bolje saznanje o stvarno akumuliranim padavinama na tlu. Ovo je naročito potrebno za različite klimatološke i hidrološke analize i prognoze, kao i za aktivnosti vezane za veštačko povećanje padavina.

Ključne reči: Oluje; Kondenzaciona jezgra; Akumulirane konvektivne padavine; Mikrofizička merenja; Radarska merenja; Život oblaka; Premeštanje oblaka.

Naučna oblast: Meteorologija

Uža naučna oblast: Fizika oblaka

UDK:551.576.1(043.3) 


\section{Contents}

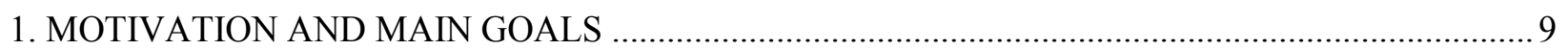

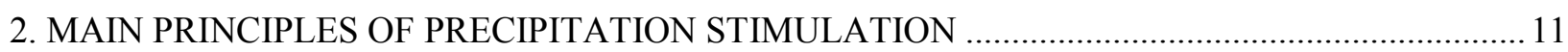

3. SUMMARY OF THE PROJECTS OF PRECIPITATION STIMULATION IN THE WORLD ........... 14

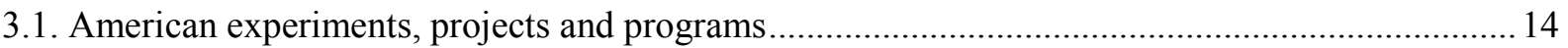

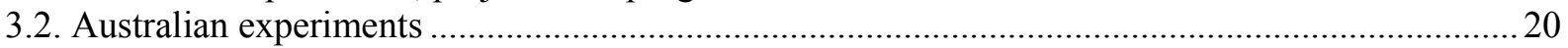

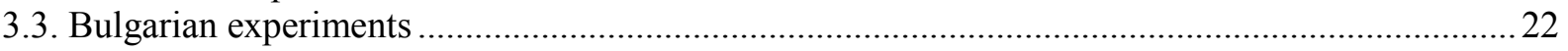

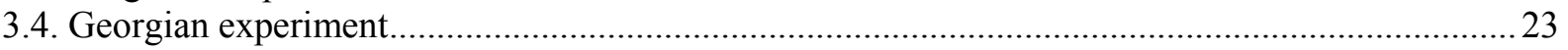

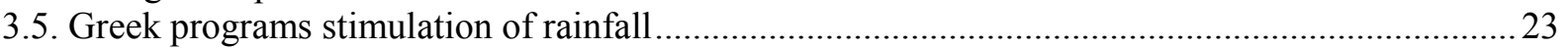

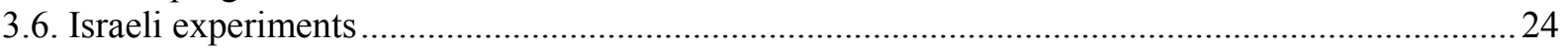

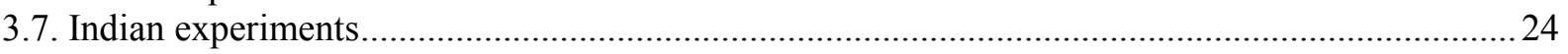

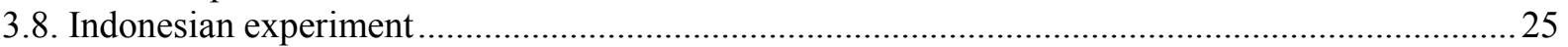

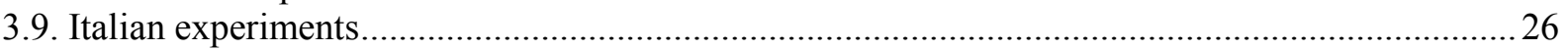

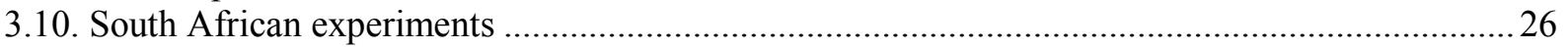

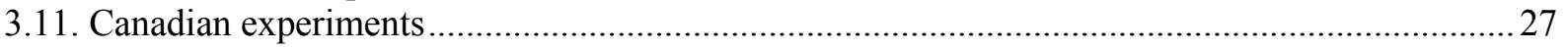

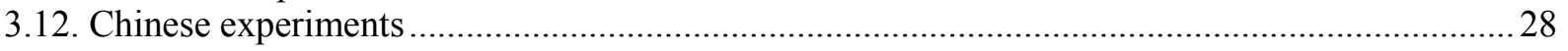

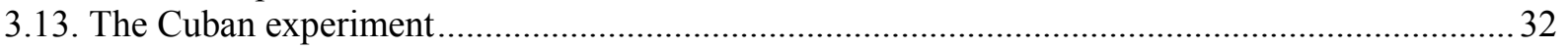

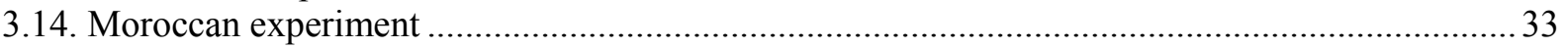

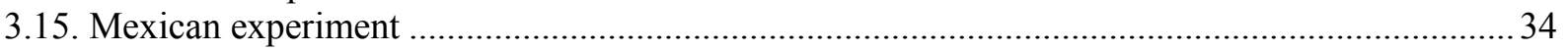

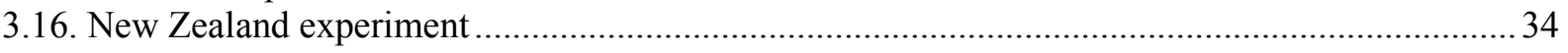

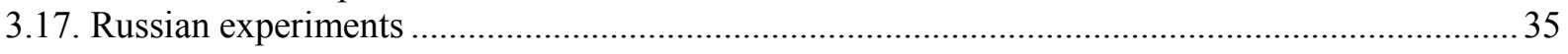

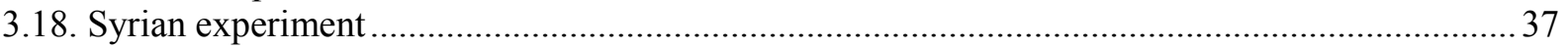

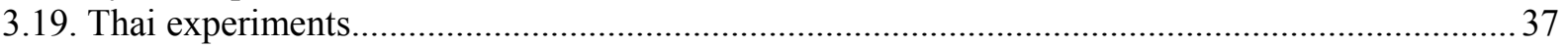

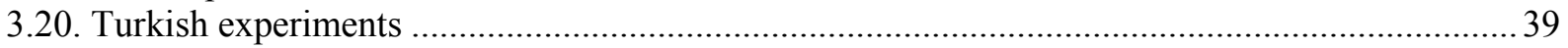

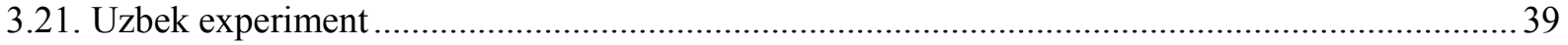

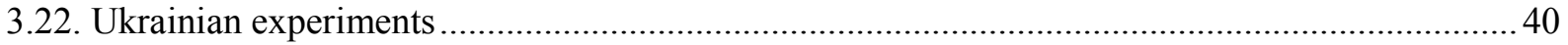

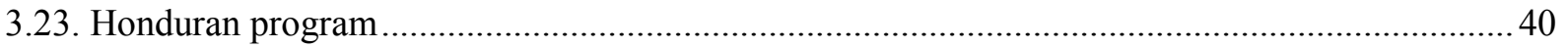

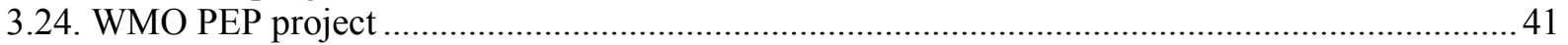

3.25. Japanese Cloud Seeding Experiments for Precipitation Augmentation (JCSEPA) ..................... 42

3.26. Investigation of AgI Seeding Efficiency in Saudi Arabia........................................................... 43

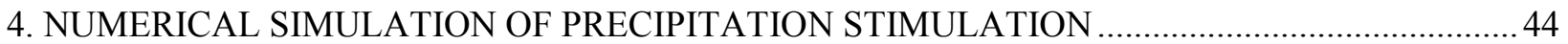

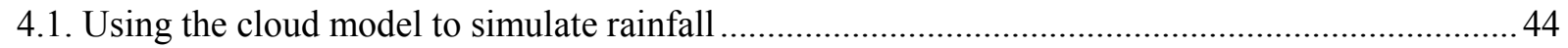

4.2. Numerical simulation of rainfall stimulation from convective clouds......................................... 45

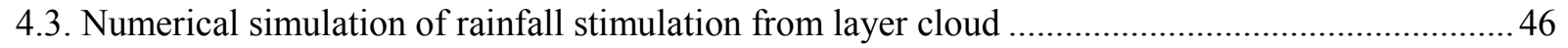

4.4. Numerical simulation of rainfall stimulation from frontal cloud.............................................. 47

4.5. Numerical simulation of rainfall stimulation from orographic cloud .......................................... 47

5. GENERAL WEATHER CONDITIONS DURING Cb CLOUDS DEVELOPMENT IN UAE ............ 49

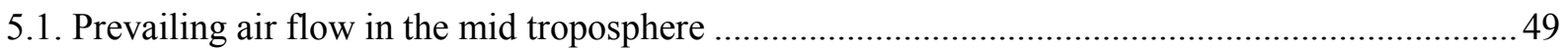

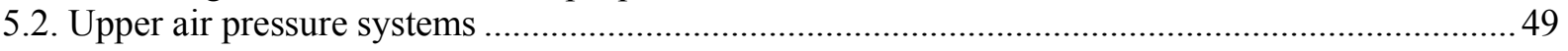

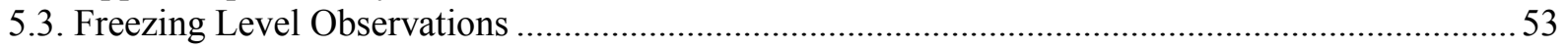

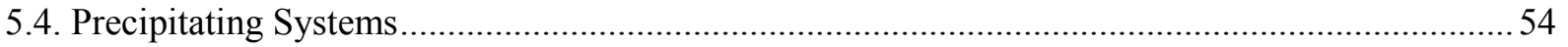

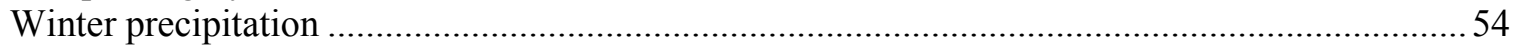

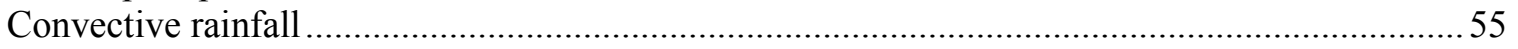

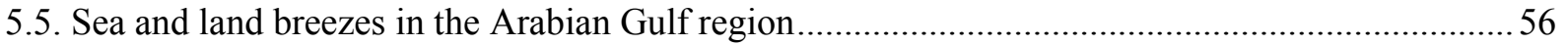

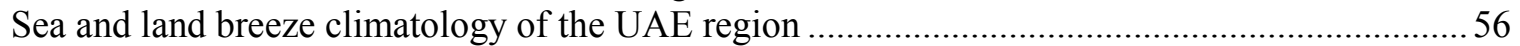

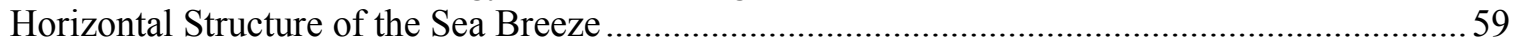

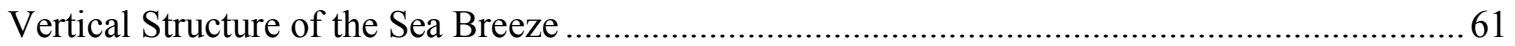




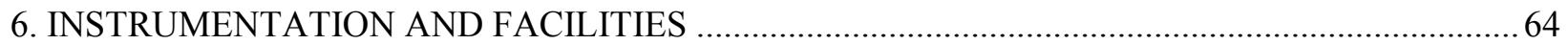

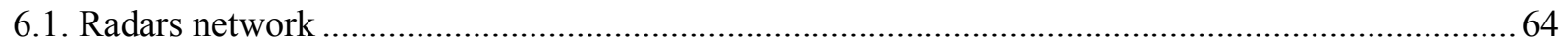

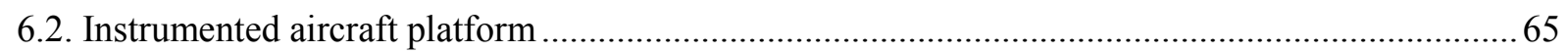

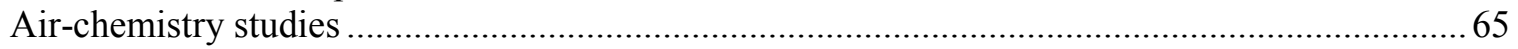

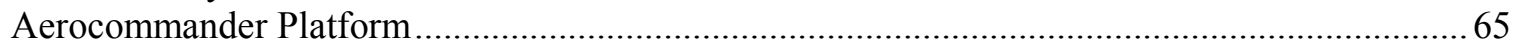

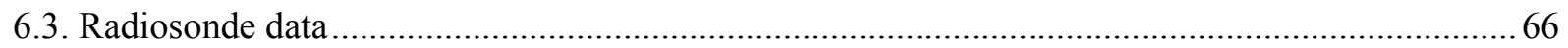

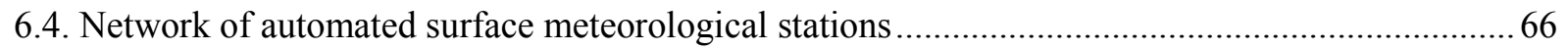

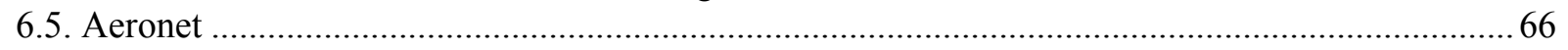

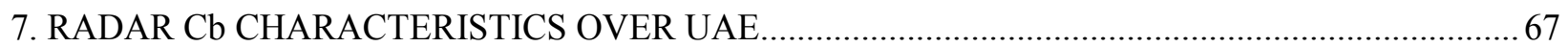

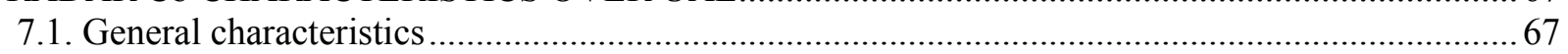

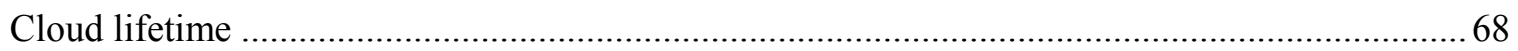

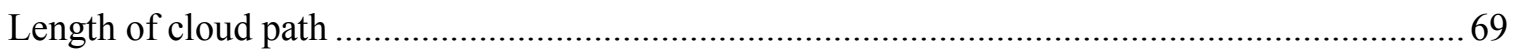

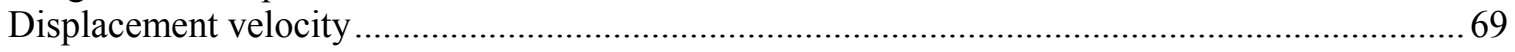

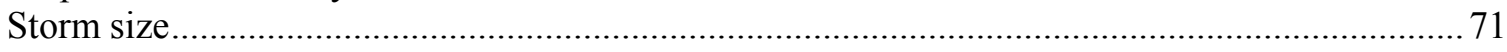

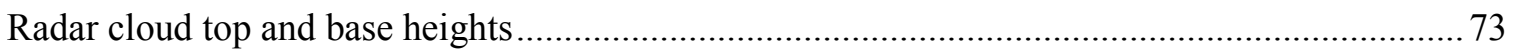

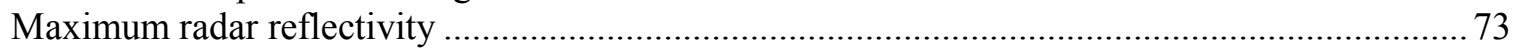

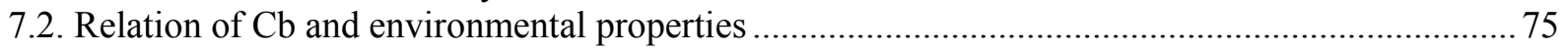

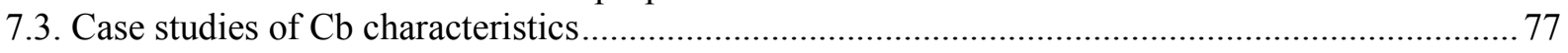

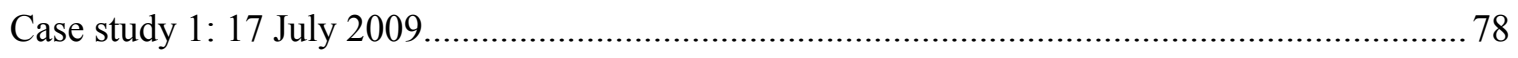

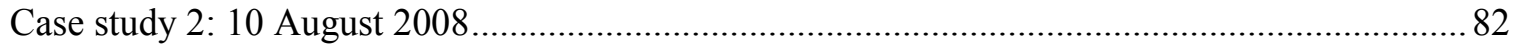

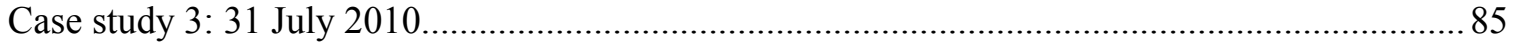

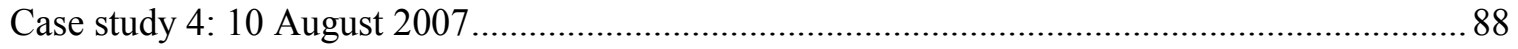

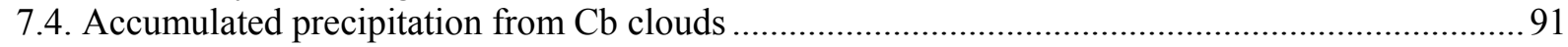

8. RELATION OF NATURAL AEROSOLS AND

PRECIPITATION DEVELOPMENT: IMPLICATIONS FOR CLOUD SEEDING …....................... 94

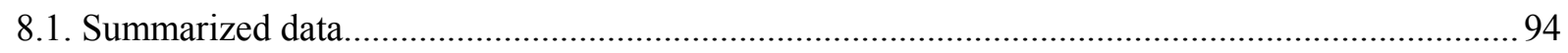

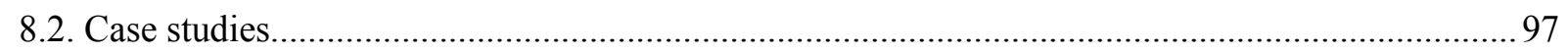

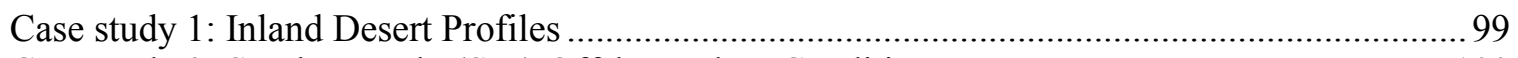

Case study 2: Southwesterly (SW) Offshore Flow Conditions............................................... 100

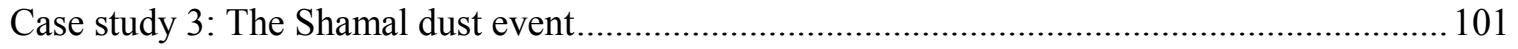

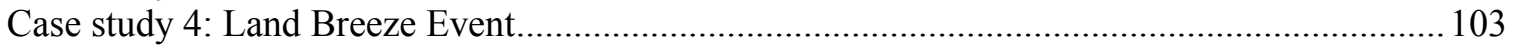

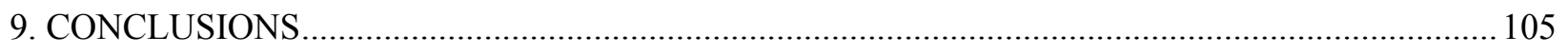

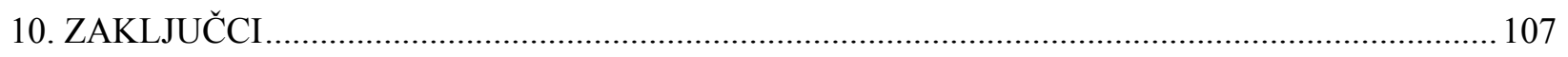

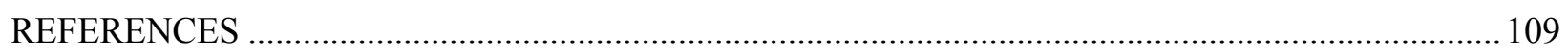




\section{MOTIVATION AND MAIN GOALS}

The water resource community in the United Arab Emirates (UAE) has had a growing concern about the sustainability of its fresh groundwater resources since ground water levels and well yields in many locations have declined substantially over longer than the last two decades. Simultaneously, the search for new groundwater resources has met with only marginal success. Currently, the majority of freshwater for municipal and industrial demand in the UAE is derived from the desalinization of seawater, a relatively expensive and somewhat vulnerable approach to deriving freshwater for socio-economic development.

The UAE is located in the subtropical desert climate zone. The winters are historically the wet season in the UAE. The summers are characterized by heat waves and sandstorms often associated with convective outbreaks. Thunderstorms occur frequently over the mountainous area along the eastern border with Oman and less often over the south-western parts of the UAE.

In order to enhance precipitation the concept of cloud-seeding is to seed with appropriate cloud condensation nuclei $(\mathrm{CCN})$ or ice nuclei (IN) to either make precipitation develop or more efficiently. Precipitation augmentation in the United Arab Emirates confronts difficult meteorological conditions considering that clouds develop over a dry mountain region and that rain evaporates below the cloud and from the ground. This situation presents tremendous scientific and technical challenges which are typical for desert regions. A sound basis for a new experiment has been established by adopting the best elements of the successful cloud seeding experiments in the world.

The UAE project goes beyond established top standards. It also addresses the role of the weather active aerosol (CCN) which ultimately determines the evolution of the clouds and the precipitation they contain. This adds a new dimension which will have profound effects on the physical understanding of rain forming clouds that had never been considered before.

By recognizing the importance of the aerosol background for determining cloud characteristics, the UAE project established an extensive network of measurement sites for monitoring aerosol properties.

By networking data from meteorological observations, weather radars, aerosol sites and more, a detailed set of meteorological data are achieved. The results of this thesis are based on these data. We analyzed the summer Cumulonimbus clouds: Their specific development in presence of strong temperature inversion, motion in the specific environmental conditions, production of precipitation in presence of desert dust and possibilities of the modification of natural precipitation process. 
The main attempt is to understand cloud seeding with hygroscopic flares against the background of varying natural aerosol concentrations in the atmosphere. In addition, the program of research is strongly based on the using of the data from technologically very sophisticated infrastructure.

Another innovative and important component is the additional knowledge and understanding of the climatology of these processes in this region. The program showed the importance of summer rainfall in the UAE that was not known before in the climatological records.

Emissions into the atmosphere in the United Arab Emirates were thought to be mostly aeolian desert dust, often termed mineral dust, that are considered to be inefficient cloud condensation nuclei. The data presented in this thesis to study the distribution of atmospheric pollutants and their effects on clouds in the UAE were collected using airborne measurements, obtained from the aircraft during the summer.

Some of the specific scientific objectives of this dissertation are:

- Determine conditions and locations favorable for convective cloud development and document subsequent evolution of convective clouds;

- Characterize the convective storm development under influence of surface and boundary layer nonuniformities, such as sea-breeze and heated mountain regimes;

- Characterize the CCN spectrum and its variability over the range of these convective conditions;

- Determine the severity of storm concerned with its precipitation production. 


\section{2}

\section{MAIN PRINCIPLES OF PRECIPITATION STIMULATION}

The first hint of the possibility of producing rain artificially gave Louis Guttmann 1891 in Chicago (JWM, 1989). He said that the rain can be produced just by cooling the upper layers of the atmosphere enough to condense water vapor. The broader view is expressed Napier Shaw 1921, saying that there are different methods for the production of rain, including electrical methods, throwing sand into the atmosphere, explosions, etc. Canadian pilot Cole suggested that the rain can be produced by injection of liquid air from the aircraft in the form of spray. Sporadic tests of some methods have shown that they can produce condensation of water vapor in the atmosphere, but most of the droplets are evaporated during the fall and have not reached to the ground.

Scientific basis for the precipitation enhancement can be based on two principles (Ćurć, 2001). First one is that the energy that drives the processes in the atmosphere confront with the same artificially produced energy, and the second is to use the unstable state of the atmosphere, where a small intervention can achieve a great effect.

Looking the atmosphere as a part of the geophysical system, in energy terms it represents an enormous heat engine. A smaller part of a thermal energy that comes from the Sun is absorbed during passes through the atmosphere and main part come to the Earth's surface heating continents and oceans. This causes heating of the lower layers of the atmosphere and especially the intense evaporation from the ocean surface, which transfers enormous heat in the atmosphere in the form of latent heat. Due to differences in the amount of heat energy that the atmosphere in this way receives at different latitudes and over land and sea, the atmosphere is establishing a system of general atmospheric circulation. Through this system of circulation is established various winds such as the trade winds, antitrade, the western winds and eastern winds in certain geographical zones, then the formation and motion of different air masses, water vapor transport and so on. Solar thermal energy which the atmosphere and the Earth's surface receive by shortwave radiation, this system looses by long-wave radiation into space. Thus, the atmosphere and Earth's surface are in thermal equilibrium in the long period of time.

The energy that comes from the Sun and influence on the Earth's atmosphere motion is such that the energy produced by main can be almost ignored. In other words, when all sources of energy which main produce, including thermonuclear weapons, would be activated at once it would be equal with the amount of energy that earth receives from the Sun in the short period of time. Even the local short time-scale processes, such as local winds, then a smaller cyclones or even local storms, have so much energy that people can neither produce or prevented. Therefore, 
artificial influence on the weather can not be based on bringing or taking away energy to the natural processes, but in an entirely different principle.

The principle upon which the artificial influence on the weather can be conducted is the use of certain instability in the weather conditions in which a small intervention can achieve great effects in the development of weather phenomena. Such an unstable situation occurs in the clouds at various phase transitions of water vapor. Namely, the condensation and crystallization processes in the atmosphere saturated with vapor are still need condensation or crystallization nuclei. In an atmosphere where these processes take place usually there are not enough of these nuclei or they are inactive. So, it often happens that in air saturated with water vapor condensation fails or is slow, and supercooled cloud droplets do not freeze.

Scientific basis for an artificial influence on the weather, and thus to stimulate rainfall, resulted from the research project entitled: "Cirrus Project", which were carried out 1946th and 1947th in the General Electric Research Laboratory, Schenectady, NY, USA. The main objective of this project was to study the process of capture of ice on airplanes during flight through storm cloud. The realization of this research project involved scientists: Langmur, Schaeffer and Vonegut. The main results obtained in this study were presented in a series of papers contained in the first summary report, "First Quarterly Progress Report" (1947) and work (Vonnegut, 1947. The first finding was that in many clouds exist superscooled drops. A touch of such drops with a solid object leads to their icing. So, when the plane flight through the zone of supercooled storm the supercooled drops catches on the surface as ice. Another important finding was that by inserting a specific reagent in the cloud can cause icing of supercooled drops.

After a certain laboratory studies, Vincent Schaefer on 13 November 1946, was first performed an experiment in nature. He threw about $1.5 \mathrm{~kg}$ of granulated dry ice (solid $\mathrm{SO}_{2}$ ) from the light aircraft in stratocumulus clouds near the Berkshir mountains in the west state of Massachusetts. For approximately 5 minutes from the clouds began to fall the snow flakes, which have plunged to about $600 \mathrm{~m}$ in height, and then in a lower layer of dry and warmer air to melt and evaporate. This date may be considered early science-based artificial effect on weather, or as the world's commonly called, the modification of weather.

The essence Scheffer's experiment consisted in the fact that granules of dry ice on its surface have a very low temperature $\left(-70^{\circ} \mathrm{C}\right)$, and their evaporation into the atmosphere in the vicinity of the air lowers the temperature to $-40^{\circ} \mathrm{C}$. At such temperatures all the water droplets freeze and water vapor turns into ice crystals through the sublimation.

Shortly after this very successful Scheffer's experiment, Vonegut (1947) with several other scientists continued to find out other types of artificial crystallization nuclei. They found that there are a large number of artificial crystallization nuclei, which can cause a similar effect as dry ice. It is shown that the most effective is silver iodide (AgI).

These successful experiments have prompted numerous studies and practical applications in many countries. Already 1950th in the United States were founded many companies for cloud seeding activities which covered about $10 \%$ of U.S. land area (Dennis, 1980). However, it was soon realized that it is a very important and economically promising area, but to achieve these objectives has lacked many of the findings.

The most serious scientific approach to the problem at that time was in the former USSR. There was established more specific institute whose first task was to determine the actual 
effect of cloud seeding. One of the foremost scholars in the area was Academician Fedorov, who found the effect of granulated dry ice in the cloud. In his account comes to entering the $200 \mathrm{~g}$ of $\mathrm{SO}_{2}$ in cold clouds convert from liquid to solid, about 1000 tons of water and released at about $4.1011 \mathrm{~J}$ of latent heat. Such a large effect is achieved by creating a huge number of ice crystals by evaporation of small amounts of reagents. Thus, according Nikandrova (1959), depending on the temperature of the cloud in which is entered, during the evaporation of reagent $1 \mathrm{~g}$ of solid $\mathrm{SO}_{2}$ formed $10^{14}$ to $5 \times 10^{11}$ ice crystals. During the evaporation of $1 \mathrm{~g}$ of silver iodide is formed until $10^{13}$ to $3.2 \times 10^{12}$ ice crystals.

During the 1950s, had been found hundreds of reagents for the processes of crystallization and condensation in the clouds. For the precipitation enhancement is important to mention the results of Ludlam, 1955. He found in the laboratory that the particles of salt weighing 10-19 g lead to the formation of droplets of diameter 30- $\mathrm{m}$ during of a few seconds This process takes place so that the hygroscopic particles by inserting into the cloud produces intense condensation. After a sufficient increase in droplet diameter formed on hygroscopic substances, their further growth is prolonged by colliding with smaller droplets. According to this method the stimulation of rainfall is based on the principle changes of the microstructure of clouds by artificial means.

Based on the above mentioned facts it can be concluded that the characteristics of artificial hygroscopic nuclei and nuclei of crystallization, which can effectively change the natural microstructure of clouds, are sufficiently known and practically applicable. However, their actual efficiency depends on several factors. The most important are: 1) type of cloud, 2) cloud dynamics and 3) the general state of the atmosphere.

Type of cloud droplet spectrum reflects the structure of which we want to change. The dynamics of the clouds, together with the turbulence generated, enables delivery of reagents in the clouds and changing cloud microstructure. The general condition of the atmosphere reflects the static stability, vertical and horizontal velocity shear and air flow, humidity and temperature stratification of the atmosphere. All these factors significantly limit or encourage the efficiency of artificial nuclei condensation and crystallization in a place where seeding is done. The desired results can be achieved only when all these factors take into account. 


\section{SUMMARY OF THE PROJECTS OF PRECIPITATION STIMULATION IN THE WORLD}

\subsection{American experiments, projects and programs}

Under the applicable law in the United States all the activities carried out in the field of weather modification are obliged to apply the Ministry of Commerce. The Ministry submitted the reports to the National Administration for Oceans and Atmosphere (NOOA) for processing and storage. Reports shall be submitted no later than 10 days before the start of activities, each year of the activities and final report no later than 45 days after the completion of activities. Here we will briefly present some important experiments, projects and programs that weather modification is carried out in past years in the United States.

\section{HIPLEX program}

In the period 1975 - 1980 the State of Texas and Oklahoma, in cooperation with the Bureau of melioration was carried out HIPLEKS (High Plains Cooperative Experiment) program. This experiment was performed on an area of $150 \mathrm{~km}^{2}$. His aim was to assess the validity of the set of physical hypotheses of cloud seeding, and the validity of statistical hypotheses that are evaluated results of seeding. Studies were performed on small multicell convective cloud systems. It is shown that these systems have substantial amounts of supercooled water and that their seeding leading to strong dynamic effects. This experiment confirmed both the above hypotheses. (Jurica and Scro, 1985; Jurica and Pani, 1985).

\section{PACE experiment}

During the summer 1986th is derived PACE (Precipitation Augmentation for Crops Experiment) project in Illinois. This experiment was aimed to show how increasing the amount of precipitation affects the crops in the central parts of the United States. It is seeded 19 convective clouds in the three experimental periods.

It was found that differences in weather conditions can greatly mask the results of seeding. It was also found that the height of the first radar image at the time of seeding has a major impact on its growth. Then, the larger the reflection at the time of seeding produces more increase of its size and intensity. 
On the other hand, the radar reflectivity of a longer period of existence will increase smaller and slower after seeding. The explosive growth of the radar reflectivity can be expected shortly after his appearance on the radar screen and to a height of about $6 \mathrm{~km}$. (Westcott, 1990).

\section{SCPP experiment}

Scope of the SCPP (Sierra Cooperative Pilot Project) was to examine the seeding winter orographic clouds. It has been carried out on the west side of Sierra Nevada in California. This experiment was performed in the period since 1976 to 1987. The experimental area is encompassed environmental Anburn places in California, and in performing this experiment are cooperating federal, state and local agencies led by the Bureau of reclamation.

All SCPP experiments were based on the hypothesis of static seeding, ie. the hypothesis that increase of rainfall may be attained if in some clouds bring artificial embryos. Although only a few cases in these experiments showed clear effects of seeding, most of them provided a valuable data set of observations, which indicate a process that takes place in the clouds during seeding. These observations have revealed the following:

1) The limited horizontal dispersion requires to repeat many times a given cloud seeding in order to seed his entire volume;

2) When AgI released in the cloud from the generator it is shown as effective as vertical curtains of ice crystals formed by using dry ice. Reagent $\mathrm{AgI}-\mathrm{NH}_{4} \mathrm{I}$ with the addition of perhlorid proved to be effective nucleant at a temperature of $-6^{\circ} \mathrm{C}$. Because the $\mathrm{AgI}$ is much easier to handle, and it is a lot efficient than dry ice, it is recommended to use it as a reagent for cloud seeding.

3) Because of the limited amount of liquid water in a supercooled cloud seeding effect is small. It is therefore expected that a plane seed about $50,000 \mathrm{~m}^{3}$ along the lines of seeding to increase rainfall in the treated area of $0.25 \mathrm{~mm} / \mathrm{h}$. (Dennis and Reznolds, 1989).

\section{LATE experiment}

Pacific Gas and Electric Company was organized the LATE (The Lake Almanor Tracer Experimet) conducted as an the long-term and non-randomized seeding experiment of orographic clouds in the area of Lake Almanor in the mountains of Sierra Nevada, northeastern California. Relatively pure silver iodide burns in acetone solution in the generator of the propane flames. Generators have been placed on high ground on the extended sites.

In this experiment the following processes are discussed regarding the incorporation of AgI in precipitation in the basin of Lake Almanor:

1) Functioning of AgI as an aerosol for contact freezing nuclei;

2) Functioning of $\mathrm{AgI}$ aerosol as a mechanism of rapid condensation - freezing mechanism and rapid formation of ice crystals at a temperature of $-6^{\circ} \mathrm{C}$.

From these experiments it was found:

1) AgI aerosol remains moist if air is saturated in respect to water and frees when it is raised at a sufficiently low temperature; 
2) $\mathrm{AgI}$ dehydrate in a dry aerosol and make nucleation at temperatures below $-20^{\circ} \mathrm{C}$;

3) AgI aerosol being collected by ice crystals or water droplets, which later joined the snowflake.

Tests have shown that in the days when was done seeding the most snow fell in the vicinity of the generator. The reason is that the greatest concentration of aerosols AgI. Also, AgI particles were found in the snow around the entire lake basin Almanon. It was further shown that the maximum efficiency is achieved if seeding generators located in the cloud and the air temperature of $-8^{\circ} \mathrm{C}$. (Chat et al., 1989).

\section{BLACK HILLS experiment}

Since 1963 to 1972 the School of Mines and Technology, South Dakota, performed a series of cloud seeding in the western Black Hills in Dakota. The aim of these experiments was to examine the effects of seeding on precipitation from summer convective clouds. The immediate cause of these experiments was the decrease in water levels in reservoirs in the Black Hills area from which to perform the irrigation of large agricultural areas and supply a number of settlements. The water level in most of the reservoir was lowered to below $50 \%$ of their capacity, and some even dropped to $10 \%$.

The analysis performed experiments showed that it is possible to increase the amount of natural rainfall by about $12 \%$. This increase is achieved by combining microphysics and dynamic effects. It is estimated that the convective clouds thick about $6 \mathrm{~km}$ are most suitable for seeding in order to increase the amount of summer rainfall. (Dennis, 1990).

\section{UTAH experiment}

Fundamental problem in the seeding of orographic clouds during the winter with $\mathrm{AgI}$ is to determine the required amount of $\mathrm{AgI}$ to be inserted into the atmosphere in the given weather conditions. It depends on several variables such as transport and dispersion of aerosols, ice crystals activation mechanism, the amount of supercooled droplets, the temperature at which are the particles AgI, and growth of ice particles on the nuclei AgI and its deposition Weather modification program, which aimed to clarify some of the above problems, led to a Utah 1991st In support of the Bureau of reclamation . More airline flights were made over the Central Plateau in Utah. They followed AgI propagation in the atmosphere and traces of emitted gas in order to determine the impact zone and the concentration of the reagent, which is released from ground generators mounted on the protruding points.

In this experiment used two methods to determine the concentration of $\mathrm{AgI}$ and number of ice nuclei at temperatures of clouds with the sampling plane. One method was used for measuring the concentration of gas tracing. The second method is based on observations of acoustic ice nucleus counter. Both methods are partly based on laboratory calibration of the simulation of clouds and AgI generator. The results obtained using these two methods were compared and showed that they correspond to samples taken in certain meteorological conditions. (Super and Holroyd, 1994). 


\section{CREST experiment}

The natural amount of water the Colorado River and its tributaries is fast becoming insufficient to meet the needs in the basin of this river and the areas that supply with water. This demand for water is directly related to the historic arid conditions in these areas and the inability to compensate for this lack in other ways. In the near future, it is estimated that in this area lack the multi-billion $\mathrm{m}^{3}$ of water per year. This lack of water will occur due to rapid population growth, irrigation, power generation, maintenance of watercourses due to the flora and fauna, recreation and others.

The only alternative to the lack of water is seeding clouds to be in this mountainous area of increased snow cover. To attain this, an experiment was conducted under the name of CREST (Enhanced Snowpack Colorado River Test). Preliminary studies and performed the experiments showed that the seeded orographic clouds can expect an increase in annual precipitation for at least $10 \%$. That would bring Colorado River basin is used by about 145 million dollars annually. In addition, such increase is especially significant economic impact, because the seeding procedures is relatively inexpensive and does not require large funds for the construction and maintenance of the system, as is the case with large dams and irrigation systems. (Lease, 1985).

\section{NDCMP program}

In North Dakota weather modification (stimulation of rainfall and hail) is being implemented since 1950. Newer program called NDCMP (North Dakota Cloud Modification Project) was introduced in 1980. The main tasks of this program were to investigate the effectiveness of the method of seeding if it is done by appropriate reagents delivered in the appropriate part of the cold clouds, experimental and numerical study of these processes, the introduction of new monitoring techniques to study trace gas transport, and dispersion of reagents in the clouds. Preliminary results of this study include the following three categories:

1) A better knowledge of transport and dispersion in convective clouds, especially when inserting the reagent in the cloud base and its extension to supercooled parts.

2) Examination of the activity of artificial ice nuclei (for comparison with results obtained in a cloud chamber) and to compare the efficiency of different reagents.

3) Better understanding of the process of mixing cloud mass with the surrounding atmosphere and their impact on the physical processes in clouds. al. (1989).

Preliminary results of these investigations are presented in the work of Smith et

\section{The project of the southern Sierra massif}

In the area of the southern Sierra massif since 1948 the three projects were carried out with cloud seeding. They include three river basins: Kings, Kern and Kanjeah. Each of these projects focused on seeding "cold clouds" during the winter months. At that time most of the cloud contains a supercooled droplets, in the liquid state at temperatures below $0^{\circ} \mathrm{C}$. Inserting microscopic particles of reagents, which are the nuclei of ice, forming ice crystals that grow at the expense of water vapor in the surrounding atmosphere, because the water vapor pressure over 
ice is lower than over water. After a sufficient increase of ice crystals are excreted from the clouds and fall to the ground as flakes of snow, or if melt like drops of rain.

The performance of the cloud seeding was based on analysis of annual flow of rivers and determining the amount of rainfall using radar reflectivity. Multiple regression showed that the average increase in flow in the range from 5.7\% to 17.4\%. Analysis of radar data supported these results and showed that the cloud seeding produced an increase in such parameters as the maximum intensity of reflectivity, the maximum height of reflectivity, the area affected by rainfall and the length of the drainage of rainfall. On the overall analysis showed very convindently that the seeded clouds flow in river flows for 50 -season project the amount of water increased by more than $5109 \mathrm{~m}^{3}$ (Surakul et al., 1989).

\section{Program modifications of the atmosphere in Arizona}

The goal of Arizona atmospheric modification is to assess the potential for increased snow by seeding clouds over the Mogollon Rim and of his environment. Also the goal is to analyze cloud seeding technology for the increase of the amount of winter precipitation from orographic clouds. Studies are focused on better understanding the natural processes that determine the spatial and temporal distribution of water in clouds and precipitation on the surface in the region. A combined approach of modeling and observations are taken to better understand these problems. Clark uses the NCAR three-dimensional cloud model to simulate the mesoscale wind clouds and precipitation in the area Mogollon Rim. A more detailed description of the program which was developed in 1995 is shown in the work Bruintjes and Betterton (1994).

\section{The project increased runoff from the Lake Orville}

Department of Water Resources California pursued the project 5-year randomized cloud seeding to increase runoff from Lake Oroville. This lake is the main reservoir for water supply of Northern California. The primary objective of this project was to demonstrate the physical and statistical analysis of the increase in snow cover in winter by seeding clouds with liquid propane.

In this study, emphasis is given to documenting the transport and dispersion of the tracer and seeding which produces ice crystals downwind of target areas. It is released sulforheksaflorid (SF6) at $22 \mathrm{~kg} / \mathrm{h}$ from two separate sites set higher. One of them was on top of the mountain ridge Sierra, and another $5 \mathrm{~km}$ west of it.

Measurements of SF6 emissions, which are carried from the air plain showed that this tracer is rarely found above $2700 \mathrm{~m}$ above sea level or $500 \mathrm{~m}$ above the height of which was released in atmosphere. Air plain measurements showed 35 curtain of seeded reagent in 4 separate days. Only in 11 of 35 curtains determined the effect of seeding. Precipitation measured at rain gauges directly in the direction of flight, have shown an increase in the amount of five cases. 


\section{OWRB project}

The aim of the project OWRB (Oklahoma Water Resources Board) was to investigate the effect of seeding convective clouds in Oklahoma. We used a cloud model for the Great Plains to provide a maximum height of clouds and compare the natural icing conditions with increased freezing caused by surface seeding with silver iodide and dry ice. They then carried out sounding of the atmosphere at a time when measurements were performed using the aircraft in order to assess the capability of the model to simulate clouds and the possibility of its use for evaluating the effect of seeding. Preliminary indications suggest that there are possibilities to determine the increased growth caused by the seeding of clouds in the days when convective clouds are in the area of Oklahoma. It was also determined to achieve something greater effect if the seeding is done with dry ice compared with silver iodide seeding. (Pflaum et al., 1989).

\section{San Angelo Program}

The aim of the seeding was filling reservoirs, canals and reservoirs by increasing the amount of rainfall, including that used to increase the farmers and other industries and thus reduce the demand for water. This program lasted five years (1984-1988) and for the time spent is $125 \mathrm{~kg}$ of silver iodide by seeding 2315 tops or cloud bases. Most seeding is done within 50 $\mathrm{km}$ of San Angel, and to the west and southwest of the city.

The efficiency of seeding is evaluated by using regression for target and control area, which is derived from historical data of rainfall. Historical data of monthly rainfall existed for many years for 9 precipitation stations in target and 5 stations in the control area.

Analysis of results showed a positive effect (increased rainfall) for each of 5 years. The probability that these results are obtained using a random case is only $3 \%$. The overall effect for the entire seeded area for the entire period of seeding is increasing annual precipitation by 17\%. (Woodly and Solak, 1990).

\section{Illinois experiment}

During the 1989th in Illinois conducted an experiment with an index of seeding. This index is compiled based on 20 predictor variables, which represent the state in the cloud, mesosynoptic conditions and radar parameters. According to them should determine the suitability for a cloud seeding. For each predictors are determined certain thresholds that indicate whether the conditions for seeding are attained. Each of the predictor has a certain weighting factor, so that the most favorable conditions for seeding has an index of 100, a minimum 0 .

To test the validity of this seeding index two groups of clouds are formed. One of them had high and second low index of the seeding. Validation of this index showed that this methodology is not appropriate. Some radar parameters are far better indicators than other predictors, which indicated that the whole system has to reconstruct the predictors (Czys et al., 1993). 


\section{California - Idaho dispute}

Cloud seeding has raised many scientific and law questions. One of the greatest uncertainties is related with prolonged down wind effects or effects in extended area around the target area (area in which the seeding is done). According to many researchers downwind effects are similar to those arising in target area. Most studies of orographic cloud seeding in the winter conducted in California showed that the effect is transmitted downwind beyond the target area. This effect can reach a maximum of about $300 \mathrm{~km}$ downwind.

At the beginning of the 1990s in Idaho was expressed the lack of rainfall. This was attributed to seeding activities in California. The expert teams are nominated to review this effects and the court to decide. However, Idaho is located over $600 \mathrm{~km}$ away from the target area in California, that is a distance on which is not possible to have the effect of seeding carried on by a large distance. Second, if the seeding produces a greater amount of rainfall, it was found that this can result in a reduction in rainfall in the surrounding areas, but only if seeding is conducted in the summer convective clouds. However, in California were performed seeding of stratus clouds during the winter. Thus, the court had no reliable indicators on which to bring an appropriate judgment.

Legitimate rights to water from the atmosphere and the effects of water appropriation so far remain unresolved. People who are considered to be damaged by these activities and their legal representatives usually exaggerate the effect of seeding rate. Since it can not prove it disputes boil down to the recommendation that the matter be postponed until conditions are created for a reliable estimation of the effect of seeding and its range. With regard to expert opinion, it holds that cloud seeding in California has no positive or negative impact on precipitation in Idaho. (MacCracken and O 'Laughlin, 1996).

\subsection{Australian experiments}

\section{Convenience of cloud seeding in Western Australia}

In the period 1976-1979 the Western Australia was hit by severe drought. This has prompted many farmers to support scientific research facilities in seeding clouds to stimulate rainfall. The aim of this study was to:

1) determine whether in this area appear suitable for cloud seeding;

2) define the synoptic situations that arise clouds suitable for seeding;

3) examine the characteristics of clouds suitable for seeding;

4) conduct a test of seeding to determine the visual effect;

5) assess the economic value of cloud seeding.

The performed studies have shown that the areas discussed above appear sufficiently favorable for cloud seeding to justify the performance of the proposed experiment. Moreover, they occur in the time of year when additional precipitation was very helpful. Because of the high cloud top temperature, it is estimated that the use of dry ice as a reagent for seeding was more effective than silver iodide.

However, in this area are observed clouds with very specific characteristics. It was found that they contain a very small number of larger drops, which determine the efficiency of 
precipitation. Due to this reason a relatively small amount of precipitation can be released. In order to produce more raindrops it would be better to use as a reagent hygroscopic materials. Then, in this area appear very compact layer widespread clouds with extremely uniform tops. Due to the flat terrain in the coastal wind do not forces air to rise and the precipitation occurs rarely. With all the cloud tops are relatively warm, leading to uncertainty about the possible positive effect of seeding. From all the above mentioned reasons, the researchers concluded that it can not be expected enhancement of precipitation in Western Australia, without more detailed study of these issues. (Bailey, 1985).

\section{Seeding experiments in southwestern Australia}

In the period 1955-1971 the cloud seeding experiment is conducted in Southeast Australia. Seeding was done with silver iodide and sodium iodide. Seeding was carried out from aircraft generators. Special experiments were carried out in the snowy mountains, and in Tasmania.

The best result was achieved in the seeding area of snowy mountains. There is an increased amount of rainfall for the $19 \%$, with the level of significance of about 3\%.Tasmanian experiment showed the greatest increase in rainfall in the fall, less in winter, with no significant increase in the spring. During the summer there is very rare seeding. The evaluation was done partly by comparing the amount of rainfall from target and the control area, and partly by using randomization. (Bigg, 1985).

\section{Experiment of winter cloud seeding in Melbourne}

The aim of this experiment was to determine the potential for stimulation of rainfall in the vicinity of Melbourne, where the water tanks for supply of the population are placed. The capacity of these reservoirs is significantly higher than the rainfall that is excreted naturally. Therefore, they are half empty most of the time. In addition, water consumption increases by about $2 \%$ per year.

The experimental area is located east of Melbourne. Mean altitude of the area is 780 m. The experiment was conducted in the period 1988-1992 during the cold season (MayOctober). Most rainfall in this season is related to synoptic scale weather systems and the prevailing wind from the west. The control area is the area taken upwind of the target area. It is also used unbalanced randomization, so that in two thirds of the rainy days seeding was done on, and one third did not.

The experimental activities were limited to the hours when the visibility was sufficient for the safe performance of seeding. Seeding is done from a plane equipped with a generator attached to the aircraft wing. The generator was burnt the solution of silver iodide, ammonium iodide and acetone perhloride additives.

Weather parameters are collected in the meteorological department at the airport in Melbourne. In addition to traditional meteorological data, the satellite and radar data are collected in order to determine the direction and speed of moving clouds and their suitability for seeding. When the clouds were suitable for seeding and moved to the experimental area, an order is issued for take-off planes and start seeding. 
The evaluation of this experiment was performed using several different statistical methods. It is shown that the amount of rainfall in winter could increase by several tens of millimeters. If you take the size of the area where the seeding was done, which is $487 \mathrm{~km}^{2}$, it is equivalent to the increas of the water for 10-20000 megalitars. (Long, 1989).

\section{Queensland Cloud Seeding Research Program}

During the Queensland Cloud Seeding Research Program (QCSRP, Tessendorf et al. 2010) in southeast Queensland, near Brisbane, Australia, between November 2008 and February 2009 were conducted in situ aerosol measurements. Having a good understanding of the natural aerosol that are present in the atmosphere and affecting cloud droplet formation is paramount toward understanding such implications on precipitation formation or whether or not using hygroscopic cloud seeding techniques could enhance rainfall in a given region. The goal of this study was to define the typical aerosol regimes observed in the southeast Queensland region, and present representative characteristics of each of those regimes. Such representations can be used for further detailed study of the precipitation processes in the region, including initializations for cloud resolving microphysical models (Tessendorf et al. 2011).

\subsection{Bulgarian experiments}

\section{Experiment in Plain Trakijskoj}

In Trakijskoj Plain (Southern Bulgaria) since 1990 began the randomized experiment of the simulations of precipitation. The surface on which is performed the experiment is 2000 $\mathrm{km}^{2}$. The purpose of the experiment is to identify and analyze the changes of parameters of convective clouds and precipitation from them after seeding.

The seeding period is from April to September. 35 dBZ.> N5 $9.0 \mathrm{~km}$; $\mathrm{Z}<<$ TN5 $-30^{\circ} \mathrm{S}$, $4.0>>$ Seeding is performed under clouds that meet the following criteria: : $-10^{\circ} \mathrm{C}>\mathrm{TN} 5>-$ $30^{\circ} \mathrm{C} ; 4,0<\mathrm{N} 5<9,0 \mathrm{~km} ; \mathrm{Z}>35 \mathrm{dBZ}$. Here TN5 means the air temperature at $500 \mathrm{mb}, \mathrm{N} 5$ cloud top height at the threshold of $5 \mathrm{dBZ}$ and $\mathrm{Z}$ maximum radar reflectivity. Cloud seeding is done in a layer with a temperature of $-3^{\circ}$ to $-10^{\circ} \mathrm{C}$.

In the period 1990-1992 were 52 days which were met the seeding criteria. A random selected 30 days in which the seeding was done. Seeding is conducted under 44 clouds. On average in a cloud were fired four rockets "Alazanj", and 23 clouds was seedied again 2-3 times at intervals of 10-12 minutes. Cloud parameters are measured by radar MRL-5.

The differences in changes of parameters seeded and unseeded clouds is found by the test of the null hypothesis at the significance level $\alpha=0.1,0.05,0.01$. Seeded clouds in comparison with unseeded showed greater strength development, increase height, increase volume, the greater of precipitation zone, extending the period of rainfall, increasing the amount and intensity of rainfall from convective cells. It was also found that the amount of rainfall from seeded convective cells increased from 27 to $41 \%$ and rainfall intensity of 16-23\%. (Boev et al., 1994, Boev et al., 1999). 


\subsection{Georgian experiment}

In Georgia are organized rainfall stimulation experiments at two poligons - "Ivori" and "Screens". Each of them has an area of $1000 \mathrm{~km}^{2}$. Near them were two control territory with sizes 4000 and $2000 \mathrm{~km}^{2}$. In the period 1979-1980 were carried out non-randomized and in the period 1981-1984 the randomized experiments.

Tracking clouds and determination of their parameters was performed by MRL-2 and MRL-5 radars, and cloud seeded by rockets "Alazanj" and shells from antiaircraft guns like "Elbrus". Agents were thrown into convective cells between temperature levels of $-5^{\circ}$ and $15^{\circ} \mathrm{C}$.

Efficiency is evaluated by test of zero hypothesis at the significance level $\alpha=0.1$. It is showed that the increase in the amount of rainfall at "Iori" is 20-25\%, while in the "Screens" was $10-15 \%$. The same percent of increase is found in the flow rates of rivers in the area of a polygon. (Svundze et al., 1985).

\subsection{Greek programs stimulation of rainfall}

\section{Stimulation of precipitation in the basin of the river Mornos}

At the request of and with financial support of the Athens water supply area 1992nd year began with the stimulation of rainfall in the basin of the river Mornos (western Greece). Seeding is done with two planes, one of which was equipped with instruments for measuring physical parameters of clouds. They used aircraft types Cessna 340.

The first positive results of seeding were obvious, but the clouds was very low base, which is threatening the safety of flight. Therefore, in 1993 discontinued the seeding with the aircraft and was asked by a team of experts to develop a seeding by using the ground generator. (Bronjn and Tomlison, 1994).

\section{Stimulation of precipitation in central and northern Greece}

Due to frequent droughts and water shortages are planned to start the precipitation enhancement at the anti-hail sites in central and northern Greek, where the necessary infrastructure already exists. For that purpose the first phase of research is conducted, that included climatological and microphysical analysis oh clouds.

In this analysis, the clouds are grouped into six categories according to precipitation characteristics and corresponding synoptic situations. The results of climatological analysis showed that the convective clouds are dominant in the excretion of rainfall in these areas. The frequency of their occurrence was highest during the summer. By contrast, the highest frequency of the cold half of the year had layer clouds.

Microphysical analysis of cloud was performed over several seasons in the program hail suppression. Microphysical measurements were conducted in order to gain insight into the process of formation of precipitation and observing the essential characteristics of clouds in the central and northern Greece. (Dalezios et al., 1996). 


\subsection{Israeli experiments}

The most important experiments of stimulation of rainfall ever conducted are those performed in Israel, with the strong scientific base. The first experiment of this kind (Israel I) was performed during the period 1961-1967, the second (Israel II) in the period 1969-1975 and the third experiment in the period 1975-1991. All experiments were performed by seeding with AgI from aircraft type Aerocommander $380 \mathrm{FL}$. Seeding was done in the winter season from November to April.

The first experiment was performed over two separate areas where the seeding was done alternately. Results showed increased amounts of precipitation for the $15 \%$ with the level of significance $\alpha=0.009$. In the second experiment, the seeding area moved east, deeper into the continent, and the control area is designated along the coast. . Analysis of results showed increased amounts of precipitation for the $13 \%$ with level of significance $\alpha=0.028$. In the third experiment, the target area is determined in the northern part of Israel, and the control area was taken on the upwind side. Seeding is done every day when conditions were suitable for it. . Results showed increased amounts of precipitation for the $6 \%$ with the level of significance $\alpha=$ 0.02 .

The positive results obtained in these three experiments are explained by the following reasons:

1) Clouds that are seeded are cold (cold half of the year), a continental convective, in most cases associated with cold fronts and post frontal cloud zones. They had a microstructure which suggests that the processes of formation rainfall usually manifested through the growth of ice crystals, which grow quickly creating frost and not merging and colliding droplets.

2) Water budget of most convective clouds with average cloud base temperature around $8^{\circ} \mathrm{C}$, is such that further concentration of ice crystals increases the efficiency of secretion of rainfall from these clouds.

3) The tops of the clouds and their temperature show that most of them are in a temperature range from $-15^{\circ}$ to $-20^{\circ} \mathrm{C}$. For such clouds is found to be very susceptible to seeding and increased excretion of rainfall. (Gagin and Neumann, 1981; Nożyce and Rosenfeld, 1994)

\subsection{Indian experiments}

\section{Delhi experiment}

In northwestern India, near Delhi, an experiment to stimulate rainfall is organized in the period 1957-1966. Cloud seeding is done by using ground generators, which are seeded during the summer monsoon month, from July to September. At that time the prevailing clouds are cumulus and stratocumulus. In this particular experiment, the target and control area are selected, while a day of seeding was determined by randomization.. Results of statistical analysis of precipitation data, referring to the days when the seeding was done showed increase in rainfall compared to the day when seeding is not performed for about $28 \%$ at least level of significance $\alpha$ $=0.005$. Results of analysis of radar data, which were related to the size and intensity of the 
reflections were also positive for 5-year period (1961-1966) and were consistent with the data obtained from a network of rain gauges. Since the effect on warm clouds, it is unlikely that the reagent is admitted at the height of the level of supercooled droplets and ice crystals.

\section{Maharashtra experiment}

Due to the lack of physical indicators the results obtained in the Delhi experiment some scientists seem unconvincing. In order to verify the data the second experiment is organized in the state of Maharashtra. This second experiment is designed to be well-documented regarding to the response of warm cloud on seeding with salt.

The program is made precise physical measurements using aircraft. These measurements and seeding were conducted during the 11 summer monsoon seasons (1973-74, 1976, 1979-86). Seeding is done from the DC-3 aircraft, which was equipped with instruments for measuring physical parameters of the cloud. Measurements were performed in isolated seeded and unseeded warm cumulus clouds. Then, it is performed the analysis and evaluation of the effect of seeding. Using the Whitmen-Mann U-test the results showed that in the days after seeding the rainfall increased by $24 \%$ at the significance level of $4 \%$.

\subsection{Indonesian experiment}

In the recent years the use of hygroscopic seeding reagents in order to stimulate rainfall from warm and cold clouds is expanded into the world. This technology has been used in Silavasi, Indonesia, since 1998. Seeding is done from an airplane Piper Aztec. A process of development of clouds and precipitation excretion was registered with a $3-\mathrm{cm}$ automated radar.

During the spring 1998 was made 86 cloud seeding. The clouds which had more than $2600 \mathrm{~m}$ thick were seeded from base to top. Reagent composition was $76.8 \% \mathrm{KCl}, 21.9 \% \mathrm{NaCl}$ and $1.3 \% \mathrm{Li}_{2} \mathrm{CO}_{3} . \mu \mathrm{m}$. One gram of this material gave about $10^{13}$ particles of mean diameter of about $2 \mu \mathrm{m}$. Each particle is initiated by the formation of water droplets with a diameter of about $10 \mu \mathrm{m}$. Reagent is pressed into the cartridge containing $500 \mathrm{~g}$ of matter, which was burned by the expulsion of about 5 minutes. The plane carried 24 such cartridges.

Comparing the radar parameters between seeded and unseeded clouds were found that seeded clouds had on average a longer duration of rainfall by $31 \%$, higher rainfall zone by $27 \%$ and higher rainfall intensity by $9 \%$ (Henderson et al., 1999). In the recent years, the precipitation enhancement activities in Indonesia are significantly broaden, Renggono et. al, 2011.

\section{Larona Catchment Area, Sulawesi}

Nickel production at the Sorowako plant is dependent on the availability of water from the lakes surrrounding Sorowako in Sulawesi. Low water levels in the lakes feeding the hydropower stations at Larona and Balambano could limit the amount of hydropower more than those which can be generated. In order to overcome this problem, PTINCO has been conducted cloud seeding for precipitation enhancement purposes for the region. Previous studies found that lake breezes effects seemed to enhance rainfall during the night along the shores of Lake Matano (NCAR, 2006), but there are no further studies regarding lake breezes effect in this region (Renggono et al. 2011). 


\subsection{Italian experiments}

During the 1980s, in Italy there were several drought, which were disastrous, especially in the southern parts of the country. These situations and the knowledge that Israel achieved a very convincing results in artificial stimulation of rainfall, caused many professional and relevant factors to the elaboration and implementation of precipitation enhancement programs in Italy.

This program is based on the following objectives:

1) to study the weather conditions that produce precipitation in southern Italy and to identify similarities with those in Israel.

2) application of the methodology of rainfall stimulation applied to Israel over more than 20 years, which gives increasing of rainfall by $10-20 \%$.

3) pre-determine the statistical and physical methods used to objectively determine the result of increased rainfall cloud seeding.

4) to attain operational and scientific experience that will be transferred to other parts of the country.

5) for the experimental area chosen area of Puglia, Sicily and Sardinia.

To realize this program was formed the Committee who have entered Italy and distinguished experts from abroad. In Puglia the seeding was done 105 days for a total of 263 hours. In Sicily seeding was carried out only in 1990, 15 days with a duration of 56 hours. In Sardinia the experiment lasted from 1992 to 1993. Seeding was done in 12 days with a duration of 12 hours.

The effect of seeding during these experiments was recorded many visually, radar and other observations. However, the recommendations of the World Meteorological Organization regarding the duration of an experiment showed that these experiments were insufficient long to perform reliable statistical evaluations. All the experiments were discontinued due to lack of funds for their work. (Dell Angelo et al., 1994; Vento et al., 1994).

\subsection{South African experiments}

South Africa is a developing country which is due to rapid population growth, agriculture and industry 's expansion in the second half of the 20th century, faced with a lack of water. Due to reason, in 1991 is organized two rainfall stimulation experiments. The first is a research project called Betlejemsk precipitation project, and second Cloud Quest project. Both these projects were conducted as a randomized experiments which used silver iodide and dry ice in order to stimulate rainfall. In both of these projects have applied the same method of observation, analysis and study of convective clouds and storms in order to achieve a better understanding of the natural occurrence of rainfall in the area and observed the effects of seeding.

Since 1990 the two programs for stimulation of rain in South Africa were compiled into a single national program. Merge professional and technical resources has led to significant advancements of these experiments during the 1990's. In 1997 this program was amended and renamed the South African program for the stimulation of precipitation. The main changes in this program was the introduction of hygroscopic flares reagent for seeding. 
For seeding clouds and measuring meteorological parameters in the clouds and the ambient atmosphere were used airplanes SAWB Aerocommander 690, then a Piper Commanche, WRCS Commander 5005, and a Learjet 24A. All these planes were equipped with the appropriate meteorological instruments for measurements in the free atmosphere and devices for cloud seeding.

The best efficiency was performed by radar parameters at intervals of 10 minutes. They are formed two series of data. One set consisted of data pertaining to the seeded clouds and another for unseeded clouds. In the period 1991-1996. a total of 127 clouds selected that meet the requirements for seeding. Randomly were selected 62 clouds for seeding, and 65 of them have not seeded. During the first 60 minutes of cloud life seeded clouds were extracted $20 \%$ more precipitation than unseeded clouds with the significance level of 5\%. In the period 19951997, when seeding was done with hygroscopic reagent, it is selected 60 cases of clouds that were seeded and 60 non-seeded. In the first 100 minutes seeded clouds extracted by $60 \%$ greater mass of rainfall compared to the clouds that were not seeded (Terblanche, 1999).

\subsection{Canadian experiments}

\section{Alberta Research Council}

Canada was very devoted in the weather modification. Her interest is particularly pronounced in the prevention of hail falls (hail suppression) and the stimulation of precipitation. However, the intention of Canadian experts and interested institutions is primarily focused on applied research, i.e. to clarify all the important technical problems before they join the general practical application method of weather modification. For this purpose, the Alberta Research Council was established, who have been organized and carried out experiments in the field of weather modification. Here we present two such experiments. The first concerns on the monitoring by aircraft and radar of $\mathrm{Cb}$ cloud seeding in Alberta. The second relates to the study of some physical characteristics of the seeding by signal-rockets with AgI in Alberta.

\section{Cloud seeding using aircraft and radar}

The most widely used method of inserting of silver iodide in the top of $\mathrm{Cb}$ cloud is the firing of signal-rockets with AgI. This is called the method of seeding of the cloud tops. The most important advantage of this method is the spatial and temporal accuracy of the seeding.

Another method of delivery of silver iodide into clouds is the scattering of the seeding material inside the upward flow below the cloud base. With the updraft reagent is transported vertically into the cloud. Previous attempts of the measurement of the effects of seeding below cloud base did not provide a sufficiently clear picture of what happens with the injected reagent. Recent experiments with a tracer, using sulfur hexaphlorid have provided new insight into the dispersion of smoke AgI released under a cloud.

During the summer 1985 had conducted four such experiments. They used two Cessna 441 aircraft and Conquest with two turbo engines, with de-icing system, and with permission to fly in icing conditions. Research aircraft was equipped with all necessary instruments for

microphysical and other measurements in the clouds and the surrounding atmosphere. This plane 
was climbed by specified route to the level of $-10^{\circ} \mathrm{C}$, where took samples during flyby of the top of cloud in the interval from 20 to 30 minutes. The second plane was flown at cloud base and repeatedly made seeding at intervals of 4 minutes. Simultaneously S-band radar observations were made.

Measurements of ice crystals have shown that the particles of AgI, released at the cloud base reaches up to the level of $-10^{\circ} \mathrm{C}$ by updraft for 6 to 10 minutes after seeding. This time interval depends on the speed of updraft and the current distance between the cloud base height and level of $-10^{\circ} \mathrm{C}$ (Kochtubajda, 1989.

\section{Characteristics of curtains of AgI released into the air in Alberta}

During summer 1984 and 1985 the two experiments were performed with tracer released in the air, and their detection by using Lagrange's detector. In one experiment were compared the curtains of $2 \mathrm{AgJ}-\mathrm{NH} 4 \mathrm{~J}$-acetone flares, released from signal rockets fired from the airplane wings. In the second experiment was monitored the spreading of agents during three hours and seven minutes. The results showed that acetone is highly efficient and produces the same number of ice nuclei as the flares from the wing of aircraft at a temperature of $-20^{\circ} \mathrm{C}$. Curtain formed by the falling of rocket was difficult to detect. For the line seeding was found to penetrate into the large area, and the plume expansion is consistent with the existing transport and dispersion theory.

Certain conclusions are drawn which are important for seeding. Thus, for example in both cases it was noticed that the line seeding rapidly diffuses the agents in the horizontal and vertical direction. Lateral dispersion reaches the $2 \mathrm{~m} / \mathrm{s}$, while the vertical spreading is under strong influence of the boundary layer thickness. Seeding efficiency of the aircraft is highly dependent on the type of generator that is placed on the wing. There are some types of generators which are lodged in debris or clog from larger amounts of reagents. Otherwise, the use of acetone generators on the aircraft wing is cheaper than the rocket, because the acetone combustion gives for two orders of magnitude more ice nuclei than from rocket flares. Monitoring the plume over three hours showed that it is throughout the time constant and coherent. Photodeactivation or other losses do not represent a significant risk factor for acetone as the source.(Heinibach, 1990).

\subsection{Chinese experiments}

\section{General on weather modification in China}

The territory of China is frequently hit by many weather disasters. Each year an average of about 30 million hectares of agricultural land affected by droughts, floods, hail, wind storm, etc. The drought produces more than $62 \%$ of damages. China also suffers from lack of water, whose geographical distribution is very uneven. Water resources in northern China are scarce and the area north of the Yangtze River receives only about $20 \%$ of the total water available in China. Along with population growth and the national economical development, water scarcity is becoming a serious national problem. Therefore, the weather modification is very important to mitigate the lack of water resources and to combat other natural disasters. 
Work on weather modification in China began in 1958. In recent years, the government of China has devoted great attention to weather modification and provided support at various levels. Also, people who feel the benefits of weather modification highly esteem and give support to the weather modification activity. In 1997, 18 provinces and autonomous regions of China conducted stimulation of precipitation. Some of the major experiments and operational programs of precipitation enhancement in China are briefly described (Jijia, 1989; Zhiyu, 1999, Hongping et al., 2011).

\section{Gutian experiment}

In the field of Gutian, Fujian Province, conducted an experiment stimulation of rainfall during the period 1975-1986. Seeding was carried out over the area of $1500 \mathrm{~km}^{2}$, and the same areas $11 \mathrm{~km}$ upwind has been taken as control area. Seeding is done in the period April to June. During this period was observed 224 clouds out of which 122 were seeded. Clouds are grouped into three classes: 1) convective (c), stratus (s) and combined $(\mathrm{c}+\mathrm{s})$. The results showed that for the first group of clouds increasing rainfall amounted up to $55.9 \%$, for the second group $24.23 \%$ and $33.96 \%$ for third group. The mean value for all three groups of clouds the increase was $23.81 \%$ with level of significance $\alpha<0.01$.

Silver iodide (AgI) and metaldahida (MA) were used. Seeding these reagents was performed by small rockets and anti-aircraft cannons caliber $37 \mathrm{~mm}$.(Zeng et al., 1985 Changcheng and Bugue 1989, Guang-ping, 1989).

\section{Chamazi experiment}

From winter 1983/84 in the upper basin of the river in Baijang Klamai, Ksinjjang provinces, a program of orographic clouds seeding is conducted. The program is operational in its design and was supported by Ksinjjang Petrochemical administration. It started after a few very strong droughts. This represents the longest period of orographic cloud seeding in China. Seeding was carried out using aircraft and ground generators with silver iodide and acetone, and using artillery shells filled with AgI. All cloud systems are seeded without randomization. On average, the water from melted snow in the mountains contributed with $70 \%$ per year over in the total water that flow in the river Baijang. Therefore, it is aimed at seeding winter stratiform clouds, mainly in December and January. Summer convective clouds were seeded mainly in the period June-August. During the period 1986 to 1995 the seeding was done in a total of 473 days with 5178 seeding hours. During this period it is used $558 \mathrm{~kg}$ of silver iodide and sodium iodide, and $30508 \mathrm{~kg}$ of acetone. At the same time observations were carried out using a cloud physics aircraft equipped with a system for measuring the number of particles, then the $3-\mathrm{cm}$ radar and meteorological sounding. Target area was $2116 \mathrm{~km}^{2}$.

The effect of seeding for the period 1984-1987 was the increase in total river water by $22.6 \%$, with statistical significance better than $\alpha=0.0035$ (Ziya et al., 1989). The second evaluation was performed comparing the annual flow for the period 1962-1983, when seeding did not conduct, with the annual flow for the period 1984-1995, when the seeding was done. The flow in the second period is increased by $33.8 \%$. 


\section{Stimulation of precipitation to forest fire fighting}

In the northeastern part of the province Heilongxiang, which is normally dry area, since 1985 , the annual rainfall from year to year were less than normal in $30 \%-40 \%$. This led to aridity and abnormal conditions suitable for large forest fires. For these reasons, in May 1987 the forest fires have erupted in 18 areas of the province. The total area of forest affected by fires amounted to 1.14 million hectares.

From 19 to 25 May 4 days were favorable conditions for stimulation of precipitation. Much of the area affected by fires was covered with As and Ns clouds. Their composition was mixed, the cloud droplets and ice crystals, and the upper surface had a temperature between $5^{\circ} \mathrm{C}$ and $-15^{\circ} \mathrm{C}$.

For stimulation of precipitation 10 aircraft is engaged. Clouds were seeded with dry ice with the amount of $500 \mathrm{~kg}$ per $1 \mathrm{~km}$ of flight. The objective evaluation of the effect of stimulation of rainfall in this case was not possible. However, it seems everyone involved in these operations acquired by the belief that the effect was evident and contributed significantly to the closure of such a large fire.(Dashan, 1989).

\section{Sichuan Basin experiment}

Sichuan Province is characterized by frequent and lengthy drought during the growing season. It is strongly reflected in agricultural crops. For this reason, in this area was introduced stimulation of precipitation since 1959th year.

Stimulation of precipitation is conducted on the territory of $2000 \mathrm{~km}^{2}$. In $1975 \mathrm{was}$ conducted a specially designed experiment. It is selected a target territory of $200 \mathrm{~km}^{2}$ for the seeding and the same control territory in the upwind direction.

The criteria for seeding in the experimental units were the radar reflectivity greater than $25 \mathrm{dBZ}$ and the top of the radar image of cloud exceed $6 \mathrm{~km}$ altitude. Seeding efficiency showed that the average amount of precipitation extracted from seeded clouds was $35 \%$ greater than those from unseeded with the level of significance of 5\%.(Hesheng, 1989).

\section{Xinjiang experiment}

Since 1978 the operational program was performed to increase the thickness of snow cover in the main area in the granary province Xinjiang in China. The main objective of this program was to increase the thickness of snow on the ground to protect the spring wheat of the freezing in the winter. Seeding operations were focused on the winter stratiform clouds in the period from November to January. Seeding is done from an airplane using a generator E-16 for dispersion of AgI. This generator is ijected $154 \mathrm{~g} / \mathrm{h}$ of silver iodide solution in the formof the smoke. From each gram of silver iodide vapor is formed 10 on 15 of ice nuclei.

According to studies was found that the spring wheat will be protected against the winter freezinh if it is set up in December stable snow cover of $5 \mathrm{~cm}$ thick. The spring wheat will be protected even at temperatures of $-24^{\circ} \mathrm{C}$ to $-30^{\circ} \mathrm{S}$. The evaluation of the effects of seeding in the period from 1978 to 1994 showed that the average snow depth is increased by $22.2 \%$ at the level of significance $\alpha=0.05$ (Zaomao, 1999). 


\section{Julin experiment}

In Xulin Province was performed the stimulation of precipitation in the period 19801987. Seeding is done from a plane with dry ice. Totally 62 seedings are performed using the randomized method of seeding. Seeding period was April-July. The criteria for seeding clouds was to meet the following requirements:

1) cloud top temperatures between $-5^{\circ}$ and $-20^{\circ} \mathrm{C}$;

2) the thickness of the cloud is greater than $1700 \mathrm{~m}$;

3) the cloud base is lower than $1500 \mathrm{~m}$.

The evaluation of the results showed that in the days of sowing, rainfall increased by $40.2 \%$. The rainfall are increased by $51.8 \%$ in the convective clouds, and about $31 \%$ in the stratiform clouds (Xinentin et al., 1989).

\section{Hubei experiment}

Davis area in Hubei province is characterized by regular droughts in August. Therefore, an experiment of rainfall stimulation was conducted in that month for the period 1975-1985. To perform the experiment is taken an area of $500 \mathrm{~km}^{2}$, and equal control area. Between them is set the buffer zone of $230 \mathrm{~km}^{2}$.

Convective clouds were seeded during August. Seeding was performed using anti-aircraft guns with shells filled with silver iodide. During this period made the 34 seeding. The evaluation results showed that the amount of rainfall in the August increased by $16 \%$ with level of significance $\alpha=0.05$ (Deshou and Keguang, 1989).

\section{Shandong experiment}

Experiment of rainfall stimulation was carried out in Shandong province in the period 1989-1995, The aim was to determine what is the cost-benefit effect on the annual yield of wheat in the field. For the the experiment was chosen one target and two control areas with total area $22500 \mathrm{~km}^{2}$. Seeding is done in autumn and spring using the plane with silver iodide.

Cropping practices and other conditions of cultivation of wheat in all three areas were the same as at the time of seeding clouds and in the period before seeding. Therefore, by applying the method of least absolute deviation regression and least squares regression of annual returns for 28 years before seeding, obtained an excellent match between the yields in these three areas. However, during the cloud seeding year yields in target areas were enlarged compared to the yields in the control areas by an average of 5.9\%. (Guili, 1999).

\section{Hunan experiment}

Test carried out in Hunan province was aimed to determine the effect and economic benefit of the rainfall stimulation in the production of electricity. For this purpose is determined the area around the reservoir Dong Jiang of the size of $250 \mathrm{~km}^{2}$, and one same control area. Near the large accumulation of Jiang Dong is 6 more smaller reservoirs. Cloud seeding was done using anti-artillery, whose shells were filled with silver iodide. 
The experiment was performed in only one season and from 21 January to 9 September. The seeding conditions were met in 50 days. Through random selection seeding was done in 23 days and not done in 27 days. Based on detailed analysis led to the following conclusions:

1) In the days when cloud seeding was done on target area compared to the control occurred in average $52.7 \mathrm{~mm}$ more precipitation, which is a relative increase of $72 \%$.

2) In the days when the clouds are not seeded, the difference in the average rainfall in these two areas was only $0.77 \mathrm{~mm}$.

3) Increase the amount of rainfall of $52.7 \mathrm{~mm}$ at target area within $250 \mathrm{~km}^{2}$ with a runoff coefficient of 0.8 represents an additional amount of water in the reservoir of 26 million $\mathrm{m}^{3}$.

4) When the additional amount of water in the main reservoirs transfer into electrical energy it is obtained direct benefit in the amount of 4625 million yuan. The average indirect benefit is 330 million yuan.

5) Direct financial gain of 6 small dams and their hydroelectric power plant is 3.6 million yuan and 252 million yuan indirect.

6) The relationship between investment and direct financial gain is 1:8. (Hu et al., 1999).

\subsection{The Cuban experiment}

During the period 1985-1990 the randomized experiment of rainfall stimulation was carried out in Gamaguey, Cuba. The aim of this experiment was: 1) to verify the hypothesis according to which increasing amounts of precipitation can be achieved through dynamic seeding, 2) to formulate a technology for seeding convective clouds in the tropics.

The criterion was to seed clusters of convective clouds if their cloud tops are located in the temperature zone of $-10^{\circ}$ to $-20^{\circ} \mathrm{C}$ and peaks have diameter of $2-3 \mathrm{~km}$. During this period in the target area is observed 115 such clouds. According to the method of randomization 56 cloud is seeded, and 59 not. According to the observed data it is found that seeded clouds grew faster, were higher, lasted longer and had higher rainfall zone. The amount of precipitation extracted from them was a $20-25 \%$ greater than the amount of rainfall that is extracted from unseeded clouds. All these characteristics are obtained by means of statistical tests with significance level below 0.05. (Chernikov et al., 1994).

\section{Randomized Convective Cold Cloud Seeding Experiment in Extended Areas}

To mitigate the effect of a severe drought which affected the Eastern part of Cuba in 2004 and beginning of 2005, the Cuban Government decided to support the development of an operational and research Rainfall Enhancement Program. This Program was composed by a research project, designed to continue and complement the previous research program, developed in the $80 \mathrm{~s}-90 \mathrm{~s}$ and an operational cloud seeding project to enhance precipitation in the areas most affected by drought. The research project of this Program was the Randomized Convective Cold Cloud Seeding Experiment in Extended Areas The experimental units were defined as the group of clouds located within a circle having a radius of $25 \mathrm{~km}$ and centered at the location of the initial treatment. The target clouds within the experimental unit were growing convective clouds having, at least $0.5 \mathrm{~g} / \mathrm{m}^{3}$ of supercooled cloud water, updraft velocity greater than $5 \mathrm{~m} / \mathrm{s}$ and top temperature of -7 to $-20^{\circ} \mathrm{C}$. 
The clouds were seeded from an instrumented An-26 aircraft, under the dynamic seeding hypothesis. The glaciogenic reagent applied in the experiment is the pyrotechnic mixture of the Russian flares PV-26. This mixture has an output of $1.7 \times 10^{14}$ glaciogenic nuclei per gram at $10^{\circ} \mathrm{C}$ and $7.0 \times 10^{13}$ at $-6^{\circ} \mathrm{C}$. The flares burn during $40 \mathrm{~s}$ and have a descending burning track of $1.5-2 \mathrm{~km}$ in moderate updraft. The recommended flight level is near to the $-7^{\circ} \mathrm{C}$ isotherm $(5700$ 6000) $\mathrm{m}$. Experimental units are selected jointly by the aircraft and ground team leaders For a rough estimate of the rainfall increment, a non randomized historic regression method was applied. The historic linear correlation coefficient of rainfall in July for both provinces was 0.73 , significant at a 99\% level. The estimated increment for July, 2006 was of nearly 30\%. (Martinez et al. 2011)

\subsection{Moroccan experiment}

Since 1984 in Morocco began the rain stimulation experiment performed under the name Al Ghait. The experiment was aimed at increasing the thickness of snow cover in the central mountain area of Atlas. Mean altitude of the area is about $3000 \mathrm{~m}$. The experiment was performed in the period from October to April. Seeding was carried out using aircraft and ground generators with reagent AgI.The criterion for the seeding was that the cloud tops are in the layer with temperature between $-5^{\circ}$ to $-20^{\circ} \mathrm{C}$; the clouds have a thickness of at least $1 \mathrm{~km}$ and the air flow at AT $700 \mathrm{mb}$ is from the direction of $220-360^{\circ}$.

Clouds containing a supercooled drops and ice crystals, are therefore suitable for seeding, are classified into three categories. In the first category are classified layer cloud systems which come in the west or northwest flow. They have a moderate potential for stimulation and have the highest frequency. They represent $67 \%$ of the total number of clouds suitable for seeding. The second group consists of relatively isolated convective clouds that are associated with postfrontal storms. They are mainly cumulus congestus clouds. They are generally unstable and tend to have a large amount of liquid water and a small concentration of ice crystals. This indicates that this category of clouds is very suitable for stimulation of precipitation. The frequency of occurrence of these clouds is $23 \%$ of the total number of clouds suitable for seeding. The third group consists of cloud systems in the tropical air mass moving over the south of Morocco and is composed of Ac and As. These clouds are not very suitable for seeding, especially because they move in parallel to the mountain range and lack of a strong rise component, which would produce a greater amount of superercooed droplets. The frequency of occurrence of these clouds is only $10 \%$ of the total number of clouds suitable for seeding. The evaluation of the rainfall stimulation experiment success in the High Atlas Mountains was performed by comparing data of rainfall in target (seeded) and two control areas. One control area is located south and second north of the target area. Regression method showed that the rainfall in the target area increased by $15 \%$. The same increase is showed on the river flows data in those areas. Also, chemical analysis showed that rainfall in target area contained considerable amounts of AgI particles, while AgI particles were not identified in the control areas (Baddour et al., 1994). 


\subsection{Mexican experiment}

Severe drought in the early 1990s prompted the authorities of Coahuila, Mexico, to address the National Centre for Atmospheric Research (NCAR) in Boulder, USA, with a request to set up a research program of rainfall stimulation called PARC (Program for the Augmentation of Rainfall in Coahuila) in Coahuila. The goal of this program was to investigate the possibility of increasing rainfall using cloud seeding.

NCAR proposed a 4-year program which included physical studies, randomized cloud seeding experiment and training local staff to participate in this activity. During the 1996th the strategy of the experiment is defined and made all necessary preparations. It is proposed to fully implement cloud seeding methodology that was used in South Africa with the release of hygroscopic materials in the updraft.

The operational performance of the experiment began in June 1997. Based on radar data and observations that are made from aircraft the clouds suitable for seeding are selected. Than, the randomization procedure is applied. From the series of closed envelopes with slips of paper that read "seed" or "no seed" operations manager and pilot take one envelope. When the pilot take off operations manager opens the envelope and notify pilots about the content slips in his envelope. Then the pilot opens the envelope and looked at their inscription on the piece of paper. If the contents of both envelopes coincide pilot decided to carry out seeding. Otherwise seeding is not done. In both cases, the aircraft carried out the procedure that is defined for the seeding. The pilot do not tell to anyone on the team that is engaged in conducting the experiment. Envelope with a piece of paper is then deposited in the archives and made available to researchers only in the efficiency evaluation process. After the take off starts the TITAN software for automatic display of radar data and aircraft position in real time, which is used to manage the operation.

In 1997. and 1998 the total number of the clouds who met the conditions for seeding was 99. By the method of randomization 48 was seeded and 51 was not seeded (Bruintjes et al., 1999).

\subsection{New Zealand experiment}

Southern Alps in New Zealand are the barrier for the western flow and therefore of Canterbury Plains, which are on leeward side of these mountains, have significantly less rainfall than other areas. In addition to small amounts of rainfall a longer drought periods occur, which sometimes exceed a hundred days without precipitation in the growing season.

To mitigate such a long drought in the otherwise fertile field, it is started with rainfall stimulation experiment. Due to this reason it is selected the target area for seeding and the same control area, separated by a buffer zone. Seeding was cross randomized. During the 10 years was carried out 100 seeding experiments that had different duration. These periods are classified under the amount of precipitation increased by 10,20 and 30\% with the level of significance of 5\% (Steiner and Shaw, 1985). 


\subsection{Russian experiments}

\section{Penza experiment}

In the process of cloud formation and formation of rainfall still there are more insufficiently explained phenomenon. This significantly complicates the effective stimulation of precipitation. To better acquainted some of these phenomena, a special training centre in the middle Volga River basin near the city of Penza is established. It is equipped with all necessary ground equipment for measurement and radar MRL-5, as well as a flying laboratory AN-12 plane, which is also used for cloud seeding. Pyrotechnic cartridges with the reagents of silver iodide are expelled in convective clouds or granulated dry ice in stratiform clouds. Detailed studies of the atmosphere and the various variables in the cloud were carried out using a flying laboratory IL-18, which is equipped with the latest automated measuring devices.

Numerous studies on the training centre had conducted in the course of 1982-84 . Most of them are related on the possibility of increasing of the amount of rainfall in different types of clouds through their modification. In this study, convective clouds are seeded by a randomized method. The method of layer and frontal clouds seeding was varied during the winter. It is dependent on various physical parameters of clouds and precipitation.

During the research period it is observed hundred cases of convective clouds that meet the requirements for seeding. Based on the randomization 46 of them are seeded and 56 are not seeded. There are a number of interesting findings by comparing the various physical parameters. One of the most important findings is that the height of the radar cloud top, maximum reflectivity and the reflectivity below the base of convective clouds are increased after seeding. In layer clouds was observed the change of droplet spectrum by increasing the number of raindrops per unit volume of cloud mass in comparison with unseeded clouds (Berjulev et al., 1985).

\section{Zeravshan experiment}

In Central Asia around Zeravshan mountain range, the centre is formed on which an experimental and theoretical studies of frontal cloud systems transformation are performed and the possibility of rainfall simulation. In particular, the micro and meso-structure of orographic clouds are investigated and distance of generators from the top of the ridge on the windward side to achieve the maximum effect of precipitation stimulation.

By moving the generators to different distances from the top of the ridge on the windward side, it was found that the maximal precipitation stimulation is achieved when the generators are set at distance of 10-15 km. Maximal stimulation of rainfall occurs 30 minutes after the releasing of reagents from the generator. The maximum occurs right near the top of the ridge on the windward side while the rainfall intensity is about one order of magnitude smaller on the leeward side (Berjulev et al. 1989). 


\section{North Caucasus experiment}

Some parts of the North Caucasus are the most developed agricultural areas in Russia. However, due to the aridity it needs to increase the amount of rainfall artificially. So it begin with stimulation of rainfall, which is done by seeding of layer clouds St, Sc and convective cloud type $\mathrm{Cb}$ and $\mathrm{Cu}$. Seeding was done in the spring and summer.

The criteria for seeding were that clouds have a thickness at least $1.5 \mathrm{~km}$, and their tops have a temperature lower than $-10^{\circ} \mathrm{C}$. Seeding was carried out from aircraft-laboratory AN-26, Yak-40, Il-18 and An-12. Seeding was carried out simultaneously with 2-3 aircraft which expel the AgI pyrotechnics and solid SO2. The evaluation was done by comparing the amount of rainfall and yield of wheat on seeded and control areas. The results show that annual precipitation are increased in average by $16 \mathrm{~mm}$, and wheat yield by $80 \mathrm{~kg} / \mathrm{h}$ (Ekba et al., 1994).

\section{Yakut experiment}

Due to the frequent droughts in the Republic of Jakutia the agriculture suffers severe damages. In order to mitigate damages and Yakutia government decided to introduce a stimulation of precipitation. It is entrusted to the Central Aerological Observatory in Moscow. Objectives of Jakut's experiment were: 1) to study the characteristic of weather systems that provide precipitation in the central area of Yakutia, 2) to apply modern technology to stimulate rainfall in the spring and fall, 3) to analyze the results of stimulation of rainfall using statistical methods.

The experiment was performed in the period 1995-1997 in the area of 30000 $\mathrm{km}^{2}$. Instrumental equipped aircraft AN-26, "Cyclone" and AN-30 are used. With these aircrafts the measurements of meteorological parameters in the atmosphere and the physical parameters of the clouds were performed. Also, from them are carried the cloud seeding by signal rockets and ejection of cartridges filled with AgI. In addition, for the first time the seeding of clouds are carried out with the generators of liquid nitrogen and scattering techniques is applied.

The evaluation was done by using a regression method based on historical data and data from monitoring stations. The results showed that in this experiment period the precipitation are increased by $43 \%$ with the level of significance $\alpha=0.09$ (Berioulev et al., 1999).

\section{Cloud seeding activity to modify weather conditions in cities}

During the last twenty-thirty years considerable work has been done in Russia on the development of methods and technical means to dissipate some forms of clouds and preventing or substantially reducing precipitation amount over protected areas. The practical objectives of cloud seeding activity were to reduce municipal expenses for snow removal and clearing the roads and streets in large cities, to create favorable meteorological conditions for carrying out social programs, sporting competitions or some other situations when the necessity may arise to reduce the rainfall.

The first experiment on practical application of these opportunities was carried out to mitigate the consequences of Chernobyl disaster in 1986 (Beriulev et al. 1990). Since 1995 the 
organizations of ROSHYDROMET conducted more than 40 experimental projects on improvement of weather conditions in areas of the large cities - Moscow and St.Petersburg (Russia), Tashkent (Uzbekistan), Astana (Kazakhstan) (Korneev et al., 2003, Koloskov et al., 2007). The main purpose of these activities was the dispersal of clouds and reduction or prevention of precipitation over the protected areas. The technology of rain mitigation has been successfully used during Beijing 2008 Olympic Games opening and closing ceremonies (Zhang Qiang et al., 2011).

Analysis of the radar and raingauge information collected in more than 40 experimental cloud seeding operations to modify weather conditions in cities showed that: 1 ) in $38 \%$ of cases there were no need to seed clouds due to the fine weather; 2) cloud seeding with 6 to 12 aircraft caused the destruction of stratiform and precipitating convective clouds in $25 \%$ of cases, and 3 ) considerable, 3-10 times decrease of intensity and amount of precipitation was obtained over the protected territories in comparison with rain fallen over control areas in $37 \%$ of cases (Koloskov et al. 2011).

\subsection{Syrian experiment}

Syrian operational rainfall stimulation project began to realize 1991. This project is performed under the contract concluded between the Syrian Ministry of Agriculture and the Central Aerologic Observatory from Moscow. Under this project, cloud seeding is done over the whole territory of Syria $\left(185000 \mathrm{~km}^{2}\right)$ in the period December-Mart.

Cloud seeding is done from four aircraft, two AN-26 and two Yak-40, equipped with the necessary meteorological instruments. The reagent AgI is used, which is inserted into the cloud using generators flares and signal rockets. Observation of clouds and precipitation is carried out using four types of meteorological radar MRL-5, equipped with a digital radar system.

The evaluation was done by using regression methods of historical data which used the rainfall data for the period of 30 years prior to the seeding of clouds. . Seasonal increase in rainfall caused by cloud seeded in average amount up to $12 \%$ with level of significance $\alpha=$ 0.05 (Kolaskov and Melnichuk, 1999).

\subsection{Thai experiments}

\section{Operational program of rainfall stimulation}

In Thailand the late 1960s began to perform experiments on weather modification in order to increase the amount of rainfall. In 1975 was formulated the national program for operational rainfall stimulation and formed a separate Institute for the Study and Development of the process of stimulation of precipitation. In 1986 the Government of Thailand has asked the U.S. technical and financial assistance for the development of the operating system stimulation of precipitation. U.S. has accepted this request and determined the U.S. Bureau of reclamation to be involved in the program of rainfall stimulation in Thailand. (Sukamjanaset, 1999). 


\section{Warm cloud seeding experiment}

U.S. Bureau of reclamation, in cooperation with the Thai authorities performed a program with two separate experiments, whose goal was to strengthen the way the technological basis for operational rainfall stimulation. The first experiment was related to the seeding of warm clouds and the second on the cold cloud seeding. These experiments were performed in the period 1994-1998.

To perform the warm cloud seeding experiment Bhumipol area in northwestern Thailand. was selected. Within this area it is separated two small areas where seeding of the convective clouds was done by cross randomization method. Seeding was done by calcium chloride, since this reagent is hygroscopic and has a characteristic size of the particles. Particles of this reagent are hygroscopic and relatively which accelerate the growth of droplets and their process of collision and merging. The rapid formation of raindrops cause that the clouds that naturally would not give precipitation produce precipitation, and clouds that would naturally give precipitation secrete more precipitation.

The experiment was performed during the summer monsoon months from June to September. Isolated and semi-isolated convective clouds, which had the form of cauliflower, were seeded. The criterion for cloud seeding is that it has the peak height at least $3.77 \mathrm{~km}$, and lower than the freezing level $(5-6 \mathrm{~km})$. Then, the cloud has at least $0.5 \mathrm{~g} / \mathrm{m} 3$ liquid water content at the level of plane flight of $3.55 \mathrm{~km}$ and updraft speed at least $3 \mathrm{~m} / \mathrm{s}$ and the length of the plain route through the cloud at least $2 \mathrm{~km}$, and maximum of $6 \mathrm{~km}$. Such a cloud is considered an experimental unit. The dose at each seeding is $21 \mathrm{~kg} / \mathrm{km}$.

In 4 years 76 experimental units are observed. Of these, 38 are seeded and 38 were not seeded. Based on radar parameters the precipitation volume extracted from each of them is obtained. This volume is for the seeded clouds in average $137100 \mathrm{~m} 3$, and for not seeded clouds $65600 \mathrm{~m} 3$. It follows that the seeded clouds excrete twice more rainfall than unseeded clouds (Silverman et al., 1999, Chumchean et al. 2011).

\section{Cold cloud seeding experiment}

The term cold cloud here is meant convective cloud whose dome is the area of negative temperature and contains a supercooled drops. In the northwest area Bumipol, Thailand, over territory size of $1964 \mathrm{~km}^{2}$, was performed the cold cloud seeding in the period 1991-1998. The criterion for the seeding was:

1) Top of the radar echo is greater than $10 \mathrm{~km}$;

2) The temperature of the dome of clouds is lower than $-10^{\circ} \mathrm{C}$;

3) Cloud water content of the dome of clouds is greater than $1 \mathrm{~g} / \mathrm{m} 3$;

4) Updraft velocity in the dome of clouds is greater than $5 \mathrm{~m} / \mathrm{s}$;

5) Cloud has a distance from the nearest $\mathrm{Cb}$ cloud at least $40 \mathrm{~km}$.

Under $\mathrm{Cb}$ cloud is considered a convective cloud with top height of the radar echo over $10 \mathrm{~km}$ and a maximum reflectivity greater than $50 \mathrm{dBZ}$.

During this period, 85 experimental units is observed. Each is monitored within a period of 300 minutes. According to the method of randomization, 43 were seeded and 42 were not seeded. On the basis of radar measurements were obtained that seeded clouds on average per 
experimental unit were provided 7,61.106 m3 of water, and unseeded 4,82.106 m3 of water. . This gives a ratio of 1.58 with a significance level of $\alpha=0.05$ (Woodley et al., 1999).

\subsection{Turkish experiments}

The first national experiment in Turkey was organized near the Istanbul in 1990. The goal was to increase the amount of water in the reservoirs supplying the city which after several years of drought were down to a minimum,

This experiment was performed static cloud seeding silver iodide reagent ejected from aircraft in a cold parts of cloud. After six months it was estimated that in seeded area compared to surrounding non seeded increase rainfall by $24 \%$. (Sen and Kidic, 1994).

The second experiment of rainfall stimulation in Turkey is carried out near Ankara in the period from 1 April 1991 to 31 May 1992. The goal were seeding of cold part of convective clouds in a the zone with temperature of $-5^{\circ}$ to $-10^{\circ} \mathrm{C}$. Seeding was carried out using a Cessna aircraft with generator that ijected $2 \mathrm{~g}$ per minute of silver iodide. During this period seeding was done in 15 days with 35 hours of seeding. This experiment was performed by an American company specializing in the weather modification. Comparison of rainfall over the seeded area and the surrounding control area did not show that there has been a remarkable success. (Akgun, 1999).

\subsection{Uzbek experiment}

The river basin Kashkadarija in Uzbekistan is carried out the stimulation of precipitation in peiod 1985-1991. Seeding was performed using anti-hail rockets filled with silver iodide reagent. The layer clouds (St, Sc, Ns) covering 8-10 tenths of the sky were seeded. Reagent is injected into the parts of the cloud whose radar echo was $500 \mathrm{~m}$ above the ground and the cloud temperature between $-12^{\circ}$ and $-30^{\circ} \mathrm{C}$, and the cloud water content in a cold part of the cloud is greater than $0.05 \mathrm{~g} / \mathrm{m} 3$.

The evaluation was done by comparing the results of winter precipitation in the meteorological station at 7 seeded and the same number of cells in surrounding nunseeded territory. The results showed that only one of seven stations on the unseeded territory observed increas of rainfall by $7.3 \%$, while all other observed decrease in rainfall by amount of 19$23 \%$. Of 7 stations on the seeded territory only 2 showed reduction of rainfall by $2-3 \%$, and others have shown an increase, of which 3 stations have increase of $12-43 \%$. Analysis of the results of simulation of rainfall has further shown that artificially induced increase in rainfall amounted to 10 to $50 \mathrm{~mm}$, and an additional amount of water was in the winter season from 3 to 23 million m3. (Kamalev, 1999). 


\subsection{Ukrainian experiments}

\section{Stimulation of precipitation in summer}

In the steppe part of Ukraine, in the vicinity of the Curved horn, performed the experiments stimulation of rainfall nearly four decades. Special programs are being implemented for the winter, summer and for the spring and autumn. During the summer convective clouds were seeded with silver iodide, in the winter the layer clouds are seeded with dry ice. A spring and autumn both of these types of clouds are seeded.

Convective clouds were seeded by the plane below cloud base in the area of updraft. Reagent is dispersed by burning 5\% solution of acetone and silver iodide, mixed with $1 \%$ ammonium iodide. During the period 1979-1983 randomized experiment was performed $\mathrm{Cb}$ clouds seeding over the area size of $8000 \mathrm{~km}^{2}$. Time from start to finish seeding, plus three hours was considered as an experimental unit. Precipitation is measured using a network of pluviograph placed every $30 \mathrm{~km}^{2}$. Amount of precipitation is calculated from the map of isohyet for each experimental unit.

During this period, 39 experimental units are considered, of which 19 were seeded and 20 not seeded. The average ratio of rainfall, which is extracted from the seeded and unseeded clouds is 1.4 , i.e. the amount of rainfall is increased during the summer by $40 \%$.

\section{Stimulation of precipitation in winter}

During the winter the layer clouds Ns-As with mixed of droplets and ice crystals are seeded. The clouds that had temperature lower than $-4^{\circ} \mathrm{C}$ and thickness of cloud greater than 300 $\mathrm{m}$ are seeded. Seeding is done with dry ice $(\mathrm{CO} 2)$. Evaluation of the results showes that seeding in winter season increase precipitation by $25-30 \%$ compared to the normal climate.

\section{Stimulation of precipitation in spring and autumn}

In these seasons in the steppe part of Ukraine the clouds are same as those observed in winter and summer. Cloud seeding experiment was implemented in the period 1981-1984. The experimental unit lasted 12 hours. Seeding was done over area of $500 \mathrm{~km}^{2}$. During this period, the 30 experimental units are considered, of which 19 were seeded and 11 not seeded. Three experimental units were convective, and 27 Ns-As clouds. The average ratio of rainfall between the seeded and unseeded clouds is 1.32 , i.e. the average rainfall increas by seeding was $32 \%$ (Buikov et al., 1985).

\subsection{Honduran program}

In Honduras in the river basin El Kahon conducted stimulation of precipitation in the period 1993-1995. The aim of this stimulation was the increase of the level of water in the lake for hydropower, which was very low after several years of drought. Simulations are performed by experts from the United States. Stimulation of precipitation is carried out in the summer rainy season. Seede area was approximately $6450 \mathrm{~km}^{2}$. 
Seeding is done from the Cessna 340A aircraft by ejection of silver iodide from generators and falling flares. Flares were thrown into the dome of convective clouds that reach a height where the temperature is $-5^{\circ} \mathrm{C}$ (about $5.5 \mathrm{~km}$ ). Generators with silver iodide and acetone were used for seeding of layerclouds.In addition, they used the ground-level generators. Seeding in the free atmosphere was carried out only during the day, while ground-level generators are used during both day and night. The whole process of development of clouds, precipitation and seeding was followed by the meteorological radar of $5 \mathrm{~cm}$.

The results of cloud seeding were obtained by comparing the amount of rainfall from seeded and the surrounding control territory. The regression equations derived from the historical data of rainfall for the period prior seeding and during seeding have been used. For each season, increasing of the rainfall amount for seeded territory was 13\%. It means that 366 $876 \mathrm{~m}^{3}$ of water is additionally produced for the season 1995 (Griffith and Solak, 1999).

\subsection{WMO PEP project}

Seventh World Meteorological Congress held 1975 was established the PEP (Precipitation Enhancement Project) project, as its main program in the field of weather modification. PEP was conceived as an international weather modification experiments. His main goal was to demonstrate a statistically significant level that the annual precipitation, measured on the ground over a certain area can be increased. In addition, this experiment should fully understood the physical processes that lead to this increase.

This experiment was organized in the Duero River basin in the northwest of Spain in the period from February to May in the years 1979, 1980 and 1981. The experiment consisted of his administration, synoptic lab, sounding stations, network of precipitation stations, Queen Air aircraft fully equipped for cloud physics research, digitized two-wave radar, satellite receiver, etc..

The aim of the experiment in the initial phase was to determine which clouds are suitable for seeding in a given area and how often they occur. Also, It was the aim to realize how increasing the amount of rainfall in certain types of clouds can be expected on the basis of cloud water content measurement and other available parameters. In order to systematize the weather situation and carried out some measurements, the classification of clouds was made. The first step in this classification was to distinguish between deep (thick), shallow (thin) and large clouds from isolated convective clouds. According to the specification the clouds are classified into the following four classes:

Class A: Ns; connected cloud layers Cs and As, and Cs and Ac. For these clouds were introduced two subclasses, namely: AW clouds whose tops have temperature $>-18^{\circ} \mathrm{C}$ and AS clouds whose tops have a temperature $<$ of $-18^{\circ}$.

Class V: St, As, Cu hum, Sc, Ac.

Class $\mathrm{S}$ : med $\mathrm{Cu}$ and $\mathrm{Cu}$ con;

Class D: Cb calv.

Due to the volatility of types of clouds above a particular area, it was decided to take as an experimental unit only one type of cloud that took at least 6 hours. Statistics of cloud types derived for three seasons showed that the total number of experimental units for each class 
emerged: (AS, 64\%). AW, 3\%), (S, 22\%), (D, 10\%).

The clouds are thought to be suitable for rainfall stimulation if: 1) collision / merger or warm rain process is inefficient, 2) the amount of cloud water content of formation in the cloud is greater than her volume of disappearance, 3 ) there is adequate time for the growth of artificial rainfall to precipitable elements which can reach the ground.

PEP project lasted only 3 instead of 5 years. He was stopped for financial reasons. However, a team of experts who worked on this project has enriched many knowledges of rainfall stimulation process. Thus, for example, perfected the technique of location the zone in the cloud with a supercooled droplets by using radar and airplanes-laboratories. These findings not only allow to precisely determine the space in the cloud which will be seed, but also to evaluate the additional amount of rainfall, which can be expected in each of such clouds.

Using this methodology it is estimated that in the respective area of greatest increase in average rainfall may be obtained from the cloud of class $\mathrm{S}(17 \%)$, then from the cloud of class $\mathrm{V}$ $(9 \%)$ and finally the clouds Class A (3\%). These estimates are valid only for the area of the river Duero, while in every other area the frequency of various types of clouds and their water level and suitability for seeding would be different (List, 1985).

\subsection{Japanese Cloud Seeding Experiments for Precipitation Augmentation (JCSEPA)}

In populated areas of central and western part of Japan, it have had a potential problem of water shortage. For the last twenty years, it had the problem of water shortage almost every two or three years, especially in Kanto and Shikoku district. In the summer of 2006, MRI, in cooperation with 10 other research organizations, launched the five-year research project (20062011) "Japanese Cloud Seeding Experiments for Precipitation Augmentation (JCSEPA)" to aim drought mitigation and water resources management. It isWe carried out summertime weather modification project around Sameura Dam and wintertime project around Yagisawa Dam. Sameura dam is the main water supply for Shikoku district, where they have droughts most frequently in Japan. Yagisawa dam is one of main water supplies for Tokyo Metropolitan area. In this paper some results from our wintertime and summertime weather modification projects are briefly described. The project JCSEPA is made of 4 sub-programs; analytical study by using past meteorological and hydrological data, remote sensing study by using multi-wavelength active and passive sensors, airborne and ground-based in-situ measurement study, meteorological and hydrological numerical modeling study and cloud chamber experiments. JCSEPA has three main goals. The first one is to investigate the causes of drought at different areas in Japan by analyzing past meteorological and hydrological data and identify typical weather pattern during drought. The second one is to develop a sophisticated weather modification technology for orographic snow clouds. The third one is to investigate the possibility of rain enhancement by hygroscopic seeding (hygroscopic flare and salt micro-powder) in warm season. It is shown the opreliminary results for the appearance frequency of summertime clouds suitable for cloud seeding in qualitative sense. Cloud types are based on cloud top temperature and cloud thickness obtained from a combination of several active and passive remote sensor data. Until now, results show that about 10 percents of clouds may have possibility for hygroscopic seeding and another 10 percents of clouds for glaciogenic seeding. They are still continuing to improve the algorisms for a better evaluation of summertime seedable clouds. The results obtained so far showed that 
hygroscopic seeding of warm clouds may be effective under limited conditions Hygroscopic seeding of cold, convective clouds is reported to be effective although there remain many arguments about the effectiveness. More intensive study is needed to conclude the effectiveness of hygroscopic seeding of warm and cold clouds (Murakami, 2011)

\subsection{Investigation of AgI Seeding Efficiency in Saudi Arabia}

Saudi Arabia has an area of about 2.25 million $\mathrm{km}^{2}$, most of which is located in arid regions. Studies have been conducted previously to determine if cloud seeding is able to increase the precipitation (Vali, 1991). Starting in November 2006, cloud seeding trials and cloud physics research studies have been conducted in both the central region around Riyadh and the southwest Asir region around Abha.

Carried out experiments show that $\mathrm{Cu}$ microphysical characteristics change due to seeding but quantity of additional precipitation is still a challenge in the knowledge.

Assessments of $\mathrm{Cb}$ seeding efficiency are more complicated, especially for multicell $\mathrm{Cb}$ when merging processes with feeder cells take place.

The radar parameters, primarily maximum radar reflectivity of natural $\mathrm{Cu}$ cong and $\mathrm{Cu}$ cong seeded with silver-iodide in the Asir region, precipitation flux, and rain volume are derived. A summary of the storm characteristics and an exploratory statistical analysis of the response variables are presented ( Sinkevich et al. 2011).

Cloud top seeding was conducted by aircraft flying at an altitude corresponding to the $10^{\circ} \mathrm{C}$ level, typically between 6 and $7 \mathrm{~km}$ MSL. The seeding aircraft seed $\mathrm{Cu}$ cong with $20 \mathrm{~g}$ ejectable silver-iodide flares. For storms with feeder clouds, the seeding aircraft seed the tops of the developing cumulus towers on the upwind sides of the more mature convective cells, as they grow up through the $-10^{\circ} \mathrm{C}$ altitude. The ejectable flares are typically dropped at a rate of one 20 $\mathrm{g}$ flare every $5 \mathrm{~s}(500 \mathrm{~m})$ during a cloud penetration. Seeding stopped if there were visual signs of glaciation and high ice concentrations.

Three groups of seeded clouds were studied: Group I consisted of 28 clouds seeded at a time without any radar echo, and 43 natural clouds for comparison purposes. Group II consisted of 21 clouds seeded when the radar echo was $>0 \mathrm{dBZ}$ but $<20 \mathrm{dBZ}$, and 44 natural clouds for comparison purposes. Group III consisted of 13 clouds seeded when the initial radar echo was $>30 \mathrm{dBZ}$, and 19 natural clouds for comparison purposes.

The Group I seeded clouds produced greater maximum reflectivity (ZMAX) and greater precipitation flux than their natural counterparts. The difference in the ZMAX means was 3.3 dBZ. 


\section{4}

\section{NUMERICAL SIMULATION OF PRECIPITATION STIMULATION}

\subsection{Using the cloud model to simulate rainfall}

Numerical cloud models used in weather modification over three decades. The sudden rise of the instruments and equipment for meteorological observations, then the radar and computers, which have been achieved in recent years have enabled the development of modeling clouds and phenomenons related to them. Thus, the scientists in the field of weather modification got a powerful tool for simulating the development of clouds and determine the impact of actions on them.

Until now has developed a number of cloud models, which are classified as zero-, one-, two- and three-dimensional models. Then, the models in which the water in microphysics is treated in the mass (bulk) or more detailed ( models of category). Zero-dimensional models are essentially models of particles. All these models are time-dependent cloud.

Multy dimensional cloud models are based on the solving of nonlinear thermodynamic, dynamic, and microphysical equations. These are normally fully connected models. Change a dependent variable caused by growing cloud can affect each other depending on the variable. For a detailed presentation of the microphysical elements (cloud droplets, raindrops, ice crystals, etc.) cloud models contain 50 or more equations.

The equations of the cloud model are solve by numerical methods. For this purpose it is defined the domain of the model, which is usually taken $100 \mathrm{~km} \times 100 \mathrm{~km} \times 20 \mathrm{~km}$. This space is usually devided in the interval $400 \times 400 \times 250 \mathrm{~m}$ in directions $\mathrm{x}, \mathrm{y}$, z. Time step usually takes $6 \mathrm{~s}$.

Three-dimensional cloud model to that with a tracer reagent is added, e.g. sulphur hexaphlorid (SF6), which can be traced in nature, and then simulate in the model. On that way can be reliably monitor the distribution of reagents in the cloud, its concentration and the potential effects. In addition, models of clouds in weather modification can be used for the following purposes:

1) Review of the hypotheses about the dynamical and microphysical processes in the clouds:

2) The evaluation of the criteria for cloud seeding;

3) Quantitative evaluation of the implementation of seeding (time, place and amount of reagent to be inserted into the cloud);

4) Evaluation of the effects of cloud seeding.

(Orville, 1990; Farley, 1994). 


\subsection{Numerical simulation of rainfall stimulation from convective clouds}

$\mathrm{Cb}$ cloud seeding is widespread in the world. The reasons for this are efforts to prevent the fall of hail and increase the amount of rainfall. To strengthen the scientific basis of the performance of such actions and better understand the dynamics and microphysics of convective clouds it is made a number of models of convective clouds for simulation of cloud development and a better understanding of processes occurring in them. One such model of $\mathrm{Cb}$ cloud developed by the $\mathrm{Hu}$ (1988). Briefly, here will be show how this model work.

$\mathrm{Hu}$ and $\mathrm{He}$ (1989) used the model of $\mathrm{Cb}$ cloud to simulate its natural development and changes after seeding. It will reviewed the three types of seeding: 1) seeding with AgI with rockets and artillery shells, 2) seeding of AgI by using generators from the ground, 3) seeding with hygroscopic powder. The authors came to the following conclusions:

1) This model can be realistic to simulate the development of artificial ice crystals embryos evolution and its interaction with cloud particles.

2) $\mathrm{Cb}$ cloud seeding, if done in certain ways and under certain conditions, can lead to increased rainfall or to prevent the fall of the hail.

3) The effect of seeding is associated with the characteristics of clouds. Numerical experiments show that seeding with dry ice has a smaller effect on the clouds with warm base which contain mainly the warm rain drops.

4) The model shows that embryo freezing of rain drops (large cloud droplets), formed by a process of autoconversion at low temperature is a main source for the formation of graupel in many clouds. Bergeron process is not significant in both the $\mathrm{Cb}$ clouds seeded and unseeded.

5) The increasing of rainfall is higher if the seeding is carried out earlier.

6) Reducing the concentration of embryos of dry ice from $10^{7} \mathrm{~kg}^{-1}$ in $2 \times 10^{6} \mathrm{~kg}^{-1}$ reduces the effect of preventing the hail.

7) The injection of dry ice of the same concentration but at higher level reduces the effect of preventing the hail.

8) Reducion of the concentration of raindrops by artificially produced embryos from $10^{3}$ $\mathrm{kg}^{-1}$ to $10^{2} \mathrm{~kg}^{-1}$ weakens the effect of rainfall increasing.

9) Increase of the dept of seeded layer of clouds with the same concentration of reagents $\left(10^{3} \mathrm{~kg}^{-1}\right)$ increases the amount of artificially induced precipitation.

The three-dimensional mesoscale cloud-resolving model (Ćurć et al., 2008) was used to investigate the dispersal of an inserted seeding agent within and outside a cumulonimbus. The object of such modification effort is to produce fairly substantial changes in precipitations with minimal input of seeding agents. The variety of such proposals covers almost all aspects of cloud microphysics, and also extends to direct alteration of the cloud microphysical structure. In last two or three decades, important advances in observational capacity, data acquisition, processing and numerical modeling of processes important to cloud seeding have been made. Despite these facts many fundamental problems are still open as follows: critical uncertainties are not resolved, understanding of the chain of physical processes is not advanced as well as our capability to prove exactly the success or failure of some cloud seeding concept.

However, significant amount of the AgI agent can be found in downwind direction from the target cloud during seeding. The use of ground-based silver-iodide generators often has led to uncertainties about the particular clouds or volumes which have been treated and about the 
concentrations of silver iodide reaching the target clouds. During the seeding performed by rockets the agent trail behind the rocket starts to form before reaching the appropriate zone. Finally, the aircrafts (non-rarely) inject the agent in front of the main updraft because of security or the presence of vortices in subcloud region (Ćurić and Janc, 2011a). As a consequence the agent would not be captured obviously by the target cloud but by the new cell formed above gust front head. Such scenario could be responsible for inadvertent enhancement of precipitation far from the initial seeding area. Facts about the presence of AgI particles over $100 \mathrm{~km}$ downwind from the point where the agent was released as well as unplanned enhanced precipitation are still highly controversial.

The primary goal was to answer the question whether the seeding agent transfers and lead to enhanced precipitation far from initial seeding area. It is considered the cold convective clouds in which the temperature drops below $0^{\circ} \mathrm{C}$ and both ice and liquid particles may exist. According to observations they are capable of producing significant amount of precipitation via cold rain processes. The effects of seeding to such clouds is therefore of considerable interest. They cannot be determined by observations because it is not possible to measure the precipitations from their unseeded counterparts since no two clouds are alike.

It was proved the statement about the presence of silver-iodide over $100 \mathrm{~km}$ far from the point where it was released and detected inadvertent enhanced precipitation. Since the comparison between characteristics of seeded and unseeded cloud is not possible to be measured the cloud-resolving mesoscale model remains the best tool for simulation of the cloud seeding consequences. Among different scenarios, it is found out one in which the silver-iodide agent was injected between $-8^{\circ} \mathrm{C}$ and $-12^{\circ} \mathrm{C}$ in front of the target cloud. It is shown that the area with about $50 \%$ increase in cumulative precipitation exists on the right with respect to target cloud propagation. This is over $110 \mathrm{~km}$ far from the mass center of initial seeding area

\subsection{Numerical simulation of rainfall stimulation from layer cloud}

Weather modification is started with seeding of layer clouds. Therefore, and due to the simplicity of the dynamics and cloud microphysics, they were modelled many decades ago. However, despite many years of experience with models of layer clouds, we still insufficient know some dynamical and microphysical characteristics and effects of it seeding. Here we present some important findings regarding the seeding of layer cloud by using three-dimensional models.

$\mathrm{Hu}$ (1994) performed the numerical simulation of cloud seeding layer cloud with dry ice. Three-dimensional model used had the following characteristics: horizontal domain 2100 $\times 2100 \mathrm{~km} 2,10$ vertical layers of the thickness of $150 \mathrm{hP}$, horizontal step is $70 \mathrm{~km}$, and time is 193 s, 24-hour simulation interval.

Nine hours after the beginning of the simulation at two points of the network in the northeast area are entered a number of small particles of dry ice, which is then slowly moved towards the southeast. For selected weather situation with layer cloud five experiments are carried out that differed in concentration of dry ice and the level of injection. These simulations have yielded the following results: 
1) cloud seeding layer showed a significant dynamical effect, which is reflected in the increase of temperature and velocity of updraft near seeding zone.

2) Increase of the intensity of falling snow is followed by a decrease in vapor pressure and cloud water content.

3) The amount of rainfall has increased in the seeded and downwind areas.

4) Te amount of rainfall is reduced in the surrounding around the seeding areas.

5) Reducing of the amount of rainfall around seeding zone is much smaller than the increase in the seeded zone.

\subsection{Numerical simulation of rainfall stimulation from frontal cloud}

Atmospheric fronts have their own special cloud systems with the special dynamics of a given area and rainfall. Due to this season it is given special attention to their modeling and the precipitation stimulation. One such numerical experimental situation will be displayed here. It was performed by (Pirnach, 1999) by using three-dimensional diagnostic and prognostic models. The simulation was performed with data pertaining to an occluded frontal system, which is 7 December, 1988 came from the southwest of Ukraine. This frontal system is characterized by rainy zone which was located in front of the cold front and that was several kilometers wide. The rainy zone was the subject of the numerical simulations of the experimental seeding.

The formation and development in space and time of atmospheric fronts and rain zones are simulated by integrating the system of thermodynamic equations, including equations of motion of air, water vapor content, heat transfer, cloud droplets and ice particles distribution function, the continuity equation and the equation of state of the gas, advection, horizontal and vertical diffusion, and sedimentation of particles. The simulation is performed in a moving coordinate system, which migrated with the velocity of moving frontal system.

Numerical simulation and seeding showed that different parts of the wet zone have different requirements for stimulation of precipitation. These conditions indicate that there are some redistribution of rainfall characteristics and the location of sources and sinks of humidity in the rainy zone. Numerical experiments of seeding were performed with increasing concentrations of the various particles of dry ice in a narrow zone of the rainy cold front, and compared with each other. It has increased precipitation in the fields above which are seeded deep layer of clouds. Decrease in rainfall coincided with the time and place of the heavy rainfall maximum. (Pirnach, 1999).

\subsection{Numerical simulation of rainfall stimulation from orographic cloud}

Orographic clouds are characteristic in that they usually occur and precipitation produce under the influence of the forced lifting od air caused by orography. It is therefore of special scientific and practical interest to know the extent to which the orographic clouds are suitable for seeding and increased rainfall. Such studies were carried out in several places in the world. Precipitation processes in cloud systems in the Sierra Nevada mountains are investigated for many years because of their importance for water resources in the area (Meyers et al., 1994).. The focus of these research programs (such as the Sierra Cooperative Pilot Project)was to investigate and quantify microphysical and dynamical characteristics of orographic cloud systems. Also to determine whether the weather modification is a valid alternative to the increase 
of the amount of rainfall in these areas.

The situation of 18 December 1986 is simulated with three-dimensional cloud model. The data for the simulation were obtained from the above project. The results showed good agreement between simulated natural processes of clouds and observed microphysical characteristics.

The simulation produced a large seeded areas with a concentration of aerosols one order of magnitude greater than unseeded cloud. Seeding has also produced an increase of ice crystals, the mass of raindrops and graupel in downwind area. In general increase in precipitation caused by seeding amounted to 0.5 to $1.5 \mathrm{~mm} / \mathrm{h}$. The similar values were obtained by observations. In this simulation the area with decreasing rainfall were not observed. 


\section{GENERAL WEATHER CONDITIONS DURING $\mathrm{Cb}$ CLOUDS DEVELOPMENT IN UAE}

\subsection{Prevailing air flow in the mid troposphere}

The development and the displacement of $\mathrm{Cb}$ cloud is under strong influence of the direction of the air flow in the mid troposphere. That flow is possible to find out on the base of synoptic charts of $500 \mathrm{hPa}$. The midday synoptic circulation charts of the mid troposphere, at $500 \mathrm{hPa}$, have been evaluated for each summer days with observed $\mathrm{Cb}$ cloud within the period 2005-2011. The prevailing synoptic circulations have been classified into eight circulation patterns over the region of UAE. The classification codes are: N, NE, E, SE, S, SW, W and NW. It means that we consider the eight possible directions of the upper wind. The frequency of occurrence is shown in Fig. 5.1.

On a seasonal bases the NE direction has the highest total number of occurrences $(56 \%)$ over the study period. $\mathrm{N}$ and $\mathrm{E}$ occur nearly an equal number of times $(16 \%$ and $20 \%$ respectively). The SW occur only $8 \%$. The S, W and SE directions did not occur in this period.

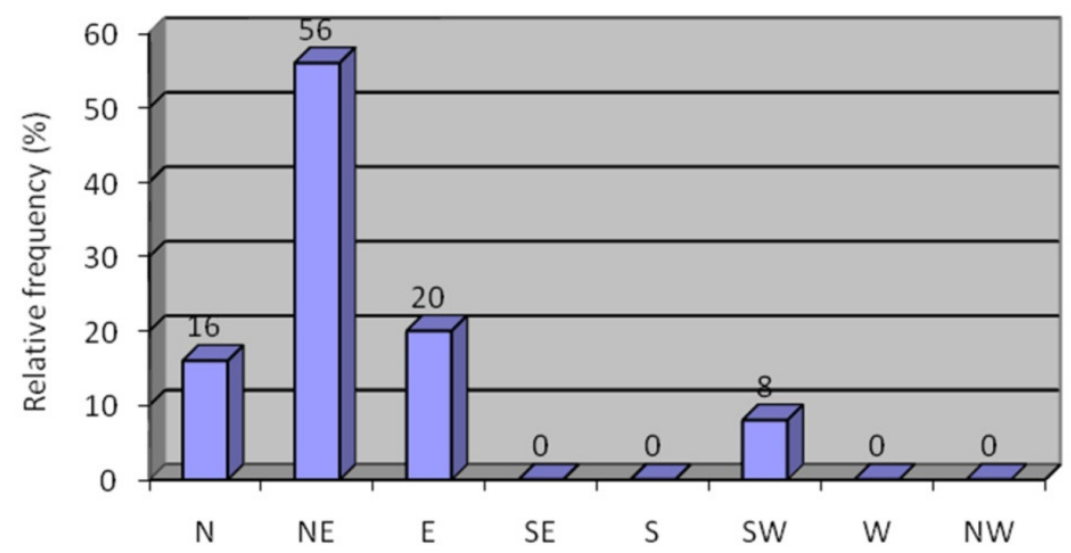

Fig. 5.1. The relative frequency (\%) of the upper air summer wind direction occurrence over the UAE region between 2005-2011.

\subsection{Upper air pressure systems}

The past analysis of the synoptic charts at the $500 \mathrm{hPa}$ level by Al Mandoos (2005) shows that the pressure systems affecting the weather of the UAE in the upper atmosphere may be classified in the following six types: Westerly through (WT), Westerly ridge (WR), Easterly 
through (ET), Subtropical height (STH), Zonal flow (ZF) and a Westerly cut-off low (WC). The analysis shows a strong seasonal variation of the upper atmospheric circulation between summer and winter months. During the summer months (April - September) STH pressure systems completely dominate over UAE. During the winter the influence of the STH diminishes significantly. The influence of the STH increases with the northward displacement of the general circulation of the atmosphere during the summer months. The ET detected over the UAE only during the summer months. During winter the WT and WR circulation dominate.

Here, the synoptic charts at the $500 \mathrm{hPa}$ level are considered for all days when $\mathrm{Cb}$ clouds are detected with radars over the UAE area in the period 2005-2011 during summer months (April-September). They are classified in the accordance with the prevailed middays wind directions at that level over the UAE.

The northern flow over UAE occurs when on the west is extended the strong ridge with the axes directed from East Africa toward the NE. At the same time over the Arabian sea is cyclon, or the through directed in $\mathrm{E}-\mathrm{W}$ direction. Such one weather condition is shown in Fig. 5.2 .

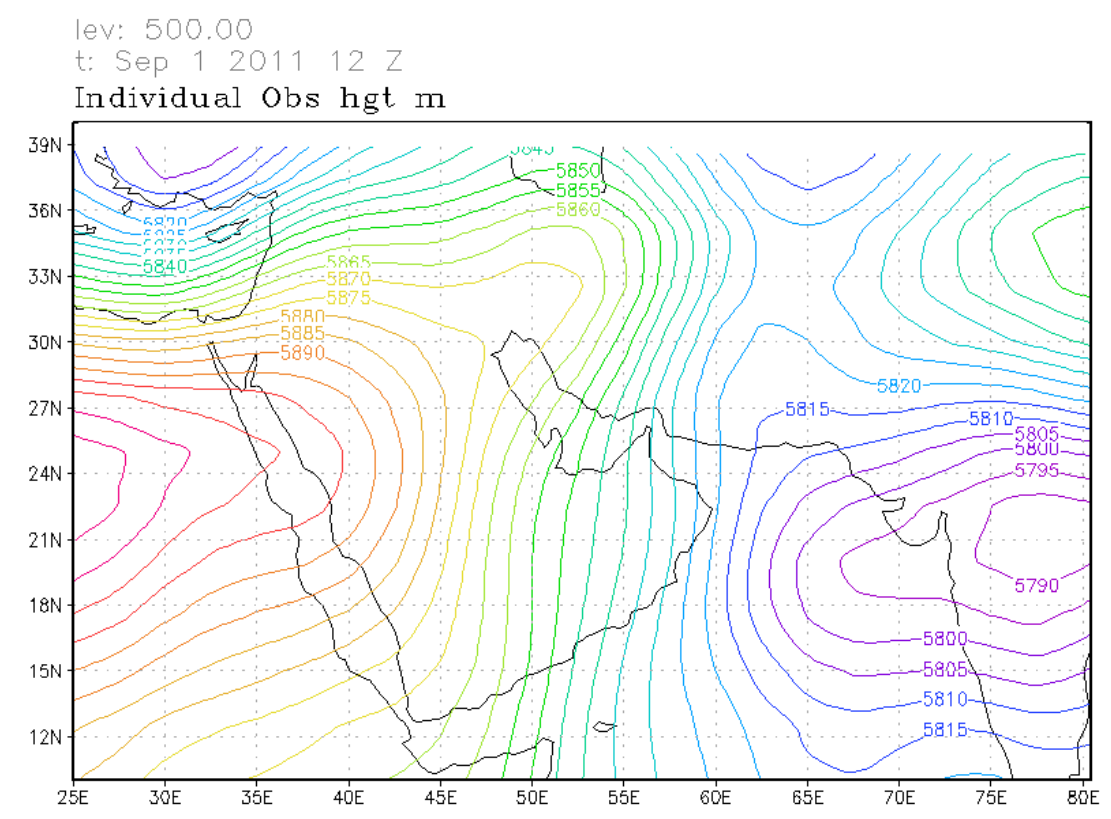

Fig. 5.2. An $500 \mathrm{hPa}$ isobaric chart indicating the dominance of the $\mathrm{N}$ (North) air flow over the UAE and surrounding regions.

The systems characterized by north easterly flow at $500 \mathrm{hPa}$ consist of the anticyclon on the west and cyclon over Indian ocean. The upper air high pressure system that in general extends from the West Africa (Sudan and Ethiopian areas) through the mid Saudi Arabian region causing subsidence west of the UAE. On the east side is easterly trough which acts as an engine for the development of the convective clouds and unstable weather conditions, especially the high mountainous terrain. The typical systems are shown in the Fig. 5.3 and Fig. 5.4. It has been noticed that such conditions are favorable in the summer season. 


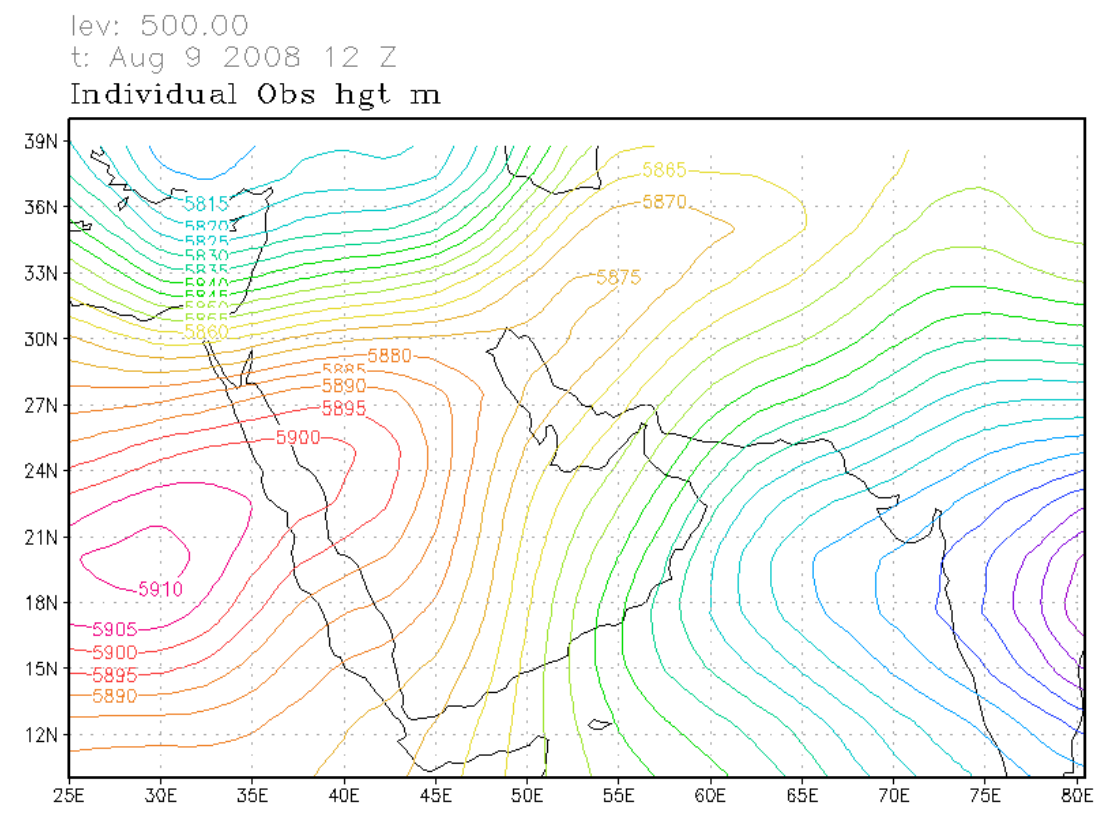

Fig. 5.3. An $500 \mathrm{hPa}$ isobaric chart indicating the dominance of the NE (North-East) air flow over the UAE and surrounding regions.

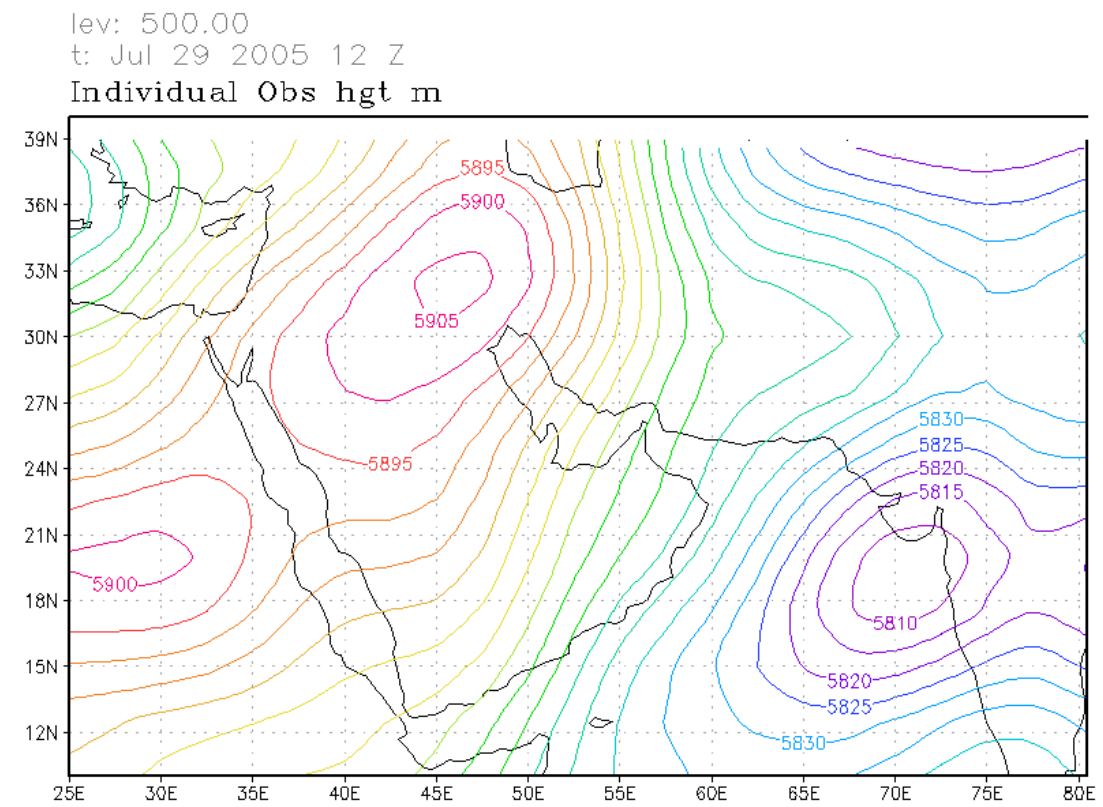

Fig. 5.4. An $500 \mathrm{hPa}$ isobaric chart indicating the dominance of the NE (North-East) air flow over the UAE and surrounding regions.

The easterly flow over UAE and small surrounding area is characterized with similar systems of high and low pressure as is for NE flow. These winds are a result of interactions between the Saudi Arabian high and the Indian monsoonal trough, with a deeper trough forcing. There are some small differences. Namely, high pressure is extended through the westerly ridge over the north, and low pressure is extended through the easterly trough over south of UAE. So, the area of the UAE is under easterly zonal flow. Such systems are shown in Fig. 5.5 and Fig. 5.6. 


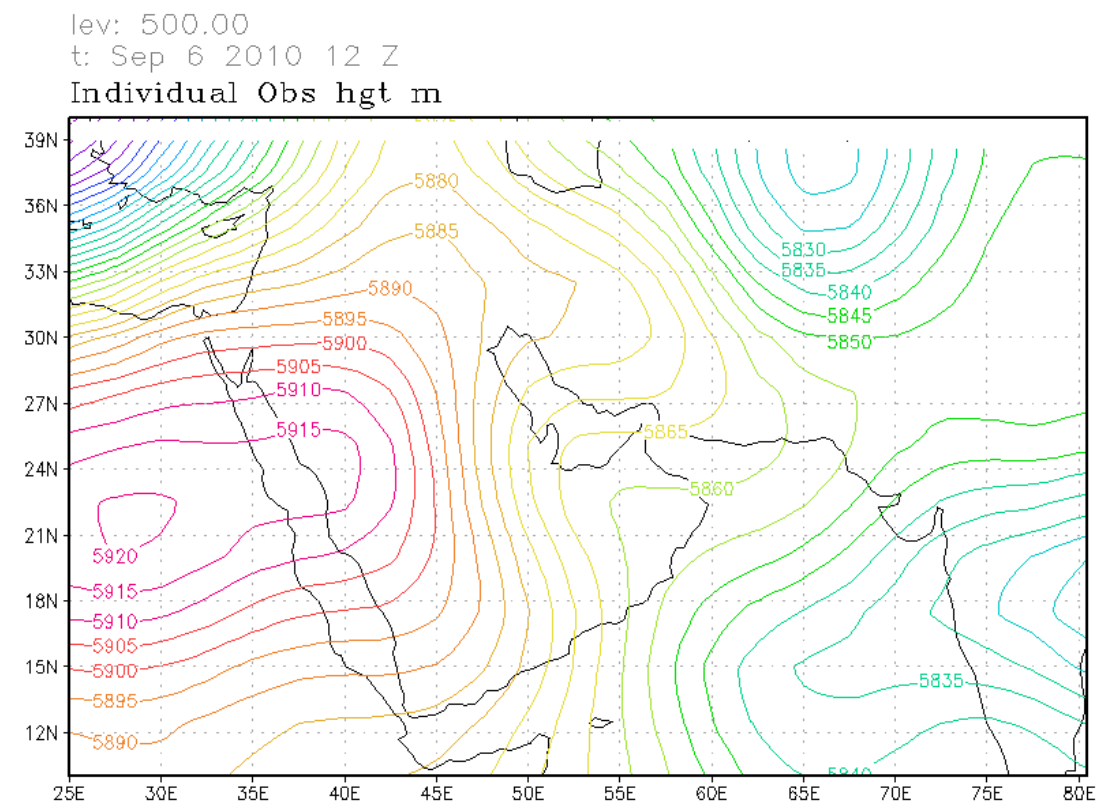

Fig. 5.5. An $500 \mathrm{hPa}$ isobaric chart indicating the dominance of the $\mathrm{E}$ (East) air flow over the UAE and surrounding regions.

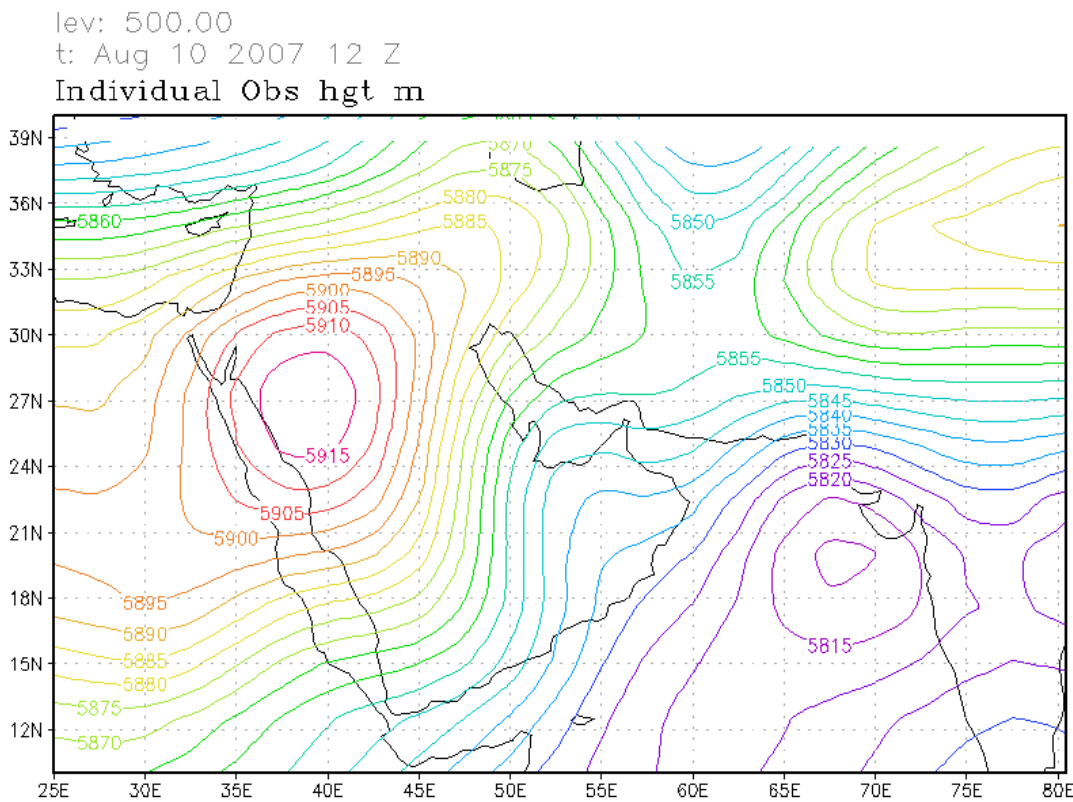

Fig. 5.6. An $500 \mathrm{hPa}$ isobaric chart indicating the dominance of the E (East) air flow over the UAE and surrounding regions.

The south westerly flow over UAE and surrounding area is characterized with the spacious north westerly trough with axis in NW-SE direction, from Mesopotamia up to Arabian sea. The UAE area is situated in the front side of this very deep through, with upper air motion from the SW direction. Unstable conditions associated with the reasonable atmospheric moisture produce good conditions for frontal $\mathrm{Cb}$ cloud activities. These cyclogenesis conditions bring the precipitation which moves from the SW toward the NE side of the UAE.. The north westerly trough is shown in Fig. 5.7. 


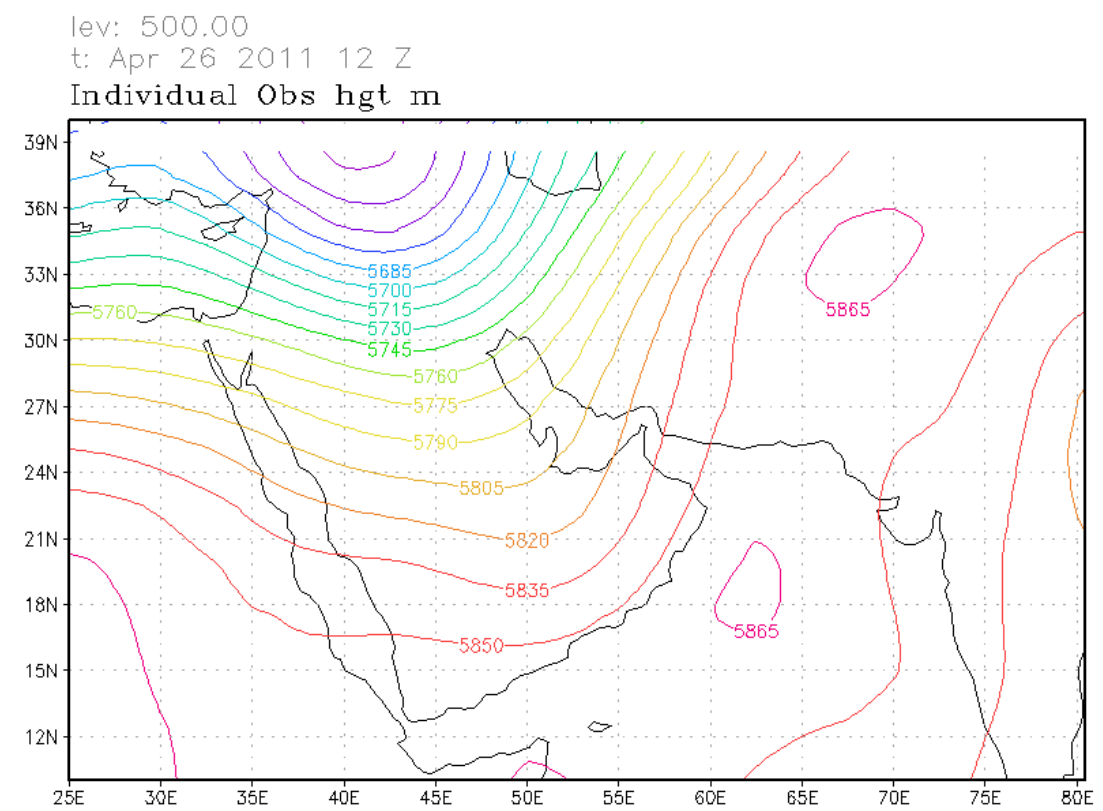

Fig. 5.7. An $500 \mathrm{hPa}$ isobaric chart indicating the dominance of the SW (South-West) air flow over the UAE and surrounding regions.

The westerly flow over UAE and small surrounding area is characterized with similar pressure systems of high and low pressure as is for E flow. In such conditions high pressure on the west is extended through the westerly ridge over south side of UAE, and low pressure is extended through the easterly trough over the north side of the UAE. So, the area of the UAE is under westerly zonal flow.

\subsection{Freezing Level Observations}

The height of freezing level (or level with temperature of $0^{0} \mathrm{C}$ ) is very important to know because in the cold part of the cloud above this level may be consist of ice particles, supercooled droplets or mixed phase. On the base of Abu Dhabi midday soundings data obtained during summer months (April-September) in the period 2005- 2011 the mean freezing level heights are shown in Fig. 5.8. The data are taken only for the days when the $\mathrm{Cb}$ clouds are identified with radar. The mean freezing levels ranged from $4.1 \mathrm{~km}$ for June to $4.9 \mathrm{~km}$ for July. The individual heights for each considered days ranged from $4.1 \mathrm{~km}$ to $5.5 \mathrm{~km}$.

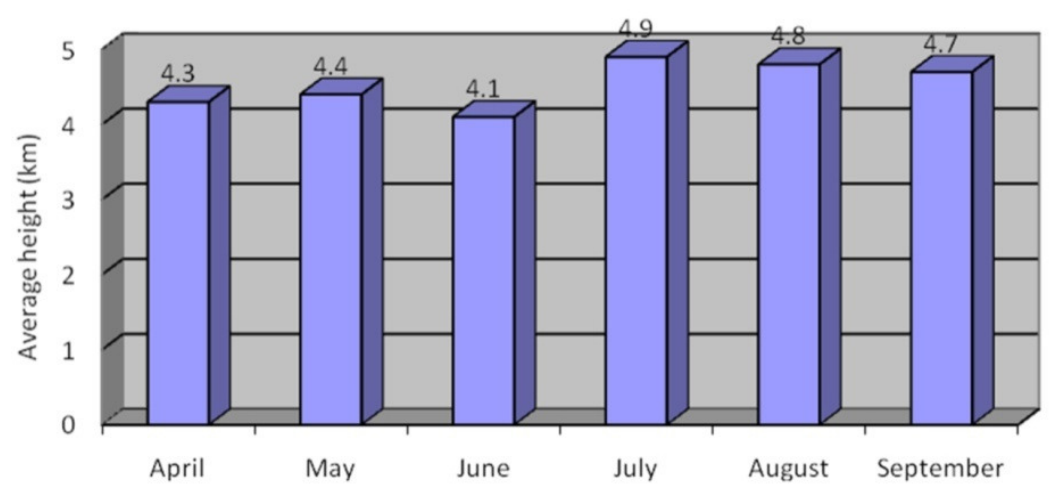

Fig. 5.8 Average height above the ground of the midday freezing level over Abu Dhabi between 2005- 2011. 
The frequency of minimal liquid water content measurements $\left(<0.1 \mathrm{~g} \mathrm{~m}^{-3}\right)$ at freezing level were high $(65 \%)$ in the 2002 winter clouds and lower $(35 \%)$ in the 2002 summer clouds suggesting winter clouds were generally more glaciated at freezing level and much more mixedphase during the summer.

Special flights were made to document the nature of cloud condensation nuclei, other aerosols, and the background chemistry across the UAE and across the Oman Mountains from the Gulf of Oman to the Al Ain region on the western side of the mountains. These measurements showed continental conditions (high concentrations of $\mathrm{CCN}$ and aerosols) throughout the region, suggesting that storms formed on either side of the mountains would be microphysically similar and generally amenable to hygroscopic seeding.

\subsection{Precipitating Systems}

\section{Winter precipitation}

Past climatological studies have identified the winter season (December-March) as accounting for the bulk of rain in the UAE ( Al Mandoos, 2005; Al Mandoos et al. 2006). Based on these studies the UAE had conducted operational cloud seeding experiments during the early 1990's. The climatological studies were based on reporting stations located primarily along the northern coast (Fig. 5.9) or in the Gulf because no rainfall measurement stations existed in the mountainous regions.

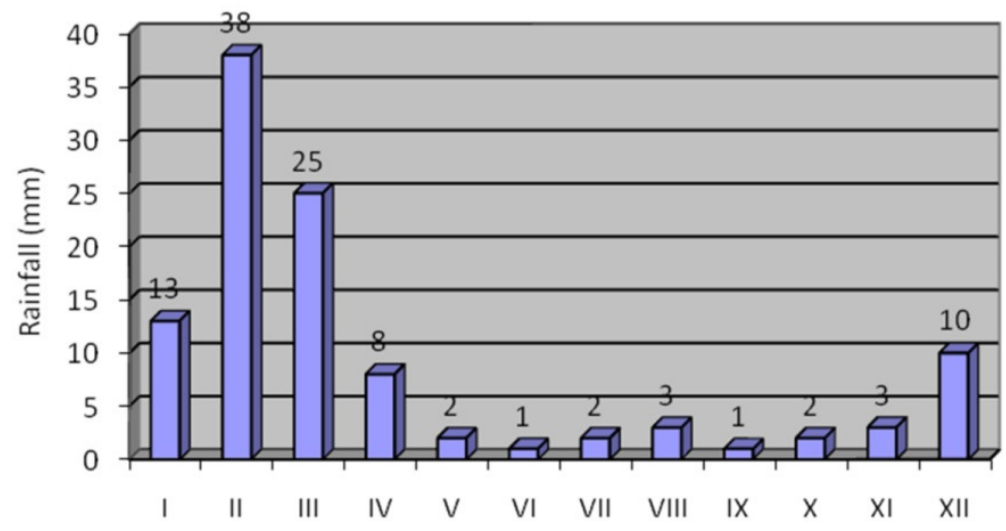

Fig. 5.9. Mean annual rainfall for Abu Dhabi.

Troughs, depressions and the occasional front, moving into the region from the west and northwest, result in large-scale systems that provide significant rainfall. Strong systems with convective instability occur infrequently, perhaps twice a year, while weaker systems occur much more often, resulting in periods of extensive cloud cover and light rain or drizzle. Some years no major strong synoptic events occurred during the winter. However, it must be emphasized the fact that the annual rainfall in the UAE is highly variable - the standard deviation being larger than the mean. Approximately four episodes per year with limited convection occurred in the winter, and these provided an opportunity to characterize the nature of the winter clouds and systems under the best of conditions. General cloud conditions during these episodes consisted of widespread stratiform clouds with embedded convection. These types 
of conditions make it difficult to identify persistent updraft regions and are therefore difficult to seed. Aircraft measurements of the cloud droplet sizes showed fairly narrow distributions, which are characteristic of continental clouds and generally favorable for modification through hygroscopic seeding. But, the droplet concentrations were quite variable (a couple hundred to over a thousand $\mathrm{cm}^{-3}$ ), which reflects potential CCN fluctuations and the variable updraft conditions associated with these winter systems. There also were marked differences between high-based clouds and clouds rooted in the boundary layer, which again likely reflect CCN variations. The best days tended to be late in the winter season (March into April) and hence were more like summer conditions. Therefore, based on the numerous cloud investigations, seeding trials, and radar depictions indicating only limited opportunities for seeding (less than five days during the winter), it was concluded that winter clouds rarely produce conditions that are sufficiently convective with warm cloud bases and identifiable updrafts to effectively seed with hygroscopic flares.

\section{Convective rainfall}

Convective rainfall over the Oman Mountains during the summer season is a phenomenon that is widely known to local meteorologists but is not described adequately or is non-existent in climatological studies. Although the Al Ain rainfall records show a slight indication of a summer convective component (Fig. 5.10), the frequency and importance of mountain rainfall is not well documented. Radar summaries for the 2001 and 2002 summer seasons show that the vast majority of convective storms occurred over the Oman Mountains, southeast of Al Ain and northward.

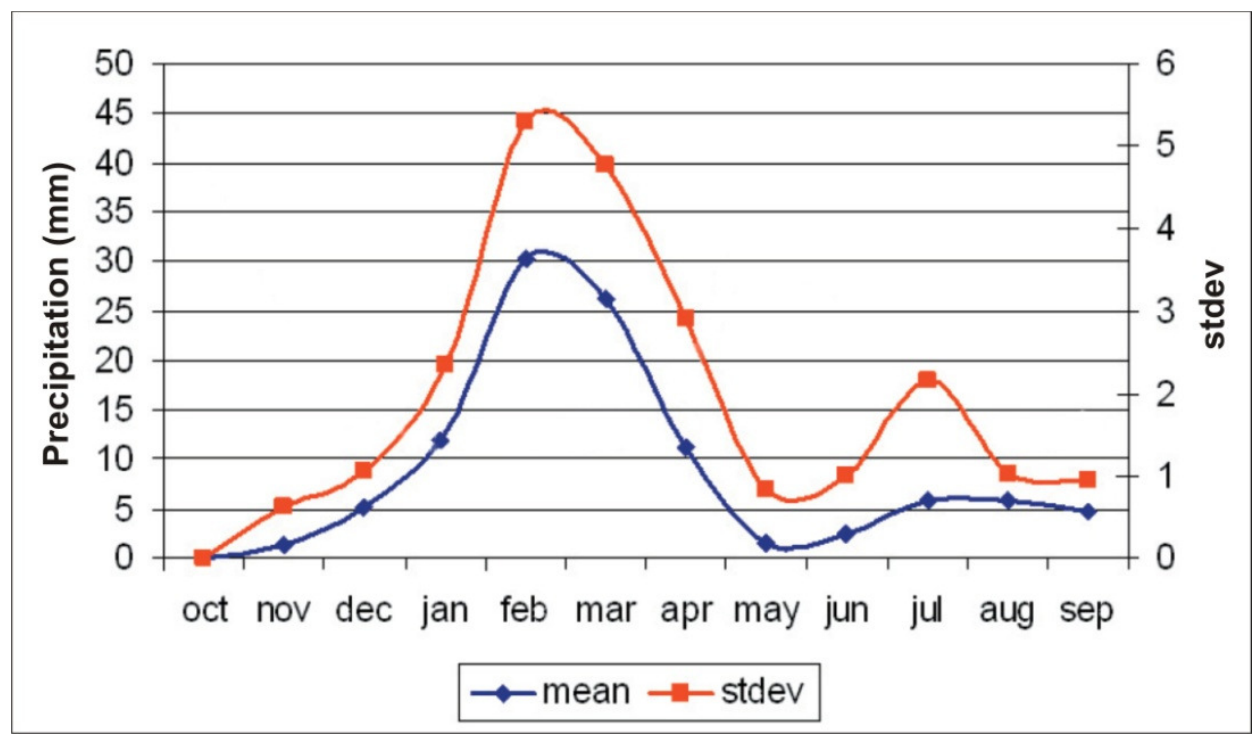

Fig. 5.10. Al Ain Mean Monthly Precipitation.

A number of convective storms also formed in the southcentral sections of the UAE (the Liwa region in particular), and some storms extended westward from the mountains into the coastal areas. Storms over the Oman Mountains east and southeast of Al Ain (in Oman airspace) consistently developed earlier and more often than over areas in UAE airspace to the north. It is important to note, as described in the hydrology section, that convective storms to the east of Al 
Ain in Oman are still major contributors to groundwater resources in the UAE. Unfortunately, a large percentage of the mountain storms occurred in Omani airspace and were not accessible for aircraft studies in 2001. During the summer studies in 2002, permission was obtained to extend the aircraft flights into Oman. The subsequent aircraft measurements were successful in verifying that the storms in Oman were microphysically consistent with the UAE storms sampled in 2001 and 2002. Furthermore, special flights were made to document the nature of CCN and other aerosols across the Oman Mountains, from the Gulf of Oman to the Al Ain region. These showed continental conditions (high concentrations of CCN and aerosols) throughout the region, suggesting that storms formed on either side of the mountains would be microphysically similar and generally amenable to hygroscopic seeding.

Most of the convective storms that developed during the summer months were relatively short-lived. The short lifetimes of the thunderstorms act to minimize the window of opportunity for cloud seeding. Accurate prediction of these situations is therefore important for planning seeding operations. Analyses of different atmospheric thermodynamic indices suggested that some of them could be useful in the prediction of convective events. Another important tool developed for the program was the implementation of a mesoscale-forecast model (described later). Besides the needs for fine-scale forecasting, these findings also suggested that a quick response time to initial convection is important. Therefore, arrangements were negotiated in 2003 to base an aircraft at Al Ain (relocated from Abu Dhabi) for part of the 2003 and all of the 2004 field project period to provide for shorter response times.

In order to conduct an evaluation of potential rainfall increases in a randomized cloud seeding experiment, a large number of samples (on the order of 200-250) are needed. Because cloud seeding opportunities occur so infrequently during the winter season, it would be impractical to conduct a randomized cloud seeding experiment during this time of the year. However, during the summer, suitable convective clouds develop on about a third of the days, and treating 2-4 storms on each of these days seemed reasonable. Based on these results a randomized seeding experiment was started in 2003, targeting the Oman Mountains in particular, including regions in the UAE and in Oman.

\subsection{Sea and land breezes in the Arabian Gulf region}

\section{Sea and land breeze climatology of the UAE region}

The local thermal circulation between sea and land has height influence on the production of convection, and consequently on the formation of the convective cloud. Due to this reason we analyze the sea and land breeze climatology of the UAE region. Both surface and upper-air observations were utilized to characterize the wind patterns over the region. During the summer months, mainly of June through September, southwest Asia is dominated by the southwest Indian monsoon. The pattern includes the low-level southwesterly winds from the Somali Jet over the Arabian Sea, an upper level high pressure system and the Arabian heat low stretching from northern Africa to Iran and Pakistan. The heat low creates light northwesterly winds over the Arabian Gulf, with wind speeds of about $3 \mathrm{~m} / \mathrm{s}$. This weak synoptic forcing associated with the southwest monsoon allows for the formation of thermal circulations, namely sea and land breezes. 
The presence of these circulations in the Arabian Gulf has previously been documented in the literature. Zhu and Atkinson (2004) and Eager et al. (2008) found the sea breeze and land breeze circulations to be perennial features over the Arabian Gulf, with seasonally and diurnally varying depth and horizontal extent. They noted the difficulty in making a clear identification of the sea and land breezes due to the ambient northwesterly winds over the Gulf. The depth of the planetary boundary layer over the northern Arabian Gulf was decreased by the sea breeze circulation, which advected cooler maritime air over the land (Warner and Sheu, 2000). On the west side of the Arabian Gulf, numerical simulations showed effects of the maritime air inland up to $100 \mathrm{~km}$ during the late winter and early spring (Warner and Sheu, 2000). The presence of mountains in Oman and Iran create additional features of thermally driven anabatic and katabatic winds. These features may augment the sea and land breezes, similar to that found in the numerical simulation studies in Brunei (Hassan and Raman, 2003). Although several case studies of sea and land breeze circulations exist in the literature, systematic climatological analysis of the sea and land breeze circulations are rare.

Climatological observations of the characteristics of sea and land breezes provide crucial information such as the horizontal extent of the sea breeze inland, time of onset of both breezes, and the intensity of the breezes on a timescale that can show persistence on weekly to monthly timescales. Such a study in the UAE region also can provide information on offshore characteristics of the sea and land breezes due to the availability of offshore island weather stations. The topography and the surface characteristics of the UAE region being predominantly sand raise questions on their effects in sea and land breeze initiation and maintenance. In addition, absence of strong synoptic scale forcing is helpful in identifying the sea and land breeze circulations with confidence.

All analysis is based on the of the following data: Radiosonde data from Abu Dhabi for Summer 2004 at both 0400 LT and 1600 LT (0000 and 1200 UTC). Additional radiosonde data were also available during the United Arab Emirates-Unified Aerosol Experiment (UAE2) from the Naval Research Laboratory's Mobile Atmospheric Aerosol and Radiation Characterization Observatory (MAARCO), located near Alsamha. In addition, hourly observations from a network of 50 surface meteorological stations throughout the UAE. The locations of these stations are shown in Fig.5.11. Sensors at the stations measure air temperature, dew point temperature, mean sea level pressure, relative humidity, wind direction, wind speed, precipitation, and solar radiation. Some of the stations also measured soil temperature and soil moisture at four depths. Times throughout this analysis will be discussed in terms of Local Time (LT), which is four hours ahead of Universal Time $(\mathrm{UTC}+4)$. 


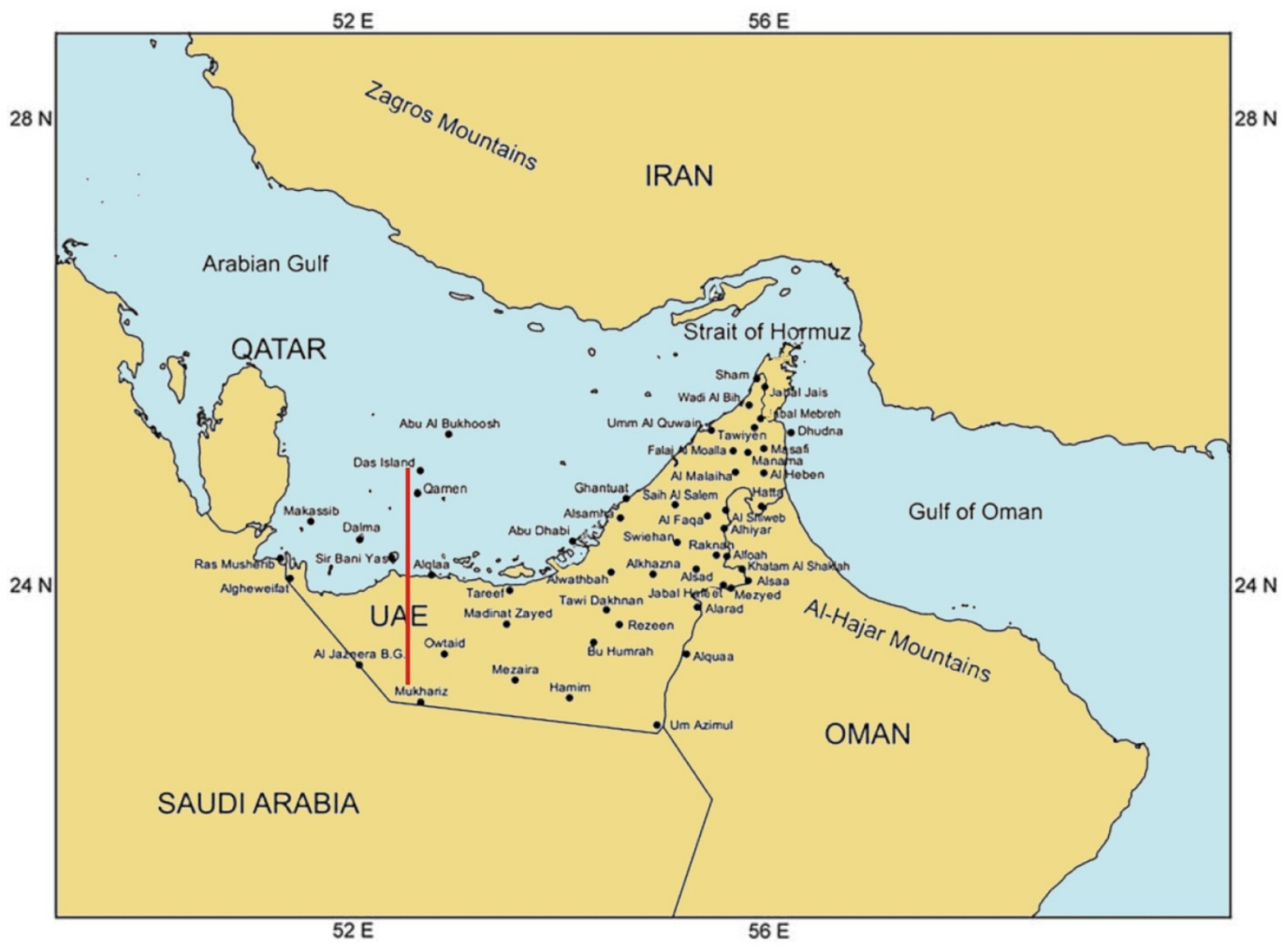

Fig.5.11. Surface meteorological stations in UAE.

The frequency of sea breezes and land breezes at Abu Dhabi International Airport was determined quantitatively using the 1995-2002 hourly surface observation data set. The sea breeze at Abu Dhabi is assumed to occur when the wind direction is onshore for four or more hours, with a diurnal change in wind direction. The land breeze is assumed to occur when the wind direction is offshore for four or more hours. For days when wind direction was not reported, a significant change in wind speed in the surface layer was used to determine the presence of the sea and land breezes. Sea breeze formation at Abu Dhabi increases the surface wind speed during the any time because both the prevailing winds and the sea breeze are from the northwest. The land breeze circulation acts to oppose the prevailing winds, leading to a weakening or reversal of the low level winds. The land breeze in this region is strong due to the added effect of katabatic flow resulting in the delay of the onset of the sea breeze. The main topographical features in the UAE are the Al-Hajar Mountains that extend from the peninsula in northern UAE into Oman, as shown in Figure 1. These mountains reach a height of about $1700 \mathrm{~m}$. The rest of the UAE is mostly flat with a slow upslope toward the south.

The percentage of days each month when a sea breeze circulation and a land breeze circulation developed for 1995-2002 is shown in Table 1. 
Table 5.1. Percentages of Days Per Month When Sea Breeze and Land Breeze Circulations Develop in Abu Dhabi, 1995-2002.

$\begin{array}{lcc}\text { Month } & \text { Sea Breeze Frequency } & \text { Land Breeze Frequency } \\ \text { Jan } & 82 & 81 \\ \text { Feb } & 77 & 71 \\ \text { Mar } & 81 & 71 \\ \text { Apr } & 93 & 84 \\ \text { May } & 96 & 95 \\ \text { Jun } & 99 & 94 \\ \text { Jul } & 99 & 96 \\ \text { Aug } & 96 & 97 \\ \text { Sep } & 99 & 99 \\ \text { Oct } & 98 & 100 \\ \text { Nov } & 92 & 93 \\ \text { Dec } & 90 & 91\end{array}$

Sea breezes occurred more than $77 \%$ of the time during all months of the year, while land breezes occurred more than $70 \%$ of the time. Two factors that allow for sea breeze development throughout the year include the weak year-round synoptic forcing in this tropical region, and the relatively consistent difference between the sea surface temperature and temperature over land during the year.

\section{Horizontal Structure of the Sea Breeze}

The horizontal extent of the sea breeze circulation is variable and depends on many factors, including the strength and direction of the synoptic winds. Observations were used to determine the horizontal extent of the sea and land breeze circulations during the summer of 2004. Stations oriented along a north-south line were selected to demonstrate the evolution of the horizontal extent of the sea breeze over the Arabian Gulf and inland over the UAE. These stations, shown in Figure 1, include Das Island (115 km offshore), Qamen (85 km offshore), Dalma (55 km offshore), Sir Bani Yas (15 km offshore), Alqlaa (on coast), Owtaid (80 km inland), and Mukhariz (130 km inland). The coastline is oriented approximately west to east, with northerly sea breeze winds and southerly land breeze winds. The sea breeze forms near the southern coastline of the Arabian Gulf and expands inland and offshore with time, reaching its maximum width in the late afternoon.

One 48-h period was selected to investigate the possible differences in the inland extent of the sea breeze for two consecutive days. Wind direction measurements for 3-4 September 2004 are shown in Fig. 5.12. 


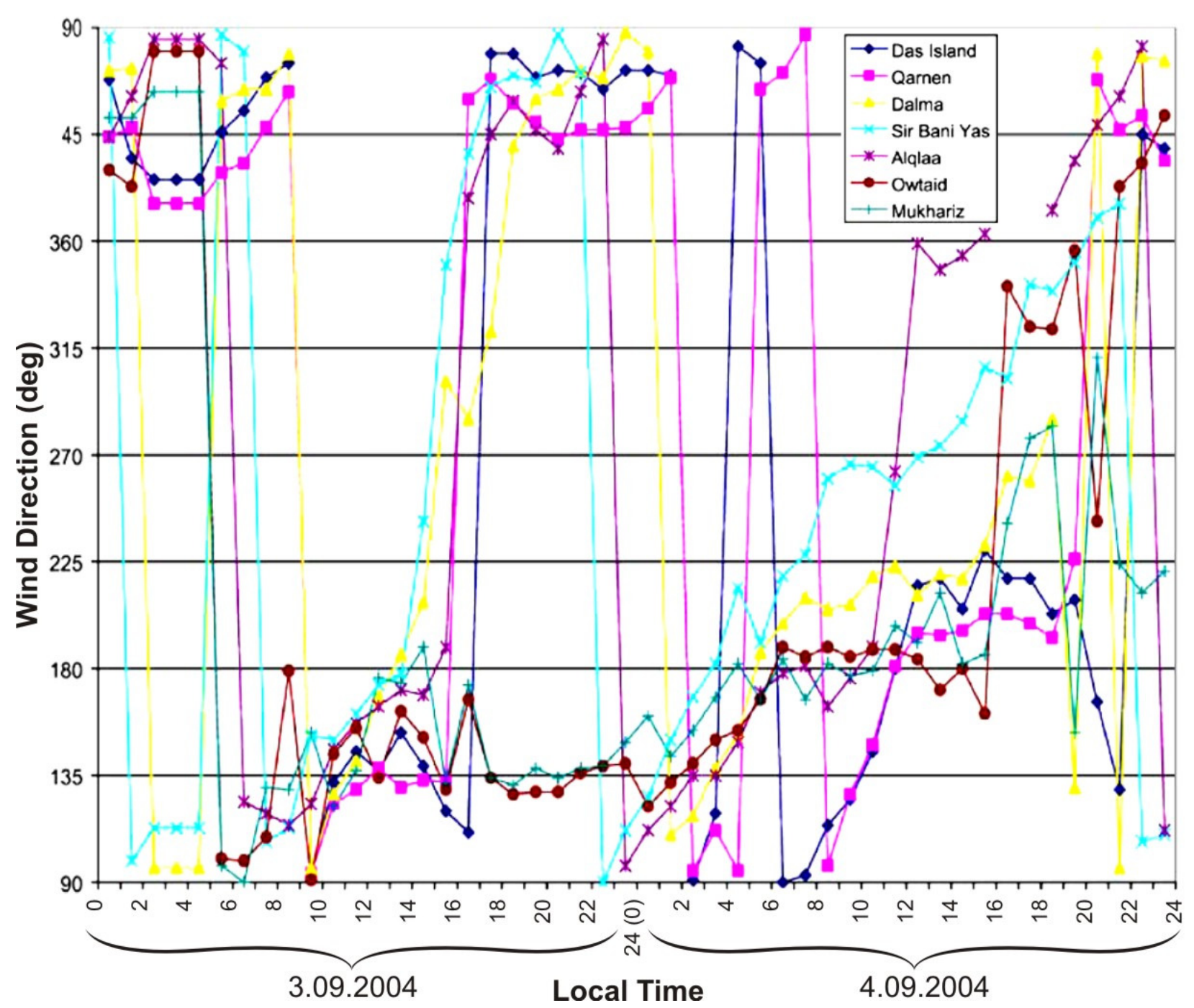

Fig.5.12. Wind direction beginning at midnight local time 3 September 2004 through midnight of 4 September 2004 at seven meteorological stations (near red line in Fig. 8.11).

Onshore winds occur at the beginning of the time period. Offshore winds form between $0100 \mathrm{LT}$ and $1000 \mathrm{LT}$, and continue through the morning until $1500 \mathrm{LT}$, when the sea breeze forms at the Sir Bani Yas and Dalma stations, located at $15 \mathrm{~km}$ and $55 \mathrm{~km}$ offshore, respectively. By 1600 LT the sea breeze has developed at the coast and at the two islands further offshore. Southerly winds remain throughout the day at the inland stations of Owtaid and Mukhariz, which suggest that the sea breeze did not reach these locations.

The maximum daily temperature occurs at $1500 \mathrm{LT}$ at stations affected by the sea breeze. At Owtaid, which is not affected by the sea breeze, the maximum temperature occurs at 1700 LT. The relative humidity also increases as the sea breeze front passes these stations. The sea breeze lasts until about 2300 LT, when offshore winds are noted on the coast at Alqlaa. The horizontal extent of the sea breeze on 3 September was at least $115 \mathrm{~km}$ offshore, although no observations are available north of Das Island. The onshore extent is estimated to be less than 80 $\mathrm{km}$. Thus the total width of the sea breeze was at least $195 \mathrm{~km}$. There are no stations between Alqlaa and Owtaid to determine the onshore extent more precisely. 
The sea breeze begins on 4 September at $1200 \mathrm{LT}$ and reaches the inland stations by 1700 LT and the furthest island station by 2200 LT. Stronger prevailing winds over the southern Arabian Gulf may have prevented the seaward penetration of the sea breeze until later in the afternoon as compared to the inland penetration. Because no stations are north of Das Island or south of Mukhariz, the horizontal extent of the sea breeze on 4 September can only be determined to be at least $115 \mathrm{~km}$ offshore and at least $130 \mathrm{~km}$ onshore, for a total width of at least $245 \mathrm{~km}$.

The difference in the horizontal extent of the sea breeze between the two days appears to be due to low-level southerly winds over the southeastern Arabian Peninsula on 3 September, inhibiting the southward penetration of the sea breeze front. On both days, a similar trend in sea breeze circulation development is observed. Onshore winds form earliest along the coast or just offshore. Throughout the afternoon the sea breeze circulation increases in horizontal extent and moves further inland and offshore. During the summer of 2004, the total width of the sea breeze varied from about $195 \mathrm{~km}$ to $245 \mathrm{~km}$ on the days investigated. The onshore extent of the sea breeze ranged from less than $80 \mathrm{~km}$ to more than $130 \mathrm{~km}$, while the offshore extent ranged from $85 \mathrm{~km}$ to $115 \mathrm{~km}$.

\section{Vertical Structure of the Sea Breeze}

The variation in the vertical extent of the onshore winds was determined using 51 soundings taken at 1600 LT (1200 UTC) at Abu Dhabi during the months of August, September and October 2004. In five of these soundings, the winds near the surface were offshore, indicating a sea breeze did not form on those days. The remaining 46 soundings showed onshore winds throughout the depth of the boundary layer, sometimes extending above the boundary layer. These soundings have a vertical resolution of about $100 \mathrm{~m}$, which leads to some difficulty in determining the exact vertical extent of the onshore winds and the boundary layer height. The vertical extent of the onshore winds varies daily and ranges between $750 \mathrm{~m}$ and $1500 \mathrm{~m}$. Located above the onshore winds is the offshore return branch of the sea breeze.

The virtual potential temperature $\left(\theta_{\mathrm{v}}\right)$ and wind direction profiles at Abu Dhabi at 1600 LT (1200 UTC) on 4 September 2004 plotted in Figure 9 show both the onshore and return (offshore) flows. Evidence of a thermal internal boundary layer (TIBL) can be seen in the lowest $30 \mathrm{~m}$ of the $\mathrm{q}_{\mathrm{v}}$ sounding.

The onshore winds at this location cause a modification of the near- surface air temperature. Onshore winds occur from the surface to a height of about $750 \mathrm{~m}$, with the return flow above extending to around $1100 \mathrm{~m}$. This gives the sea breeze circulation a height of 1100 $\mathrm{m}$. Air within the TIBL (surface to $30 \mathrm{~m}$ ) is unstable, while it is stable in the onshore layer above the TIBL from $30 \mathrm{~m}$ to $500 \mathrm{~m}$, representative of the conditions over water. However, the air in the return-flow layer above $500 \mathrm{~m}$ is well-mixed, representing conditions over land. Higher values of water vapor mixing ratio are located up to $500 \mathrm{~m}$, due to the advection of maritime air by the sea breeze. Above the boundary layer, mixing ratio values decrease by a factor of two (not shown). 


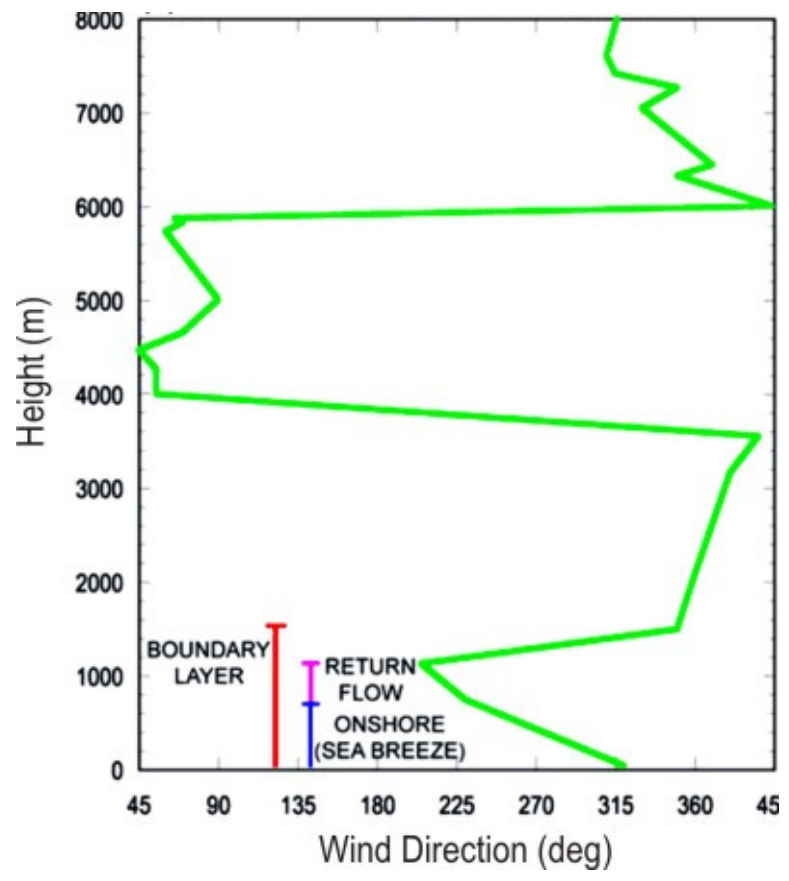

Fig. 5.13. Wind direction profiles at $1600 \mathrm{LT}$ on 4 September 2004 at Abu Dhabi. The heights of the boundary layer and onshore sea breeze flow, and the location of the return flow are indicated.

During the UAE2 experiment, additional soundings were taken between 11 September and 1 October 2004 at the MAARCO site $\left(24.70^{\circ} \mathrm{N}, 54.66^{\circ} \mathrm{E}\right)$, located to the northeast of Abu Dhabi near Alsamha (Fig. 5.11). Onshore winds at this location are from the southwest through the northeast. These soundings have a much finer vertical resolution, with measurements available every $2-5 \mathrm{~m}$. The MAARCO data indicates that the sea breeze typically formed between $1100 \mathrm{LT}$ and $1300 \mathrm{LT}$ at this site. Wind direction and wind speed profiles on 29 September at 1100 LT (0700 UTC), are shown in Figures 10. At 1100 LT-, winds in the lowest 1 $\mathrm{km}$ are south-southwesterly offshore winds with speeds of $2 \mathrm{~m} / \mathrm{s}$ near the surface increasing to $8.6 \mathrm{~m} / \mathrm{s}$ at a height of $360 \mathrm{~m}$ (Fig. 5. 14).
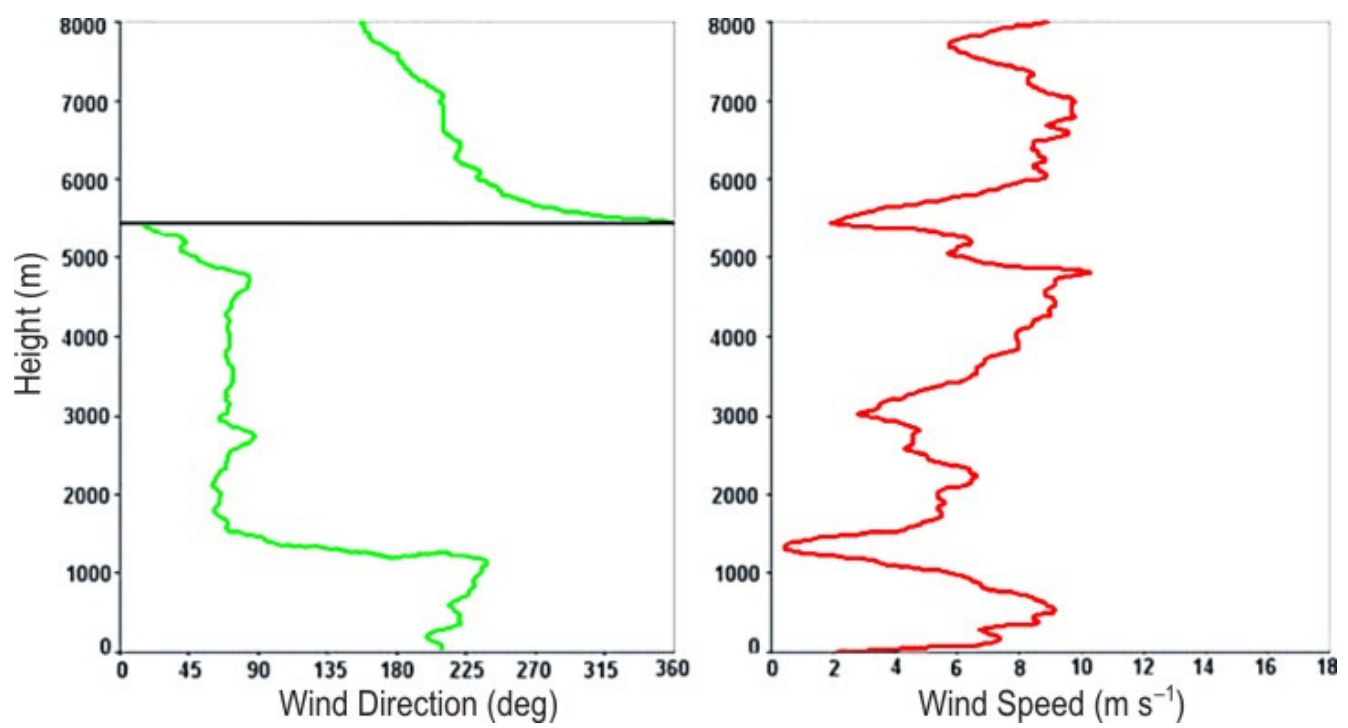

Fig. 5.14. Wind direction and wind speed profiles at MAARCO for 29 September 2004 at 1100 LT. 
The developing daytime convective boundary layer can be seen in the lowest $100 \mathrm{~m}$. Above $1 \mathrm{~km}$, the winds were east-northeasterly to an altitude of $5 \mathrm{~km}$. By $1300 \mathrm{LT}$ the winds backed to southeasterly to be parallel to the coast or slightly onshore in the lowest $430 \mathrm{~m}$ with wind speeds of $7 \mathrm{~m} / \mathrm{s}$ (Figure not shown). The winds were offshore above this layer to a height of $554 \mathrm{~m}$. Future, at $1500 \mathrm{LT}$ onshore winds extended to a height of $655 \mathrm{~m}$. The wind speed near the surface was $6 \mathrm{~m} / \mathrm{s}$. By $1600 \mathrm{LT}$ a well-mixed layer had formed in the lowest $200 \mathrm{~m}$ and onshore winds extended to $614 \mathrm{~m}$, with wind speeds of about $5 \mathrm{~m} / \mathrm{s}$. The $1600 \mathrm{LT}$ wind direction profile at Abu Dhabi (not shown) also indicated onshore winds to an altitude of $776 \mathrm{~m}$. The soundings at MAARCO show that the sea breeze has an onset time at this location similar to that at Abu Dhabi and Alqlaa, which is around 1400 LT.

On the base of the conducted analysis can be concluded that the sea breeze circulation is an important characteristic feature of the regional climate as sea and land breezes occur in all months of the year, most frequently during the summer months. This being a location in a tropical area, the difference between the sea surface temperature and land temperature does not vary much throughout the year, allowing for the sea breeze to occur in all months. The synoptic forcing is also very weak throughout the year. The sea breeze forms first near the coast and expands inland and offshore, reaching its maximum width late in the afternoon. The data from the meteorological stations showed the total horizontal extent of the sea breeze inland and offshore varied from about $195 \mathrm{~km}$ to $245 \mathrm{~km}$ on the days investigated. The vertical extent of the sea breeze as determined by daily radiosonde profiles at Abu Dhabi, and select days and times at the MAARCO site varied between $750 \mathrm{~m}$ and $1500 \mathrm{~m}$ with return offshore flow evident above the onshore flow near the surface. 


\section{6}

\section{INSTRUMENTATION AND FACILITIES}

A major effort during the initial part of the data collecting was the development of an infrastructure, especially with respect to the radar network in the UAE. A network of automatic weather stations was also installed during this period. In addition, an instrumented aircraft with trace gas, aerosol and cloud microphysical instrumentation was utilized to determine the background aerosol characteristics of the region and their influence on cloud and precipitation processes.

\subsection{Radars network}

To assist in collecting and archiving quantitative data from a network of radars installed TITAN/CIDD software on computer systems at several. Substantial effort was expended in integrating and networking these systems with the six radars in the UAE, and in evaluating the capabilities of the radars themselves. During the initial part of measurements engineers identified several problems with the operation of the radars, some of which were resolved.

One area of particular concern involved using the radar processor, controller, and display system. Its original design was meant for highly automated radar operations and for providing qualitative information to users who were not well versed in radar meteorology. As the radars were inspected, calibrated and configured for research/operational use, the system proved to be difficult to both understand and program accurately. It turned out to be overly complex, insufficiently documented, and generally unsuitable for the collection of quantitative radar data. After considerable investigation, these problems were largely resolved. It is developed a new, simpler radar processor board that was implemented. With the new processor board, calibration and maintenance of the radar became easier and five-minute volume scans could be implemented resulting in high-quality quantitative reflectivity and Doppler data collection.

Another complicating feature of the radar data in the UAE is "clutter", caused mainly by anomalous propagation (AP). AP is particularly problematic in the Arabian Gulf because of the extreme vertical gradients in moisture and therefore refractive index, resulting in severe ducting of the radar beams. Normal ground clutter and sea clutter is exaggerated during periods of AP, which commonly occurs when the nocturnal inversion develops with a high moisture gradient near the surface. The Radar Echo Classifier (REC) routine used in the radar network of other countries was implemented in the UAE network. This algorithm is redesigned to reject AP and sea clutter and it is generally successful in removing ground returns or "clutter" in the radar data. The algorithm's success is related to the radars' abilities to collect accurate Doppler velocities as well as continuous data. 


\subsection{Instrumented aircraft platform}

\section{Air-chemistry studies}

Air pollution is now known to have strong effects on the clouds and precipitation at least through (a) Acid deposition / Acid rain; (b) Climate impacts - human induced climate change; (c) Impacts on cloud microphysical processes. Therefore air pollution measurements were conducted with the instrumentation mounted on the aircrafts. The impacts on cloud microphysical process by the air chemistry are directly related to the production and altering of the $\mathrm{CCN}$ content. It is well known that the sulphates are highly hygroscopic - efficient $\mathrm{CCN}$ and they may coat large (less soluble, or unsoluble) dust aerosols - very efficient CCN.

Trace gas and aerosol instruments were mounted in a aircraft. A list of the instruments utilized during the project for the collection of the air chemistry relevant components is given in Table 6.1.

Table 6.1. Instruments mounted in an aircraft.

\begin{tabular}{|c|c|c|}
\hline Instrument & Parameter & Range \\
\hline Dasibi/TECO 48C TL & Ozone & $0-500 \mathrm{ppb}$ \\
\hline TECO 43C TL & Sulphur Dioxide & $0-500 \mathrm{ppb}$ \\
\hline TECO 42C TL & Nitrous Oxide Nitrogen dioxide & $0-200 \mathrm{ppb}$ \\
\hline \multicolumn{3}{|c|}{ TSI 3011 and TSI 3076* Condensation nuclei counter (CNC) $0.011-3.0(\mu \mathrm{m})$} \\
\hline \multicolumn{3}{|c|}{ Cloud condensation nuclei counter (CCNC100A) } \\
\hline \multicolumn{3}{|c|}{ Airborne Streaker Sampler Aerosol chemistry and morphology } \\
\hline \multicolumn{3}{|c|}{$\begin{array}{l}\text { Passive Cavity Aerosol Spectrometer Probe (PCASP100x) Accumulation mode aerosols 0.1-3.0 } \\
\text { micron }(\mu \mathrm{m})\end{array}$} \\
\hline Cimel Polarised Sun Ph & otometer Aerosol optical thickness & $\begin{array}{l}\text { AOT) } 1020,879,670,500,440,380,340 \mathrm{~nm} \\
\text { sol Particles on TEM substrates }\end{array}$ \\
\hline
\end{tabular}

\section{Aerocommander Platform}

The primary platform was the Aerocommander 690A. State variable data were also collected by the Orsmond Aviation Piper T1040 (or Cheyenne II; similar to a Cheyenne).

Thermodynamic measurements were made with Rosemont temperature and pressure instruments and an EGG dew point hygrometer. Particle measurements were made with a Passive Cavity Aerosol Spectrometer Probe (PCASP) and Forward Scattering Spectrometer Probes (FSSP).

While the PCASP has long been proved efficacious or measuring fine mode particles, for the coarse mode, the FSSP instrument suffers from significant response function degeneracy issues that result in over sizing. This produces volume distributions centered around $8-10 \mathrm{~mm}$ in diameter, regardless of the input particle size spectrum. Hence, the FSSP can functionally differentiate changes in size and particle concentration only semiquantitatively.

Despite these drawbacks, the FSSP is useful if applied properly. 


\subsection{Radiosonde data}

Radiosonde data from Abu Dhabi at both 0400 LT and 1600 LT (0000 and 1200 UTC) were available. Additional radiosonde data were also available during the United Arab EmiratesUnified Aerosol Experiment (UAE2) from the Naval Research Laboratory's. Mobile Atmospheric Aerosol and Radiation Characterization Observatory (MAARCO), located near Alsamha (refer to Fig. 5.11).

\subsection{Network of automated surface meteorological stations}

Hourly observations from a network of 50 surface meteorological stations throughout the UAE were available. The locations of these stations are shown in Fig. 5.11. Sensors at the stations measure air temperature, dew point temperature, mean sea level pressure, relative humidity, wind direction, wind speed, precipitation, and solar radiation. Some of the stations also measured soil temperature and soil moisture at four depths.

\subsection{Aeronet}

A mesonet of 14 strategically placed Aerosol Robotic Network (AERONET), Sun photometers, the coastally sited Naval Research Laboratory (NRL) Mobile Atmospheric Aerosol and Radiation Characterization Observatory (MAARCO) super site with radiation and microphysics instrumentation, the open desert Surface-Sensing Measurements for Atmospheric Radiative Transfer (SMART) for measuring dust optical properties near source regions. 


\section{RADAR Cb CHARACTERISTICS OVER UAE}

\subsection{General characteristics}

Depending of the resolution in the available observations, Cumulonimbus convection may be observed on a range of scales between that of the single sell in the ordinary $\mathrm{Cb}$, whose updraft is a few kilometers across and last about half an hour, and that of the more persistent and intense storm, whose updrafts extends about $20 \mathrm{~km}$ across its path and persists continuously for several hours. The sever storms frequently are accompanied by lesser storms, some of which may enter an intense phase, so that they are not readily identifiable from even modern ground observations.

Visible features, such as the top of the tallest cloud tower, are persistent for an hour or more, only in some kinds of severe storms, which may travel hundreds of kilometers, and their positions difficult to determine and track by optical means only. Radar echoes from $\mathrm{Cb}$ are detectable at ranges of up to $200 \mathrm{~km}$ with only one radar, but even more than hundreds and hundreds kilometers within the network of radars. The position of some feature of the echo, such as the most intense echo is easily followed using conventional radar.

The striking features of the intense $\mathrm{Cb}$ which can be seen from the ground by visual observation are the great extent of the anvil cloud, characteristic dome which reaches well above the general level of the anvil cloud and the arc cloud over the squall front. Some of them can not be seen by radar. But at present time the space and time resolution of satellite imagery of visible and infrared light has now reached the point where such data are a valuable component and supplement to weather radar in defining storm location, their development and fine structure. While the satellite pictures do not have the resolution of radar and can only see the cloud tops, their geographical coverage is unbroken, and they show pars of $\mathrm{Cb}$ clouds too tin to have radar echoes. Satellite cloud pictures tend to represent the integrated effect of dynamic processes occurring over some previous time interval. In the case of the $\mathrm{Cb}$ (or convective storms) the effective resolution of satellite imagery is often degraded by the shadowing effects of heavy cirrus anvil tops spreading over and concealing the active $\mathrm{Cb}$ cell.

We have taken into the account that the most important tool for observing the structure of $\mathrm{Cb}$ clouds (or storms) over the last period has been the meteorological radar. The radar's excellent vertical and temporal resolution enabled us to obtain an exceptionally detailed radar view of the all most important cloud characteristics. Due to this reason we used radar data to obtain the three dimensional structure of $\mathrm{Cb}$ over UEA for a period 2005-2011. The data are collected from the network of the five radars. 


\section{Cloud lifetime}

For every review of cloud characteristics it is extremely important to describe the cloud lifetime. This is especially important for convective clouds because their life is relatively short in comparison with many others meteorological processes (Isaac, 1986). This parameter describes the physical character of cloud. The lifetime can indicate whether a $\mathrm{Cb}$ will last long enough for generation of some products (intense rain shower, gust wind, etc.).

When reporting cloud lifetime the definition used must be clearly specified. The definition depends of the evaluable data. The most accurate definition is those that measure the time from the beginning of condensation to the total dissipation. But, it is difficult to measure this time in the reality. When cloud development is monitored with the radar the time from first precipitation to and of precipitation can be used as a lifetime. Or, a time over which a definable turret exits on a cloud mass. For the problem of monitoring convective cloud for seeding it is important to have cloud with stage of development over some threshold and lasts sufficiently long to produce precipitation after seeding. We take a lifetime as a time over which the radar reflectivity is greater or equal $20 \mathrm{dBZ}$. Fig. 7.1.

The percent of $\mathrm{Cb}$ clouds with lifetime within the defined interval of time are shown in

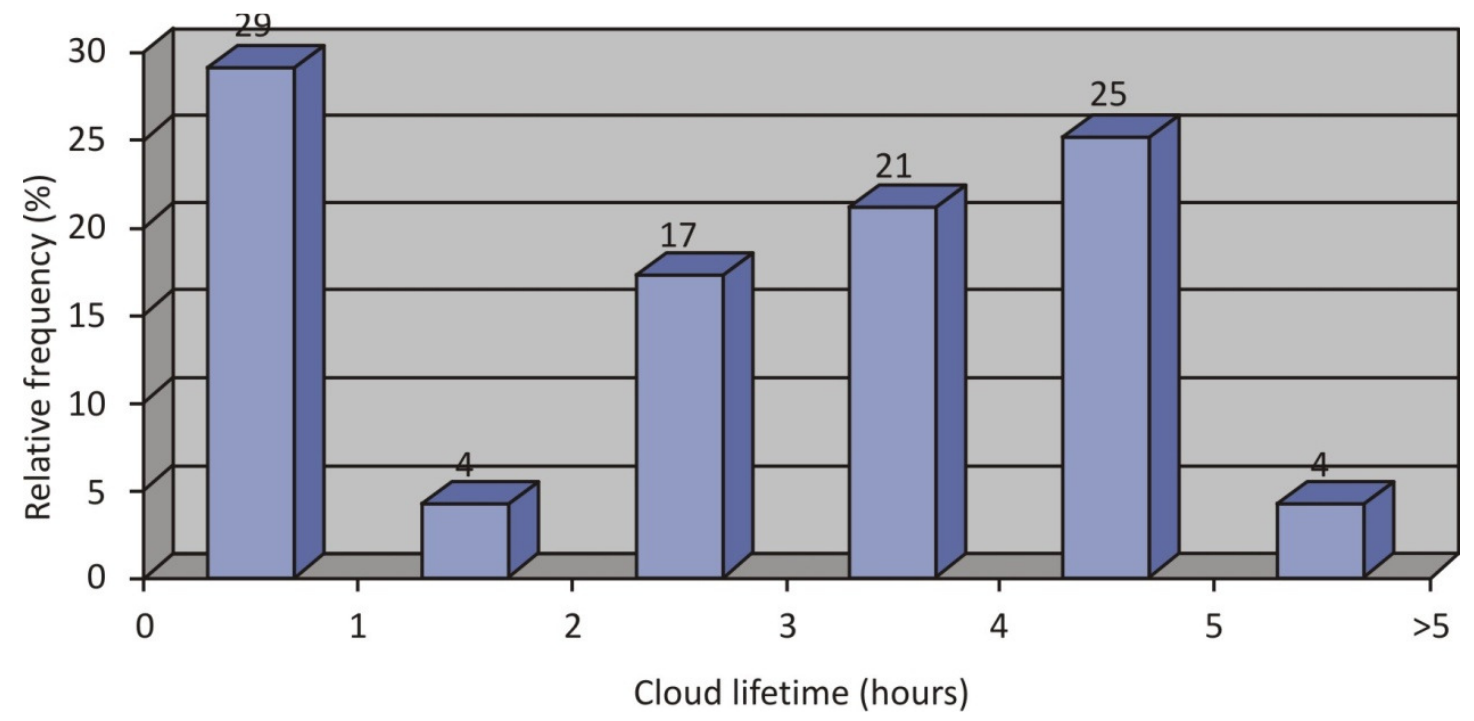

Fig. 7. 1. The relative frequency of clouds as a function of cloud lifetime for the summer period 2005-2011.

The data are taken only for the days when the $\mathrm{Cb}$ clouds are identified with radar with reflectivity greater or equal of $20 \mathrm{dBZ}$. The frequency of cloud lifetime ranged from $4 \%$ for long lasting clouds (longer than 5 hours and for those with duration between 1 and 2 hours) to 29\% for short lived clouds (less than one hour). More than half of clouds $(63 \%)$ have duration between 2 and 5 hours. The individual cloud lifetime ranged from 10-20 minutes to 9 hours suggesting that summer storm clouds may have much longer duration than 9 hours (lifetime between first appearing on the sky up to totally dissipation).

For the problem of cloud seeding the clouds last sufficiently long that the precipitation can form naturally trough the warm or cold rain process. Obviously, a seeding windows exist in the cloud lifetimes. The clouds have different lifetimes, but even the shortest with duration 10-20 
min (under our definition) lasts longer than time needed for formation of $1 \mathrm{~mm}$ sized particles by condensation and Bergeron-Findeisen process. Therefore, for weather modification purposes it would be a major step forward if a method of cloud seeding would contain the cloud life expectation from either microphysical or dynamical observations.

\section{Length of cloud path}

The severity of a thunderstorm can be judged in many ways. What we are concerned with here is the length of cloud path. Track and successive positions of radar echo greater or equal of $20 \mathrm{dBZ}$ are considered for all summer Cb clouds. The findings are shown in Fig. 7.2

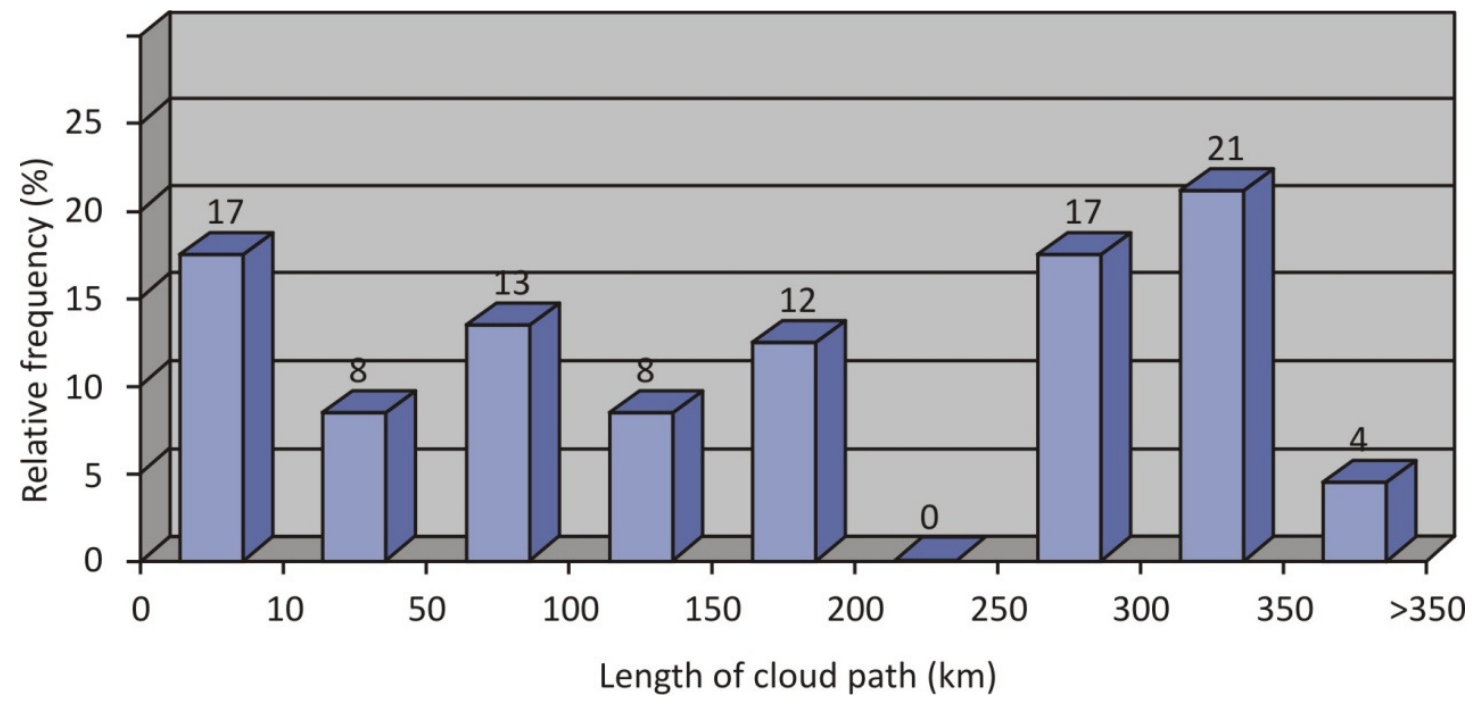

Fig. 7. 2. The relative frequency of clouds as a function of length of cloud path for the summer period 2005-2011.

The majority of convective storms, and indeed many of those that produce the significant precipitation are much more vigorous unit of convection which are long-lived and travel over a distance between 250 and $350 \mathrm{~km}$. The percent of such clouds is 36 . They sometimes can be recognized by certain characteristic visual and radar features which are discussed in Section 7.2 .

Ordinary clouds are short-lived units of convection and most at any given time consist of a succession of them at different stages of evolution, with the updraft only, with updraft and downdraft together and with downdraft alone. According to the data the typical such clouds last only 15-30 min and travel over shorter distance then $10 \mathrm{~km}$. The percent of such clouds is 17 . The majority of clouds (41\%) travel over distance between 40 up to $200 \mathrm{~km}$. The individual travelling distances ranged from 5-400 km. Obviously, some extremely long moved examples have been reported.

\section{Displacement velocity}

The storm movement or displacement is amongst other deduction of cloud properties very important to find out. Displacement (migration or travelling) velocities of convective storms are studied very intensively in the past decades (Ćurć and Janc, 2012; Ludlam,1980; Newton and Fankauser, 1975). Many noted that storms move with the velocity of the atmosphere in which the bulk of the cloud is located. In an early study of the movement of convective clouds 
seen by radar observed that small less than $12 \mathrm{~km}$ in diameter tended to move with the wind in the lower part of the cloud layer, while the larger storms moved with wind in the higher elevation (Byers and Braham, 1949).

Study of the movement using the micrometeorological network found that $\mathrm{Cb}$ cells moved to the right of the cloud-layer wind. It was suggested that thid deviation was due to the Magnus effect upon a rotating cloud. This mechanism was analyzed by Fujita and Grandoso, 1966), More recently Ćurć and Janc (2011a,b) showed that this deviation in the movement is induced by differential heating of the surrounding surface from the left and right had side of cloud.

It has been customary to compare the velocity of a weather system, identified by some persistent feature, with a mean velocity of the atmosphere in its neighborhood. If the mean velocity changes slowly, it can be used in forecasting practice to anticipate the movement of weather systems such as a convective storm. Difficulties may arise in deciding that feature best represent the weather system, how far the system extends, and how to determine a mean wind in the surroundings. These difficulties are not serious in many situations when the associated motion system is only a small disturbance in a nearly uniform flow.

Some visible features of cloud and their position is difficult to determine and track by optical means only. But, radar echoes from $\mathrm{Cb}$ are detectable. Their position, such as the most intense echo on a PPI display, is easily followed using conventional radar.

The summary of radar echo displacement velocities of all $\mathrm{Cb}$ clouds in the period 200520011 are shown in Fig. 7.3. The average speeds of the storms are calculated taking into account the positions and the time of these positions. It is easy to see that the lowest displacement velocity is from $10-20 \mathrm{~km} / \mathrm{h}$. From total number of cloud $17 \%$ moves with this velocity. On the whole the data cloud be said that more than half of could of total number move with mean velocities between the 40 and $70 \mathrm{~km} / \mathrm{h}$. One fourth travel with mean velocities greater than 70 $\mathrm{km} / \mathrm{h}$. The individual travelling velocities ranged from $17-91 \mathrm{~km} / \mathrm{h}$ suggesting that summer storm clouds may travel very fast. Sometimes in the shorter period of time within cloud life observed more rapid movement, more than $100 \mathrm{~km} / \mathrm{h}$.

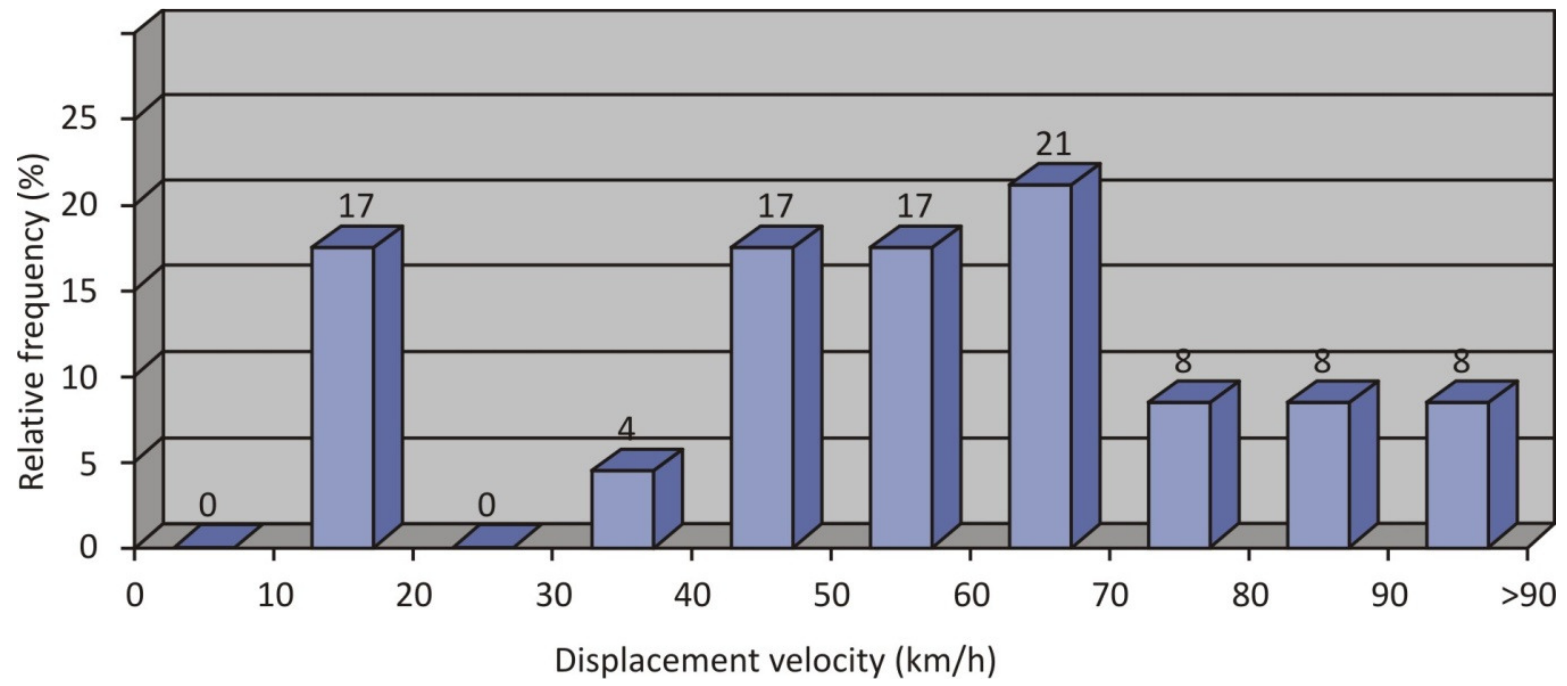

Fig. 7. 3. The relative frequency of clouds as a function of displacement velocity for the summer period 2005-2011. 


\section{Storm size}

The ordinary $\mathrm{Cb}$ extends vertically and typically has no big horizontal dimensions. They develop when the atmosphere acquire the characteristic stratification into which is small wind shear. Sometimes $\mathrm{Cb}$ occur when there is a considerable wind shear and the cumulonimbus convection is general more intense and persistent. Such clouds or storms travel for several hours over paths hundreds of kilometers long and accompanied almost continuously by severe weather over wide surface.

The importance of the shear in cumulonimbus convection is that it causes the formation of many new cells which together forms the multicellular storms which contain interspersed region of light. The movements of cell clusters are strongly influenced by discrete cellular propagation.

We consider the horizontal cross section of radar echoes of such storms at the level of maximum reflectivity. The overall storm radar echo appearance is approximated with the circle of diameter D. This parameter will be considered as a storm size. The statistics of this parameter is presented in Fig. 7.4.

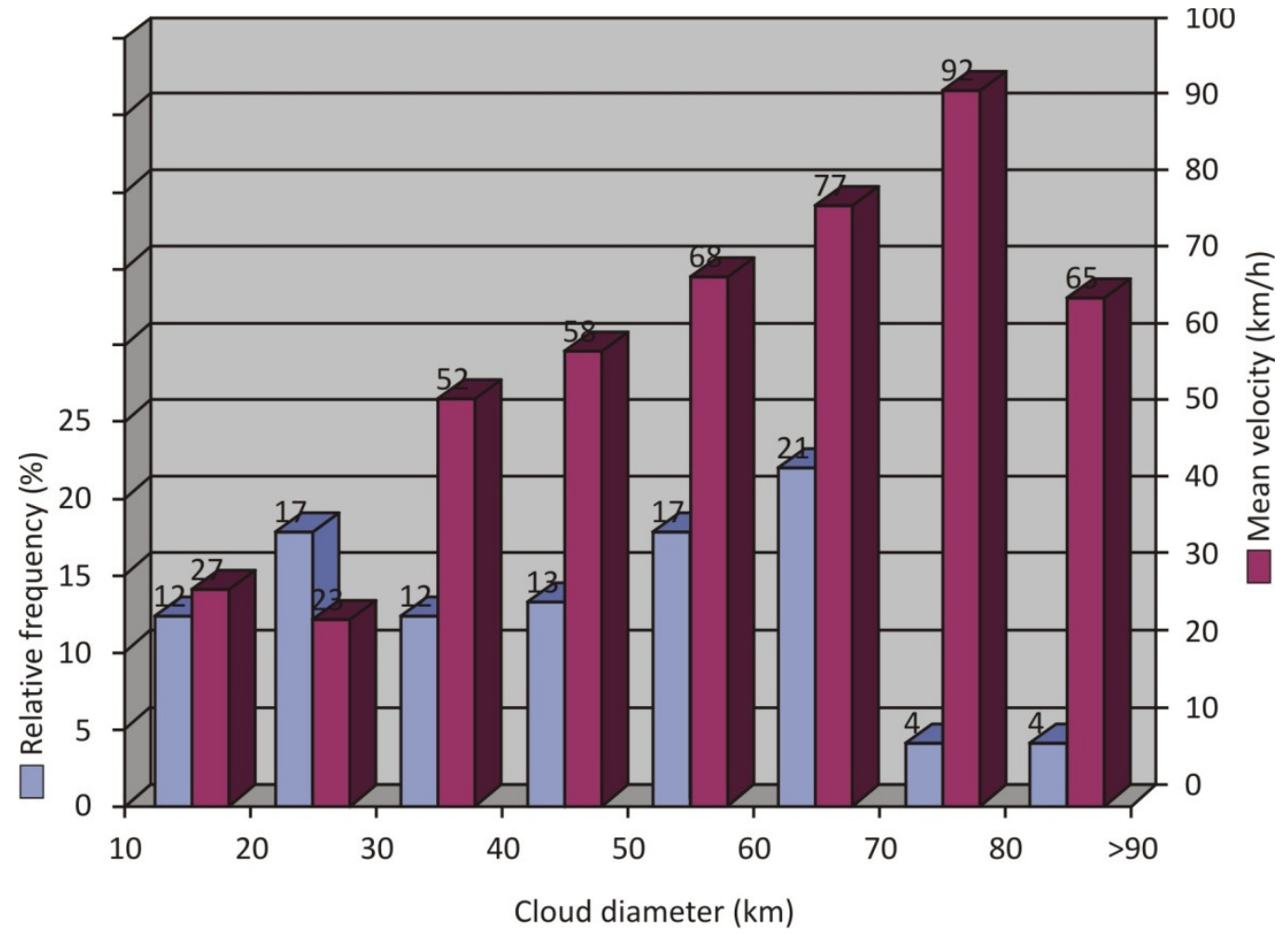

Fig. 7. 4. The relative frequency of clouds as a function of storm size and their mean traveling velocities for the summer period 2005-2011.

In the reality the radar echo is elongated in some horizontal direction, but circle approximation is quite satisfied for this purpose. From Fig. 7.4 is easy to see that $51 \%$ of clouds have diameter between 40 and $70 \mathrm{~km}$. The most remarkable fact that arise from this figure is that the mean displacement (traveling) velocity is directly linear proportional with the cloud diameter, with the exception of the wider clouds (greater than $80 \mathrm{~km}$ in diameter). 
This linear dependence of traveling velocity and cloud diameter can be seen in the scatter diagram (Figs. 7.5 and7.6) shown for each individual cloud characteristic. The correlation coefficient is good, with the value of greater than 0.7 .

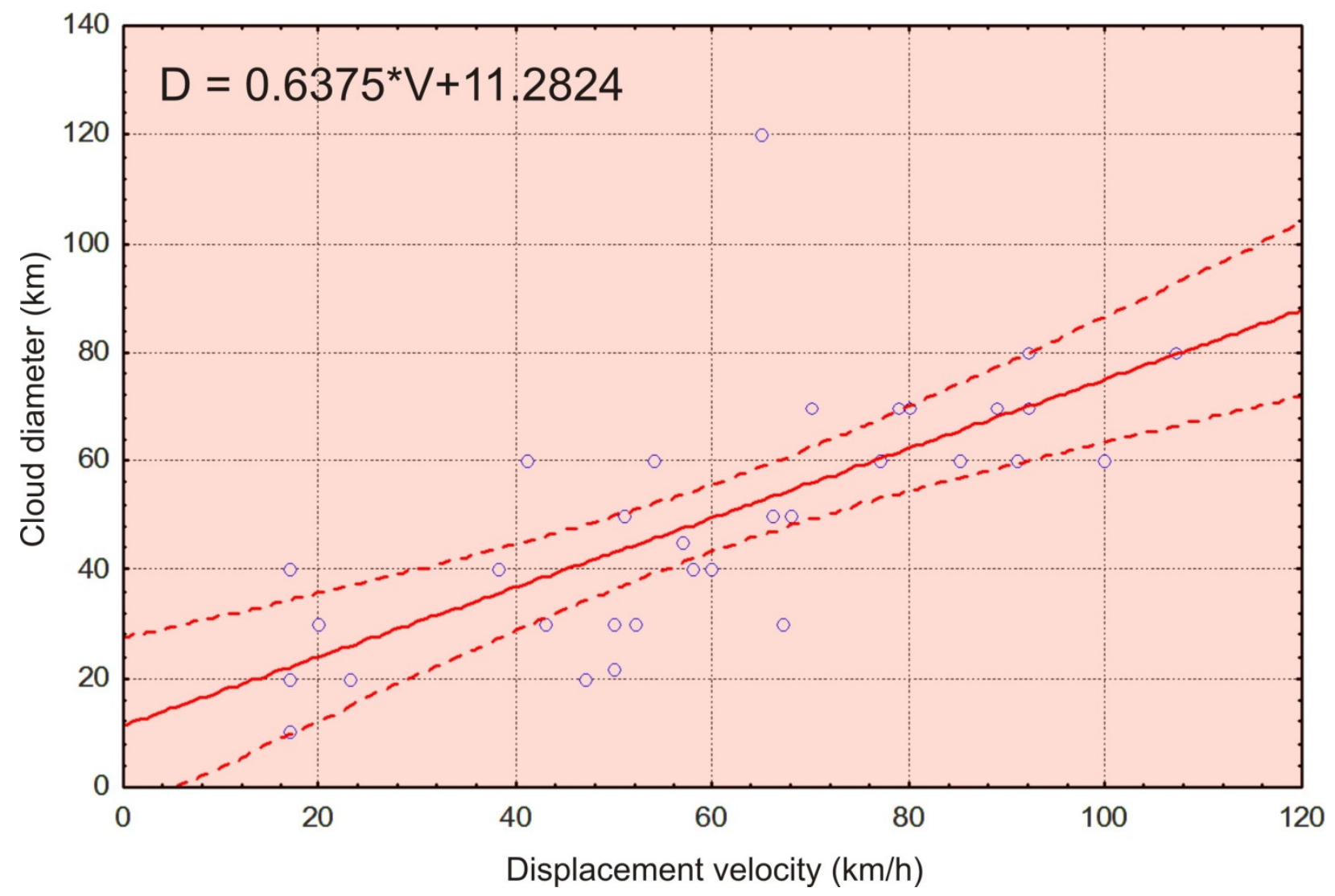

Fig. 7.5. Scatter diagram of displacement velocities $(\mathrm{km} / \mathrm{h})$ and cloud diameters $(\mathrm{km})$.

On the whole the data could be said to support the idea that the storm movement velocities are direct proportional with cloud dimensions, but occasional marked deviations were found.

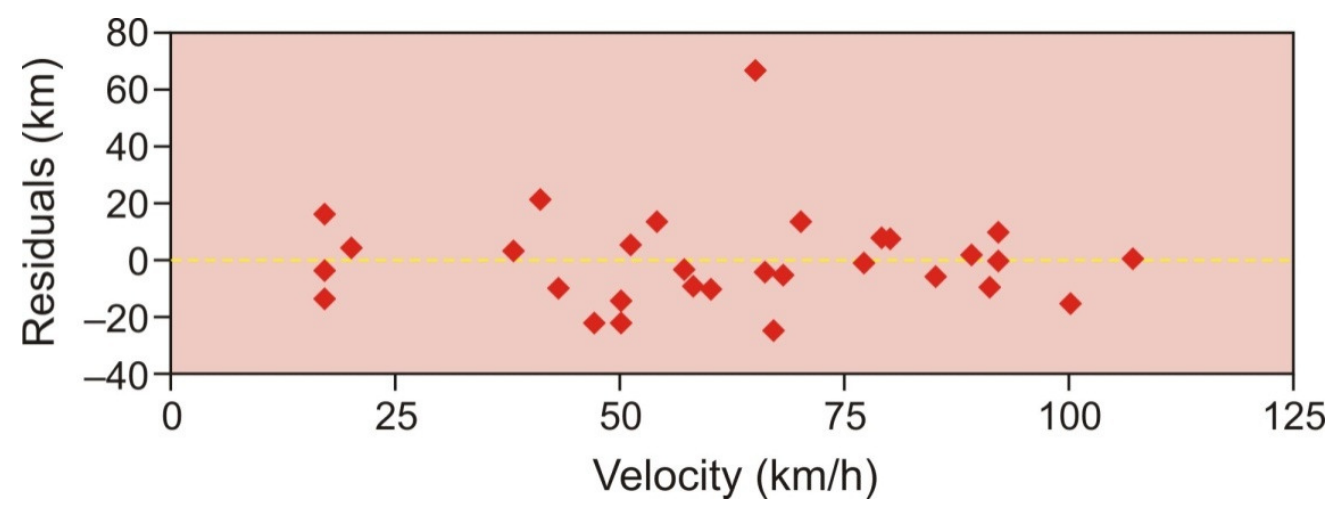

Fig. 7.6. Residuals for simple linear regression model of displacement velocities $(\mathrm{km} / \mathrm{h})$ versus cloud diameters $(\mathrm{km})$. 


\section{Radar cloud top and base heights}

The most important property of $\mathrm{Cb}$ is the height which is reached by the cloud top. This top can be measured accurately (with accurancy of about half of kilometer) by careful photogrammetry or by triangulation using coordinated observation with at least a pair of theodolites, and an approximate measure by radar or satellite. When the $\mathrm{Cb}$ is obscured visually the radar alone shoes the height of the echo top on an RHI (range-height) display.

In Fig. 7.7 are shown the frequency of clouds as a function of the radar cloud top heights. It can be seen that the lowest heights (between 9- $11 \mathrm{~km}$ ) occur with frequency of $22 \%$ from total number of cloud. More than one fourth of clouds have top heights between 17-19 km. The individual heights are ranged from 9.5-18.2.

The cloud base heights are narrower. The individual base heights are ranged from 1.5-2.5 $\mathrm{km}$. The majority of clouds $(80 \%)$ have very uniform base on height of $1.8 \mathrm{~km}$.

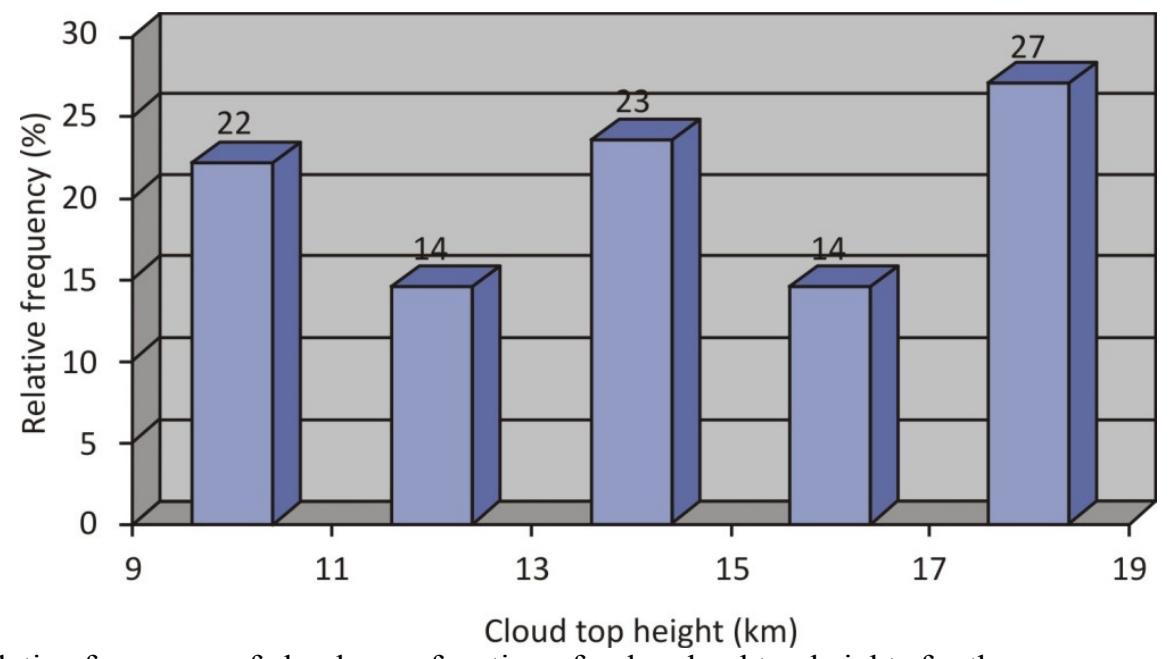

Fig. 7. 7. The relative frequency of clouds as a function of radar cloud top heights for the summer period $2005-2011$.

\section{Maximum radar reflectivity}

In the developing stage of storm the updraft is essentially erect until it reaches some height where it comes under the influence of the strong environment wind which causes it to band, thus permitting accumulation of larger amount of liquid or ice water content. The number of particles, their size and phase contribute that radar reflectivity increases with height up to that level and decrease after that level. Therefore, the structure of radar echo with height is essential to now. Especially is important to now the height of maximum reflectivity, $\mathrm{H}_{\mathrm{Zm}}$ and its amount, Zm. In Figs.7.8.and 7.9 are shown these characteristics for considered clouds.

The most clouds have maximum reflectivity height, $\mathrm{H}_{\mathrm{Zm}}$, on levels between 6 up to $8 \mathrm{~km}$. Relative height number of clouds $(18 \%)$ have $\mathrm{H}_{\mathrm{Zm}}$ on relatively low levels, between $2-4 \mathrm{~km}$. Some of $\mathrm{H}_{\mathrm{Zm}}$ are just over the level of cloud base. They are not situated on the updraft region. Contrary, they are induced by precipitation within downdraft. For the individual clouds $\mathrm{H}_{\mathrm{Zm}}$ are ranged from $2.0-11 \mathrm{~km}$.

Among all clouds $46 \%$ have $\mathrm{Zm}$ with values between $65-75 \mathrm{dBZ}$ while $36 \%$ inside the interval from 50 to $55 \mathrm{dBZ}$. Individual clouds have $\mathrm{Zm}$ between 51 up to $78 \mathrm{dBZ}$. 


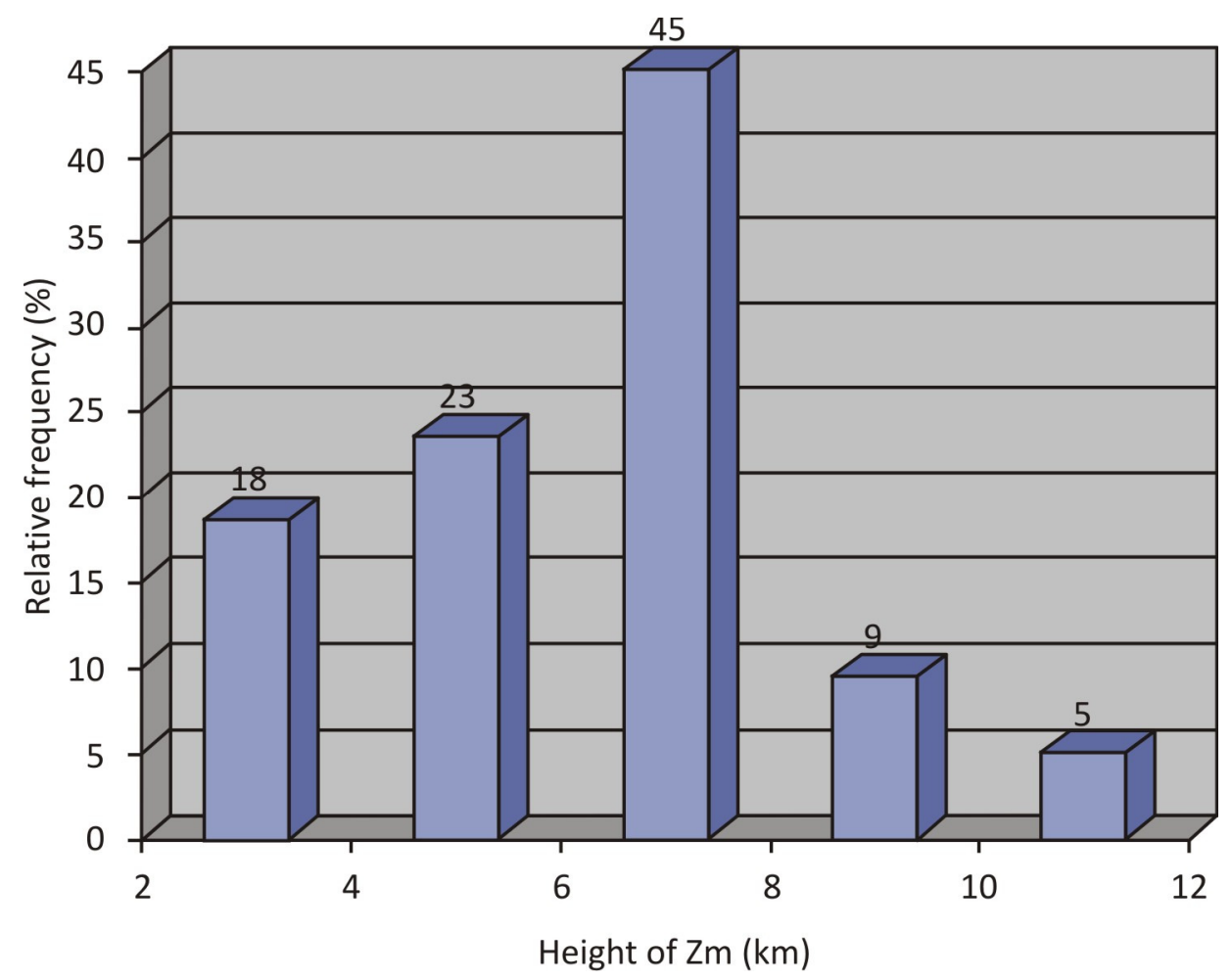

Fig. 7. 8. The relative frequency of clouds as a function of maximum reflectivity heights for the summer period 2005-2011.

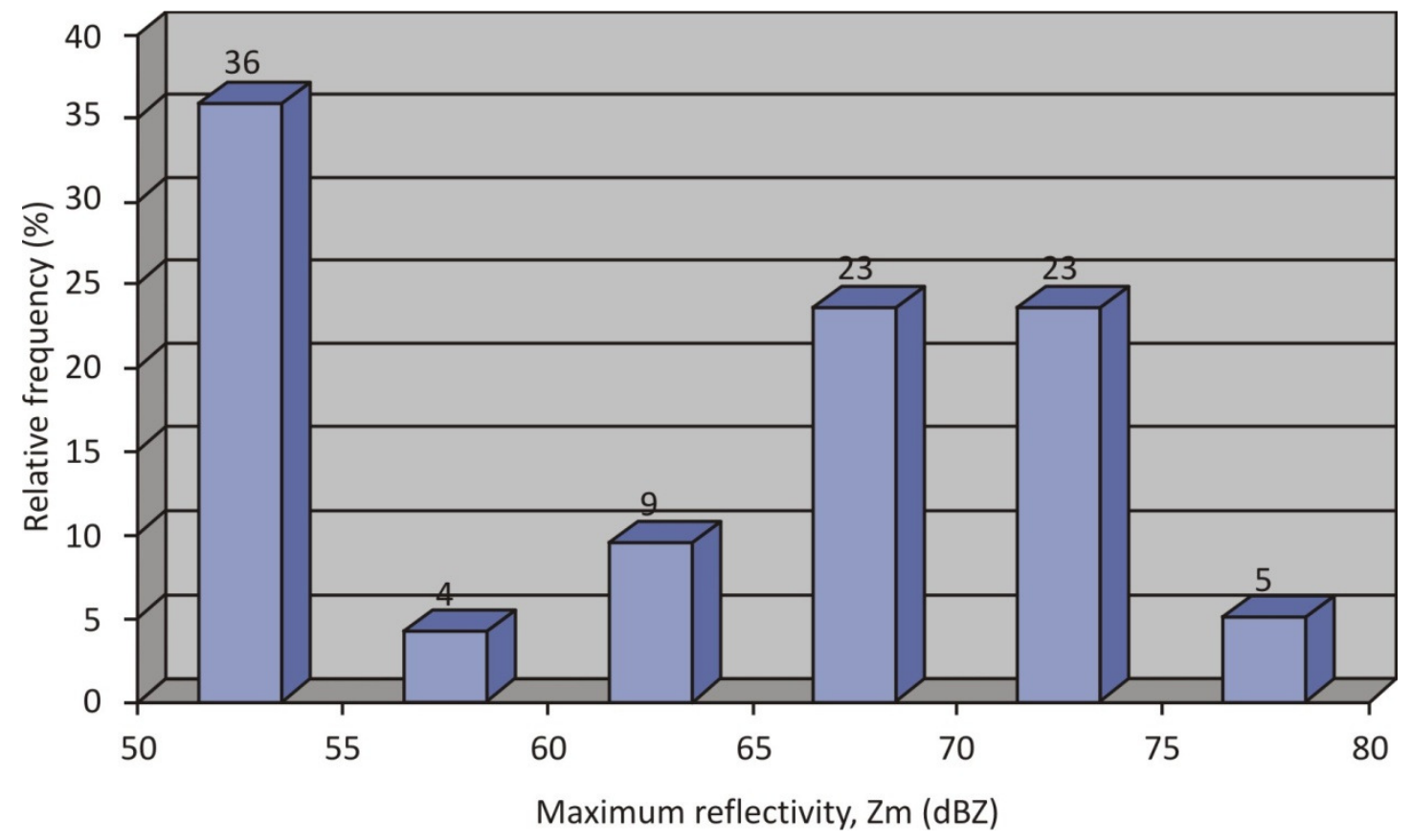

Fig. 7.9. The relative frequency of clouds as a function of amount of the maximum reflectivity for the summer period 2005-2011. 


\subsection{Relation of $\mathbf{C b}$ and environmental properties}

Recognition of the interaction of $\mathrm{Cb}$ clouds and their larger scale environment remains still one of the most challenging problems. The basic nature of the $\mathrm{Cb}$ convection has existed almost from the beginning of the modern meteorology (Humphreys, 1914). But, quantitative understanding of the dynamics of convective storms remains fully undeveloped. This is due in part to the none linear nature of cloud dynamics and the strong interactions between the widely different scales of motion that occur in the sever $\mathrm{Cb}$. The principal deficiency has been the lack of the observations of the three dimensional motion, thermodynamic and microphysical structure suitable for developing the theoretical models.

From the point of view point of the larger scale meteorologist buoyant convection is a turbulent exchange process to be treated statistically by parameterization. In the tropics, subtropics and in the summer months in midlatitude vertical overturning by cloud convection is the principal method by which the atmosphere rectifies the radiative imbalances between short wave surface heating and long wave atmospheric cooling. This overturning takes on far more complicated forms than would exist in the dry atmosphere because of the ability of water substance to exist in three phases. For this reason the parameterization process is extraordinarily difficult to formulate. This is occupied the attention of many scientists (Emanuel, 1994, Ericson and Whitney, 1973).

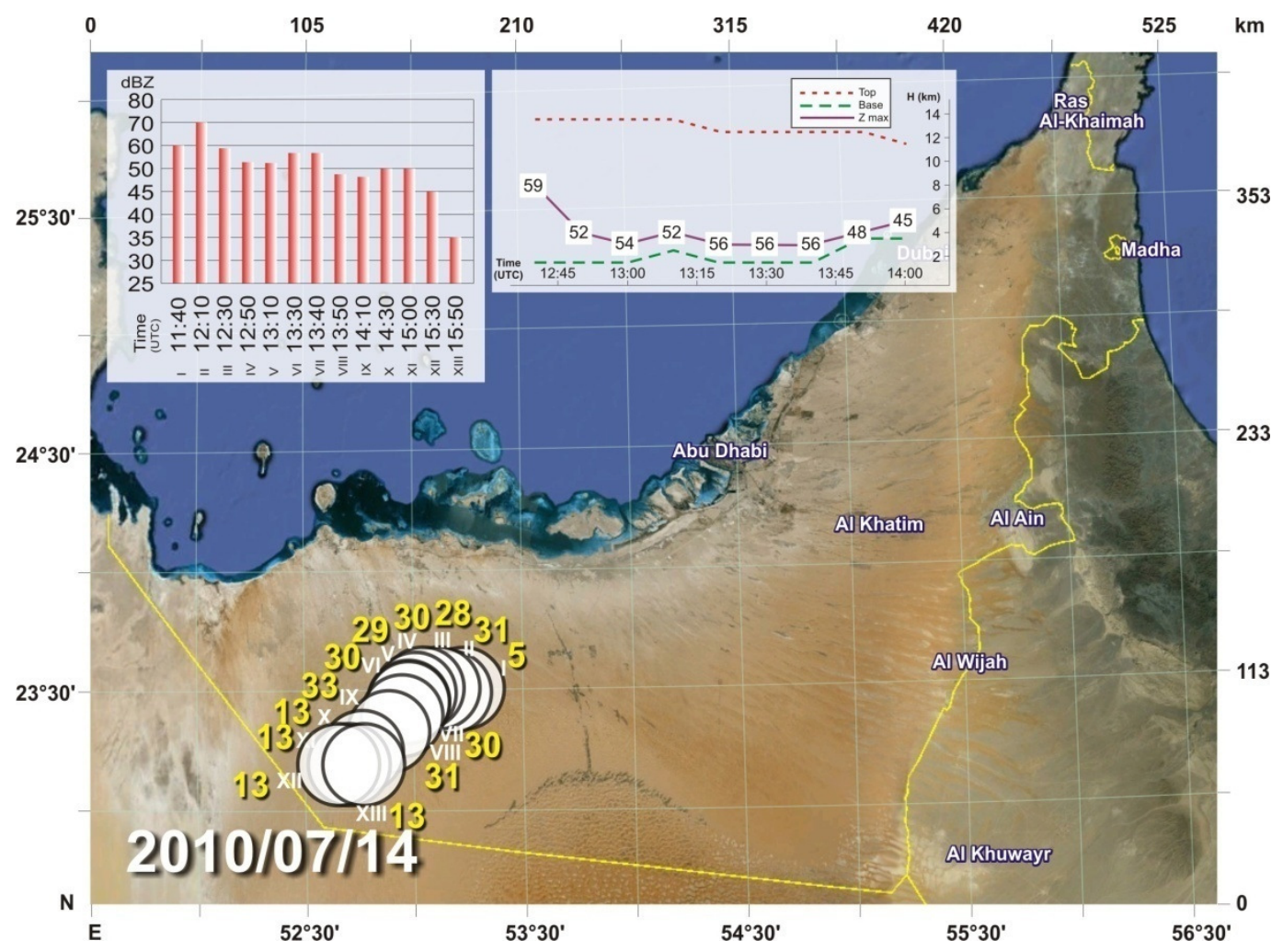

Fig. 7.10. Inland formed $\mathrm{Cb}$ cloud on the front of sea-breeze convergence. The path of cloud is presented by cycles at different times (Roman numerals, in hours and minutes) with cloud mean radius (Arabic numerals, in $\mathrm{km}$ ).

The radar cloud characteristics (maximum radar reflectivity, Zmax, in dBZ;

heights of cloud top and base, and level of Zmax, in km). 
It is desiring to understand, predict or modify convective systems. Almost nowhere can cloud convection be considered as either completely random or completely organized. Over the tropical oceans, where surface and synoptic scale forcing exist but very weak, major convective cloud usually occur in aggregates, clusters, apparently forced by those very weak larger scale disturbances. After the initiation of the clusters the energy released by buoyancy apparently overwhelms that of the initial forcing mechanism. Large islands or peninsulas in the low latitudes produce the most reliable organization since the diurnal heating cycle generates strong sea-breeze convergence and excites thunderstorms over land at nearly the same time many days during summer months (Read et al., 2008). Such one Cb cloud is shown in Fig. 7. 10. The cloud is moderately developed and moves in land, from the coast, in the direction of the sea-breeze front of convergence advancing.

When the pre convective state includes a stable layer preventing moist low level air from rising into a conditionally unstable upper atmosphere some larger scale disturbances must exist. When the stable layer is eliminated by larger scale or mesoscale uplift, the buoyant release then occurs suddenly and violently. Such one cloud is shown in Fig. 7. 11.

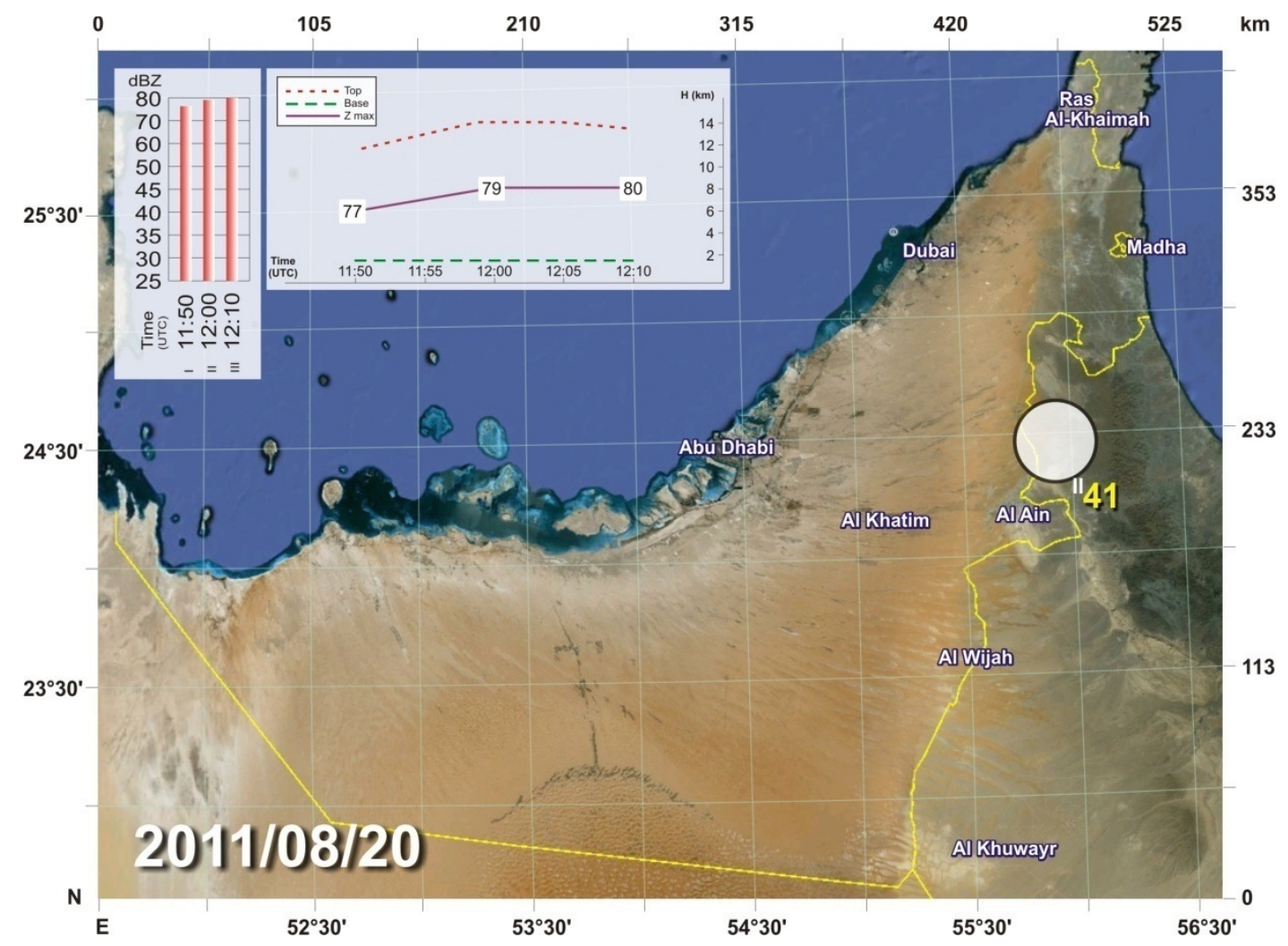

Fig. 7.11. Suddenly developed shortlived Cb cloud. Others characteristics have same meaning as in the Fig. 7. 10.

The control of convective storm developments by surface and boundary layer nonuniformities is so strong in clear cut situations such as land-breeze and heated mountain regimes. There the boundary layer influence may be suspected to be an organizing or triggering effect even in much more complex situations. In the cloud covered region is delayed in its diurnal surface heating cycle, leading to low level mass and moisture divergence with compensating convergence and early and strong convective cloud development in the previously regions. 
The outflow from the $\mathrm{Cb}$ cloud base (from old cells) is the most frequent impulse for triggering of additional new convective cells (Ćurć, 1980, Ćurć and Janc, 2011a). Although this effect should be strongest at the short distances and undoubtedly aids in maintaining the storm as a coherent entity, under some circumstances the outflow or a trapped gravity wave generated by it can extend out hundreds of kilometers from its parent storm and trigger new storms long after the original source element has died. This sequence has been detected by suitable radars and from satellite observations.

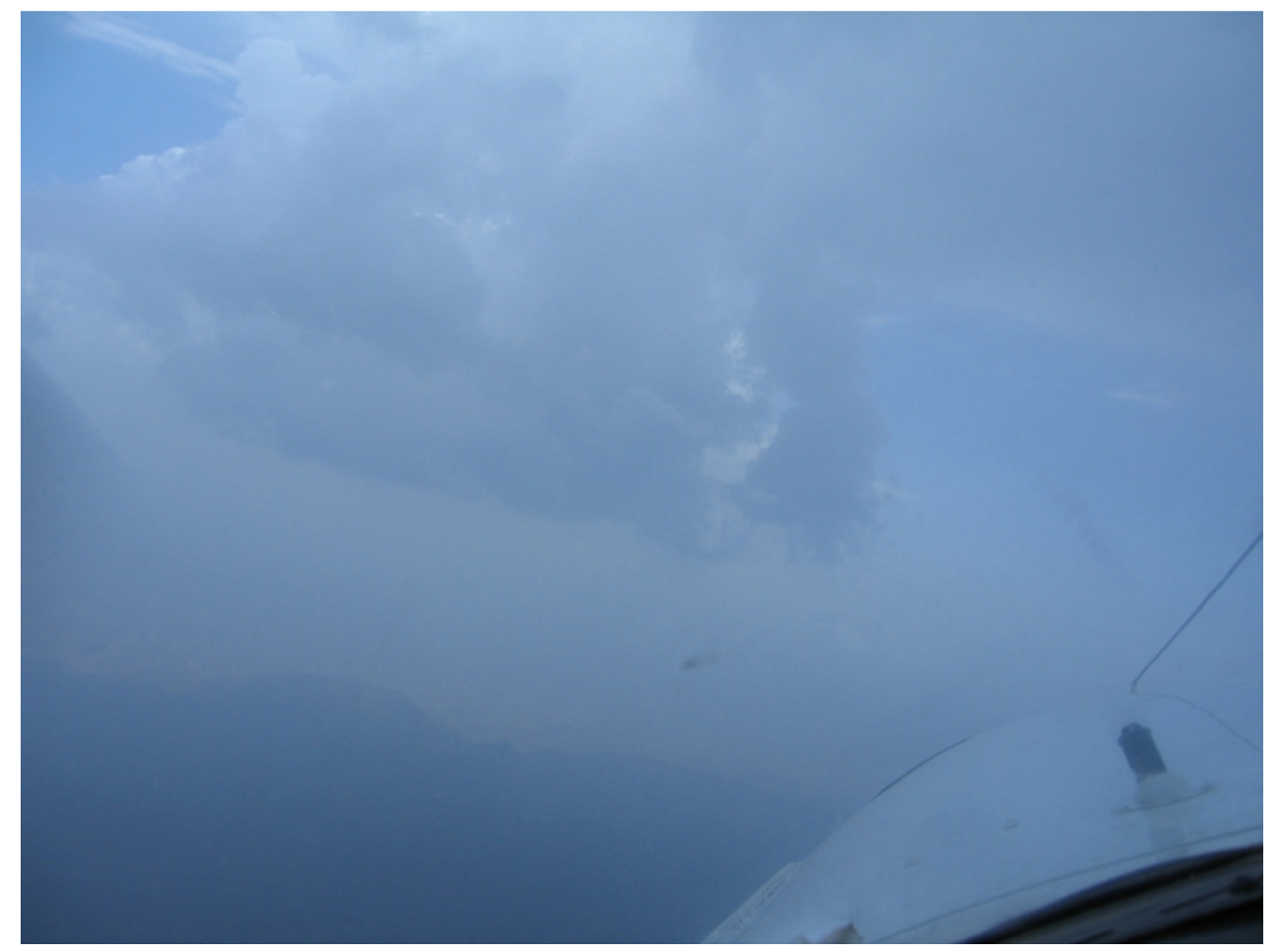

Fig. 7.12. The new formed cloud (doughter) fotographed from aircraft on the gust front head in the front of the mother cloud.

In Fig. 7. 12. is shown the yang cloud development over the gust front head due to the forcing of warm humid air to lift upward in the front of older cloud. The visibility in the boundary layer air is very low due to the large number of the send particles suspended into the air. An apparent arc cloud line is shown at the head of a train of short gravity waves (produced due to the fast spreading of gust front head) suggesting that the original cold mass outflow had become linearized into a travelling wave disturbance propagating in a pre-existing stable layer or under a strong shear.

\subsection{Case studies of $\mathbf{C b}$ characteristics}

The parts of the world in which organized $\mathrm{Cb}$ clouds are most frequent are those shown in Fig. 7.13. Red shadowed regions in the middle latitudes in which large hailstones occur are distinguished from those in lower latitudes where rain, lightning, are squalls are severe, but large hailstones are almost unknown. These low latitude regions are over or close to lands where in some seasons the intertropical confluence zone is well defined and where there is a considerable wind shear in the lower troposphere. The regions liable to severe hailstorms are also over or 
close to land in the higher latitude where large wind shears are associated with frontal zones in the large scale of slope convection (slantwise convection) and usually extend up through the whole troposphere (Ludlam, 1980)

In the southern hemisphere the storms occur in the southeastern part of the continents during excursions northward of the strong winds from their mean position, associated with the penetration of cold fronts into their latitudes.

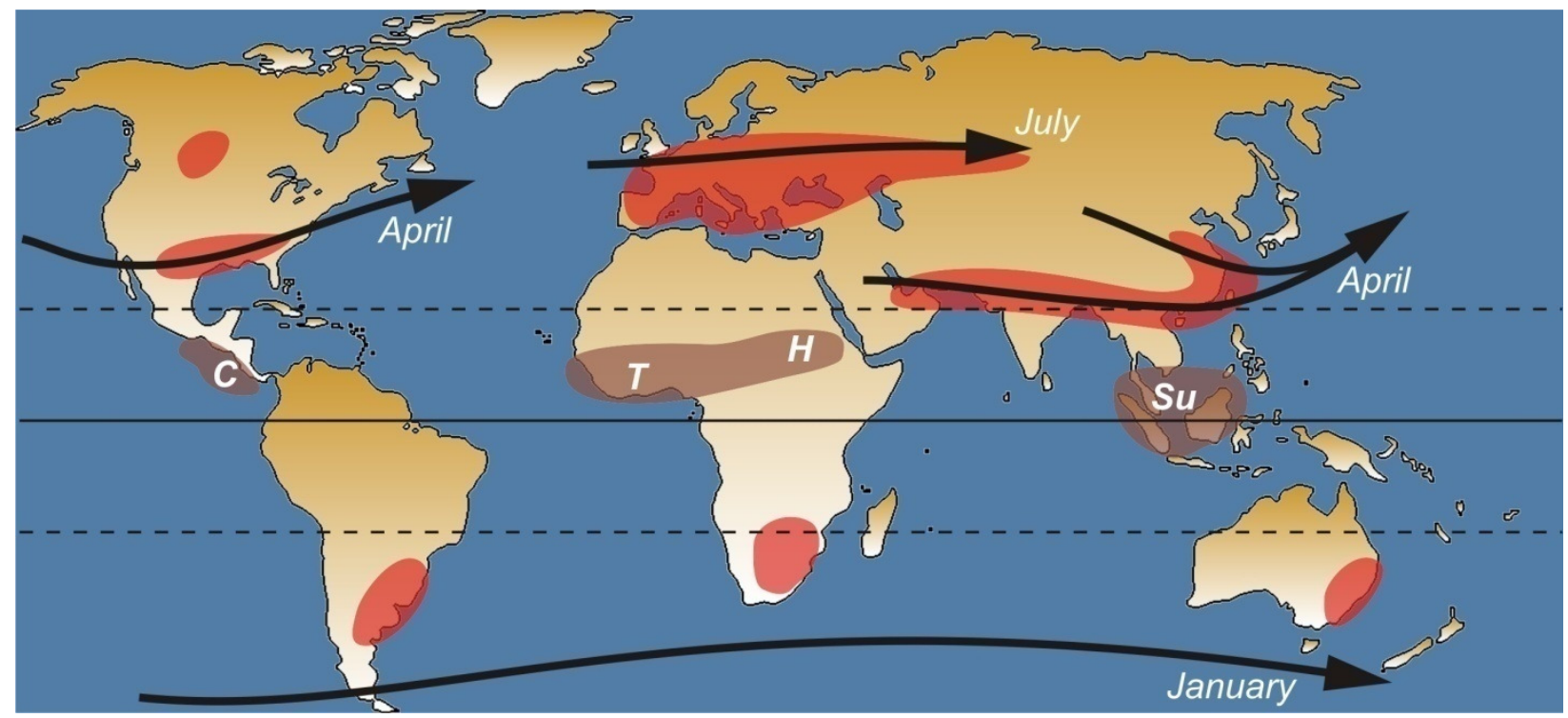

Fig. 7. 13. The regions over the world with severe $\mathrm{Cb}$ clouds. The storms are locally named as chubascos (C), tornadoes $(\mathrm{T})$, haboobs $(\mathrm{H})$ and sumatras $(\mathrm{Su})$.

As we can see the territory of UAE is a part of the lower latitudes where severe $\mathrm{Cb}$ occurr. Due to this reason a careful and extensive set of analysis and comparisons has been made of the radar characteristics of $\mathrm{Cb}$. The thunderstorm velocities, assessed from the motion of points judged to be the geometric centers of the storm echoes observed on PPI radar display, their paths, than the data observed on the RHI display are considered. The analysis which follows is selected for some more interested cases.

\section{Case study 1: 17 July 2009}

Three thunderstorms that occurred on 17 July 2009 are different to each other even they are developed under the same larger scale of weather conditions. At 1200 UTC a center of height pressure was located over the north part of the Arabian Gulf and a deep low pressure over the Arabian Sea. Over territory of UAE this system is characterized by ENE flow at $500 \mathrm{hPa}\left(\mathrm{AT}_{500}\right)$ with velocity greater than $55 \mathrm{~km} / \mathrm{h}$. Below this level the easterly flow was very slow (less than $20 \mathrm{~km} / \mathrm{h}$ ). An inversion which is lifted from the boundary layer can be seen from the Abu Dhabi sounding. The total CAPE (Convective Available Potential Energy) was 2,523 J/kg. 

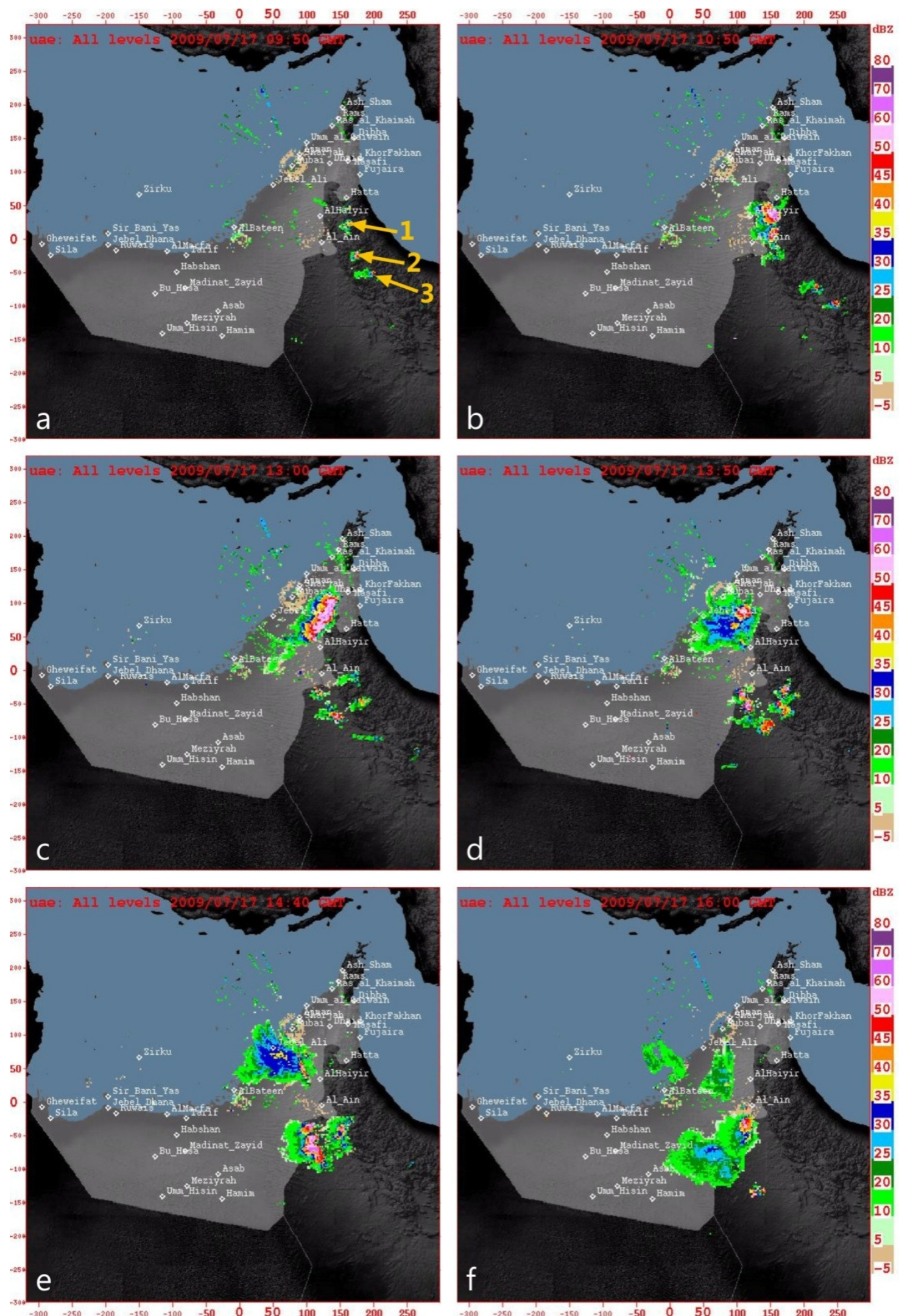

Fig. 7.14. Six consecutive positions of storms on the PPI radar display, 17 July 2009. 
The convective clouds first came under the radar surveillance just after 0900 UTC (local time 1300). At the ridge of Oman mountain many convective cells occurred at 0940 (three are more interesting due to their father lives (Fig.7.14a). They are marked by 1, 2 and 3.After that time they start development in vertical and horizontal direction so that 1 and 2 are gradually merged at 1040 (Fig. 7. 14b). This merged cloud moved westward very slow, with mean displacement velocity about $20 \mathrm{~km} / \mathrm{h}$. The height of cloud top was less then $16 \mathrm{~km}$. The radar characteristics of cloud lup to the merging are shown in Fig. 7. 15. At the same time after merging on their northern periphery start development the new separate cells. Two of them attained a much greater intensity than others. After $20 \mathrm{~min}$ they merged. The new cells of the intense storms formed on their front side and amalgamated into large echoes within which the cells could still be recognized as regions of high echo intensity (Fig.7. 14c) These echoes persisted up to 1540 UTC (Fig. 7. 14d,e,f). During a phase of maximum intensity which lasted about 3.5 hours the fused cells into one storm was very intense (about $70 \mathrm{dBZ}$ ) and very deep (above $18 \mathrm{~km}$, Fig. 7. 16). This system moved westward by mean velocity of $50 \mathrm{~km} / \mathrm{h}$. It is practically equal to the velocity of environmental wind at the $\mathrm{AT}_{500} \mathrm{hPa}$. It was found that the deviation of storm movement was to the right for about $20^{\circ}$.

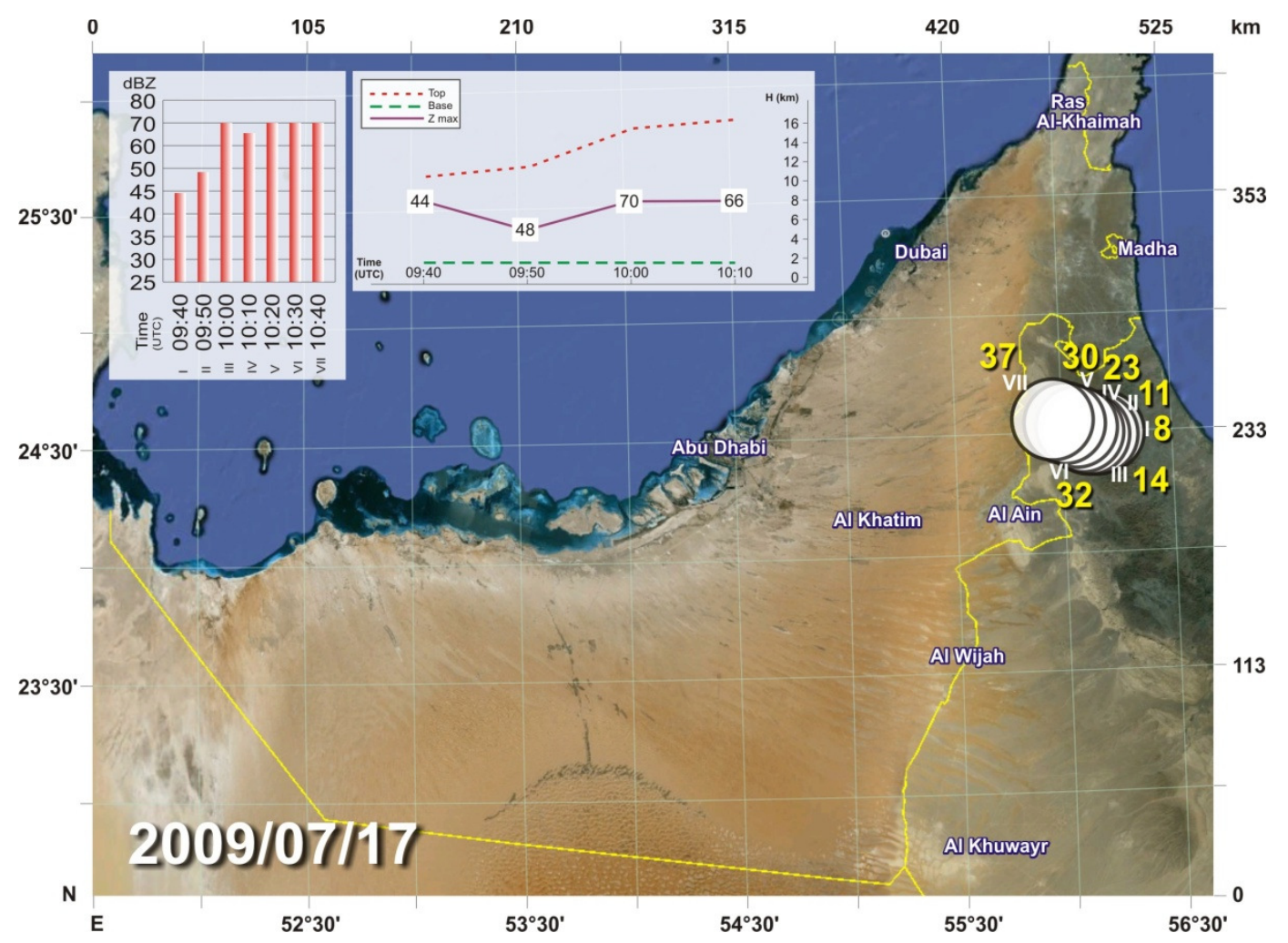

Fig. 7.15. Radar characteristics of cloud 1 from Fig. 7. 14a. The meanings are the same as in the Fig. 7. 10. 


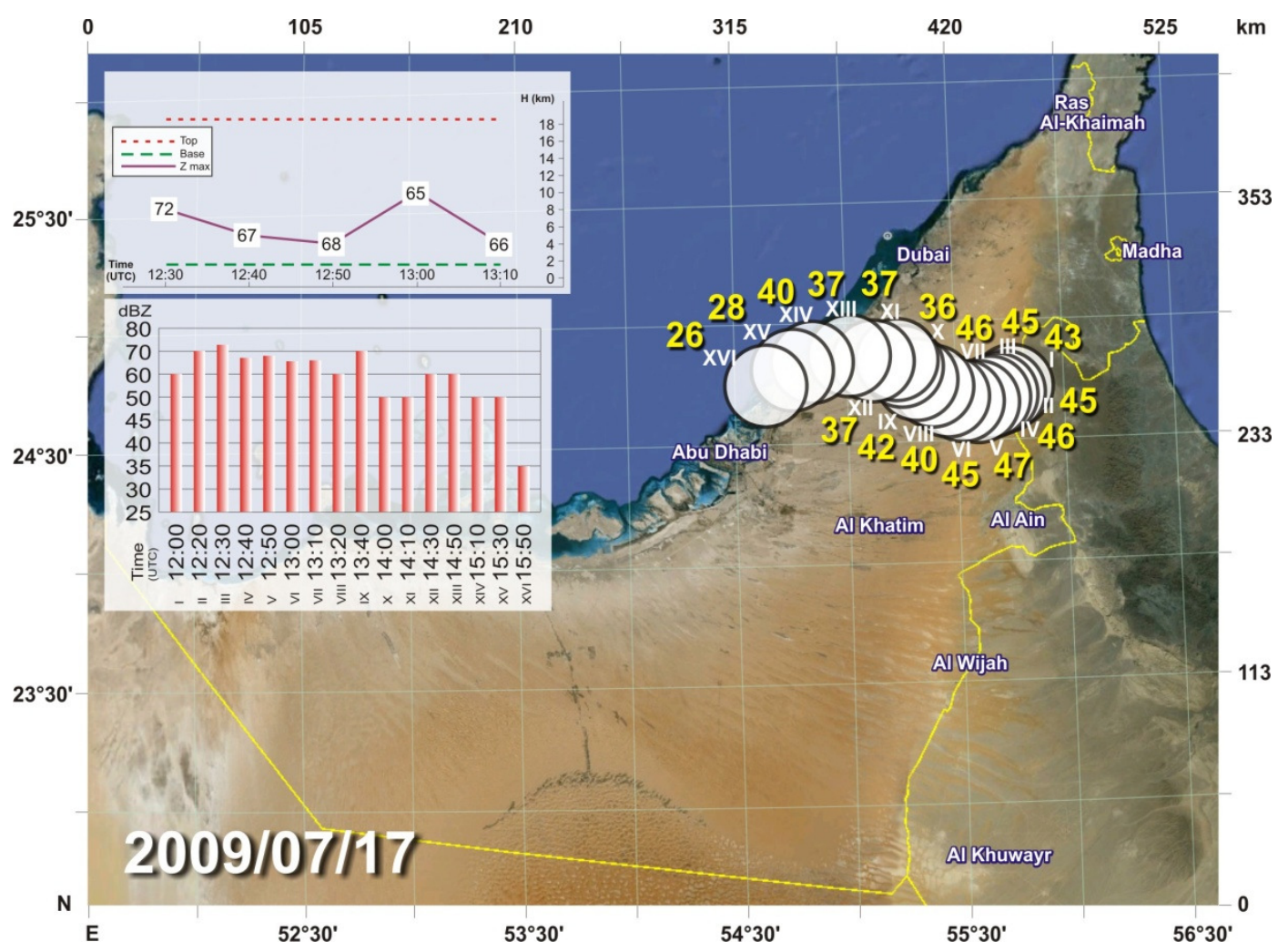

Fig. 7.16. Radar characteristics of cloud 2 from Fig. 7. 14a. The meanings are the same as in the Fig. 7. 10.

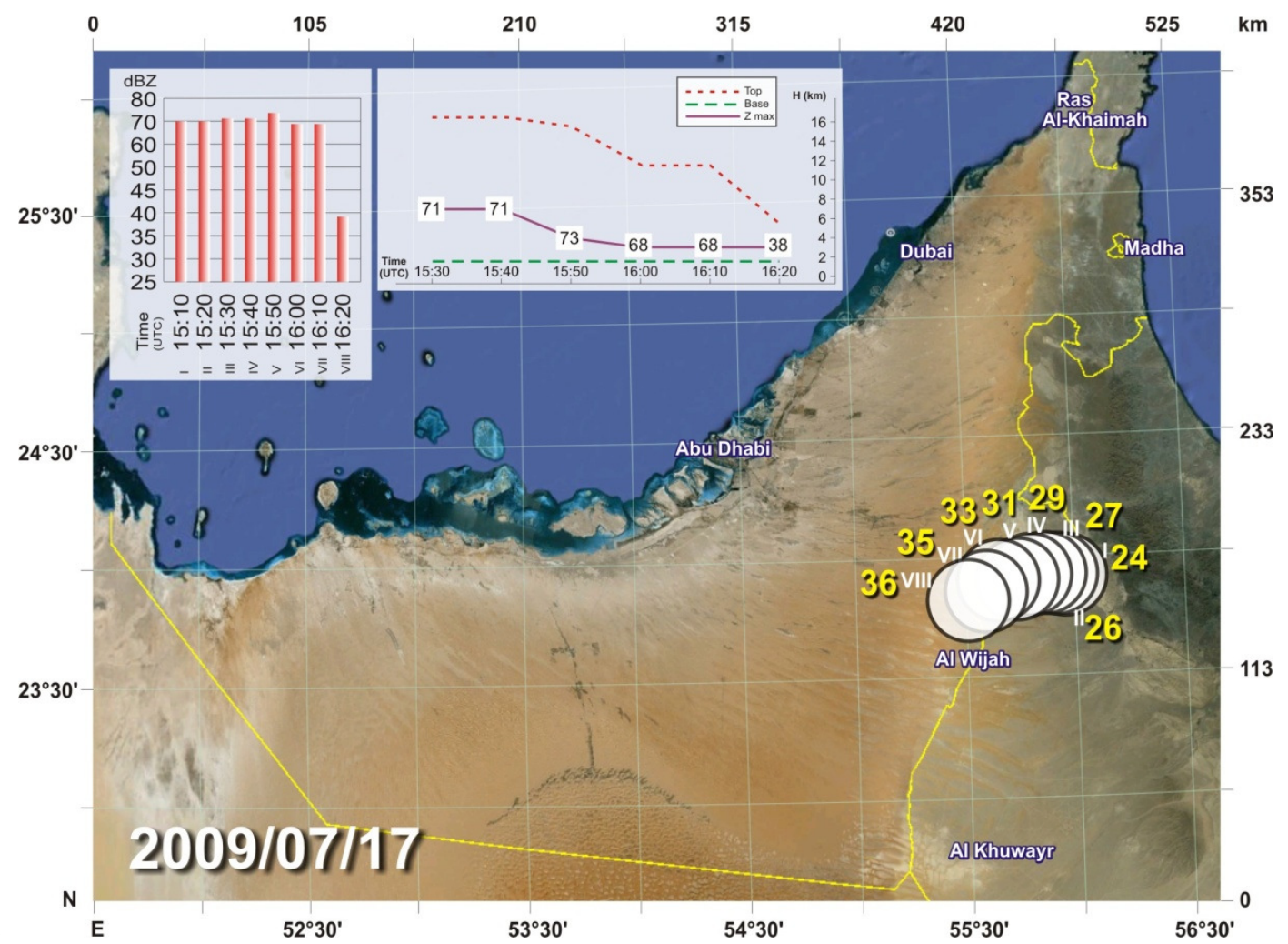

Fig. 7.17. Radar characteristics of cloud 3 from Fig. 7. 14a. The meanings are the same as in the Fig. 7. 10. 
At 1300 observations a radar cells located $150 \mathrm{~km}$ south of the first location of storms shown in Fig. 7. 15 were made. Five separate cells were identifiable at mean distance of about $25 \mathrm{~km}$. At 1450 they merged into two of which attained a much greater intensity( Figs. 7. 16 and 7. $14 \mathrm{c}, \mathrm{d}$ ). That two are lived together as one cloud system (storm) until the 1530. After that the storm starts to dissipate until the total disappearance at 1740 . During the phase of maximum intensity (which duration was of $1.2 \mathrm{~h}$ ) reflectivity reached $71 \mathrm{dBZ}$ and cloud top height 16.5 $\mathrm{km}$. Radar echo moved steadily toward WSW without any marked variation in its structure. Development of strong new cells predominantly occurred on the left flank of the cluster, so that the resulting movement was left of the ENE of the environmental wind.

\section{Case study 2: 10 August 2008}

At 0940 UTC of the 10 August 2008 there are six different $\mathrm{Cb}$ clouds developed at the ridge of the Oman mountain at a distance abut $40 \mathrm{~km}$ Fig. 7.18a. At 1020 two which are located in the northern part are especially well developed. The first one is located near the Al Haiyir, and second is situated on distance of $50 \mathrm{~km}$ toward the SE from Al Ain. Both of them grow very fast. On the right flank of the Al Haiyir storm developed one fast growing cloud which merged with his mather cloud at 1050 UTC. After that time the new clouds develop on right and left flank of the Al Haiyir storm, by forming one very power storm at 1120 UTC (Fig. 7. 18c).

At the same time on the south side exist one elongated storm in a NW-SE direction (Fig. 7. 18c). The cell (northern part) of the southern storm was splited at 1130 from mother storm. This cell propagated forward and deviated on the right side. At 1230 UTC it merged with northern storm, forming one wide spreading and very elongated storm in direction NW-SE. The length of the storm in this direction is about $200 \mathrm{~km}$. The northern part of north storm is in the dissipation phase, with the reflectivity about $25 \mathrm{dBZ}$. Both storms (southern and northern) are vigorous and grow until the 1310 UTC (Fig.7.18d). They move slow westward, while cells move in the NE-SW direction (Fig. 7.20). 

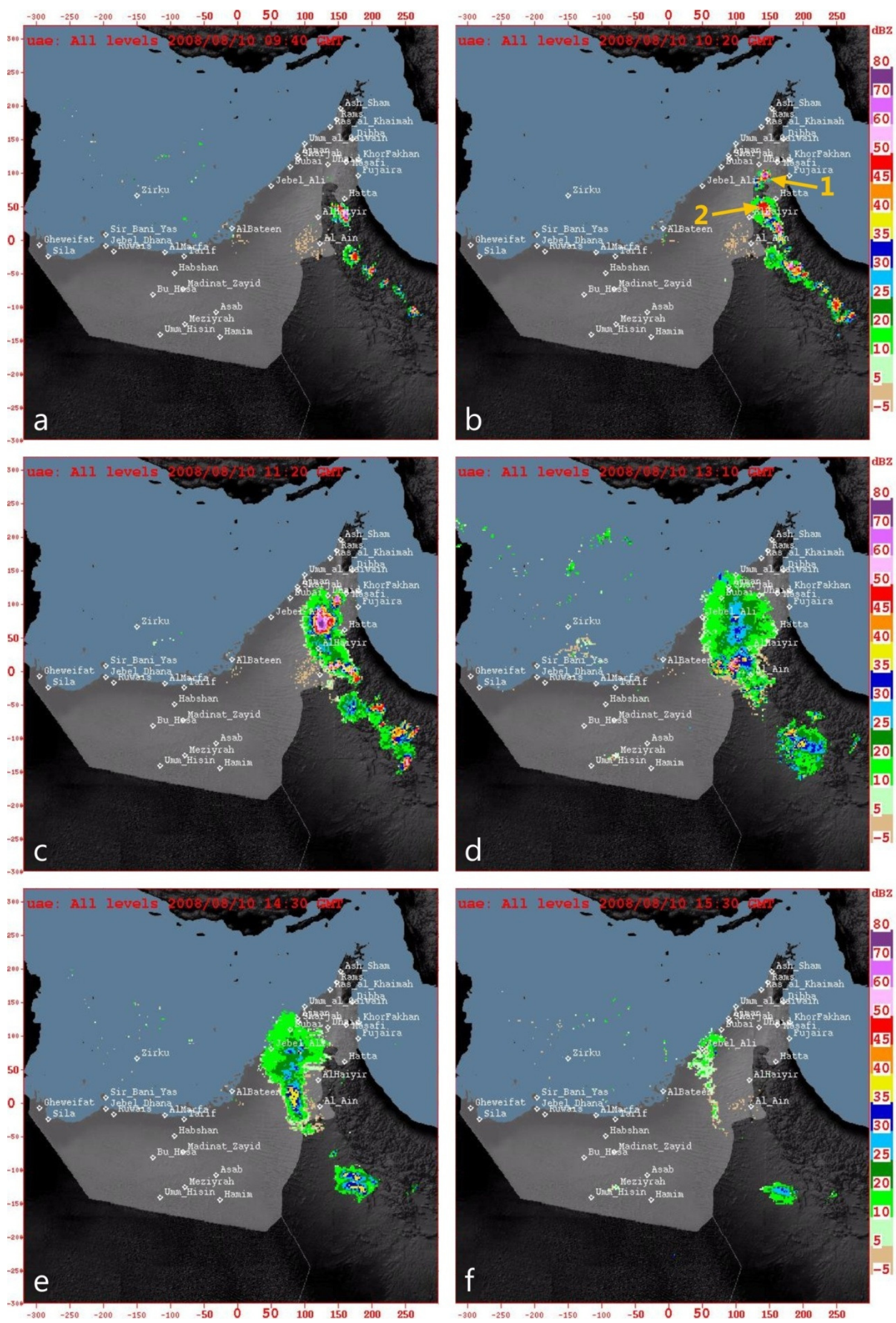

Fig. 7.18. Six consecutive positions of storms on the PPI radar display, 1o August 2008. 


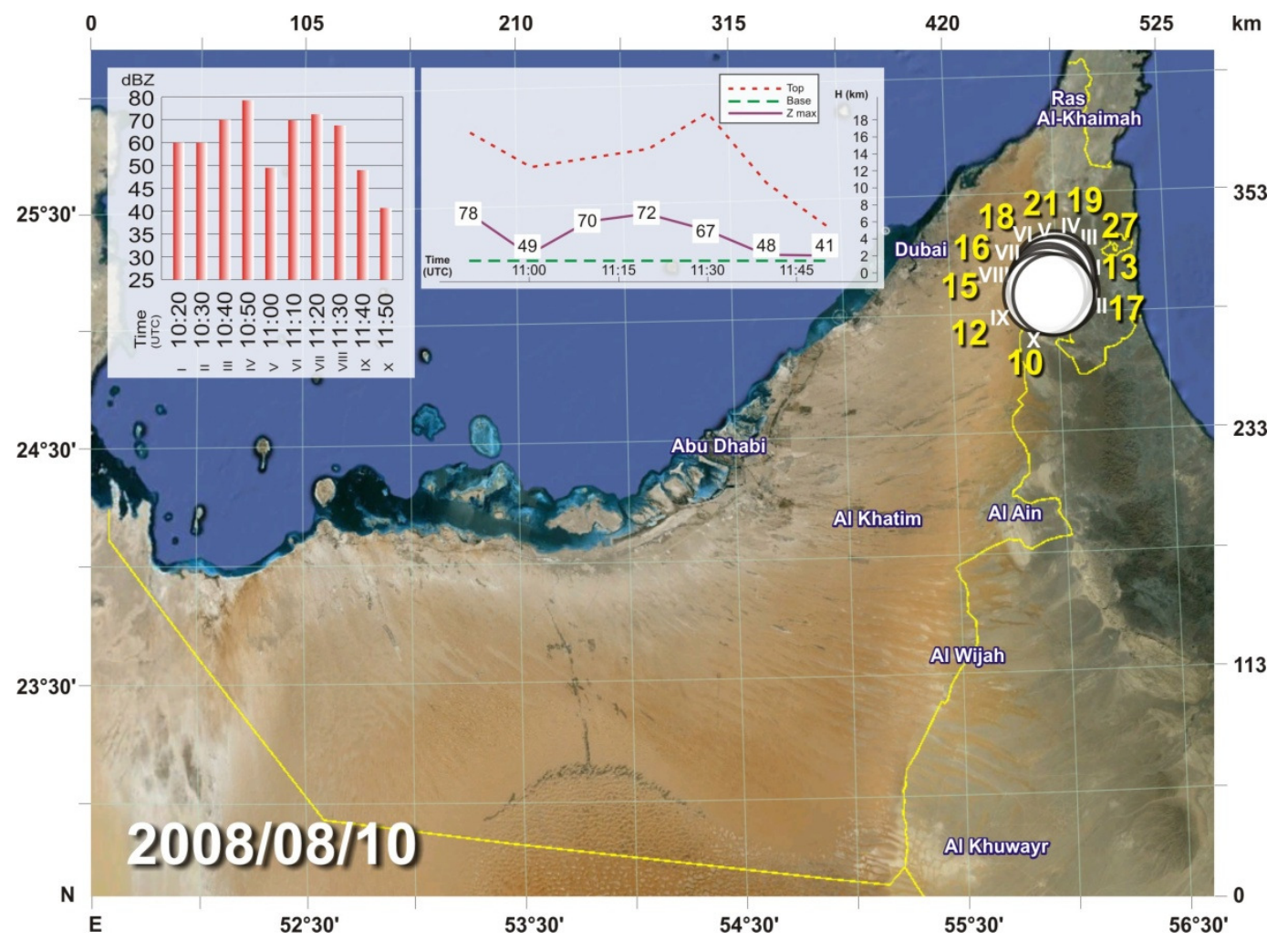

Fig. 7.19. Radar characteristics of cloud 1 from Fig. 7. 18a. The meanings are the same as in the Fig. 7. 10.

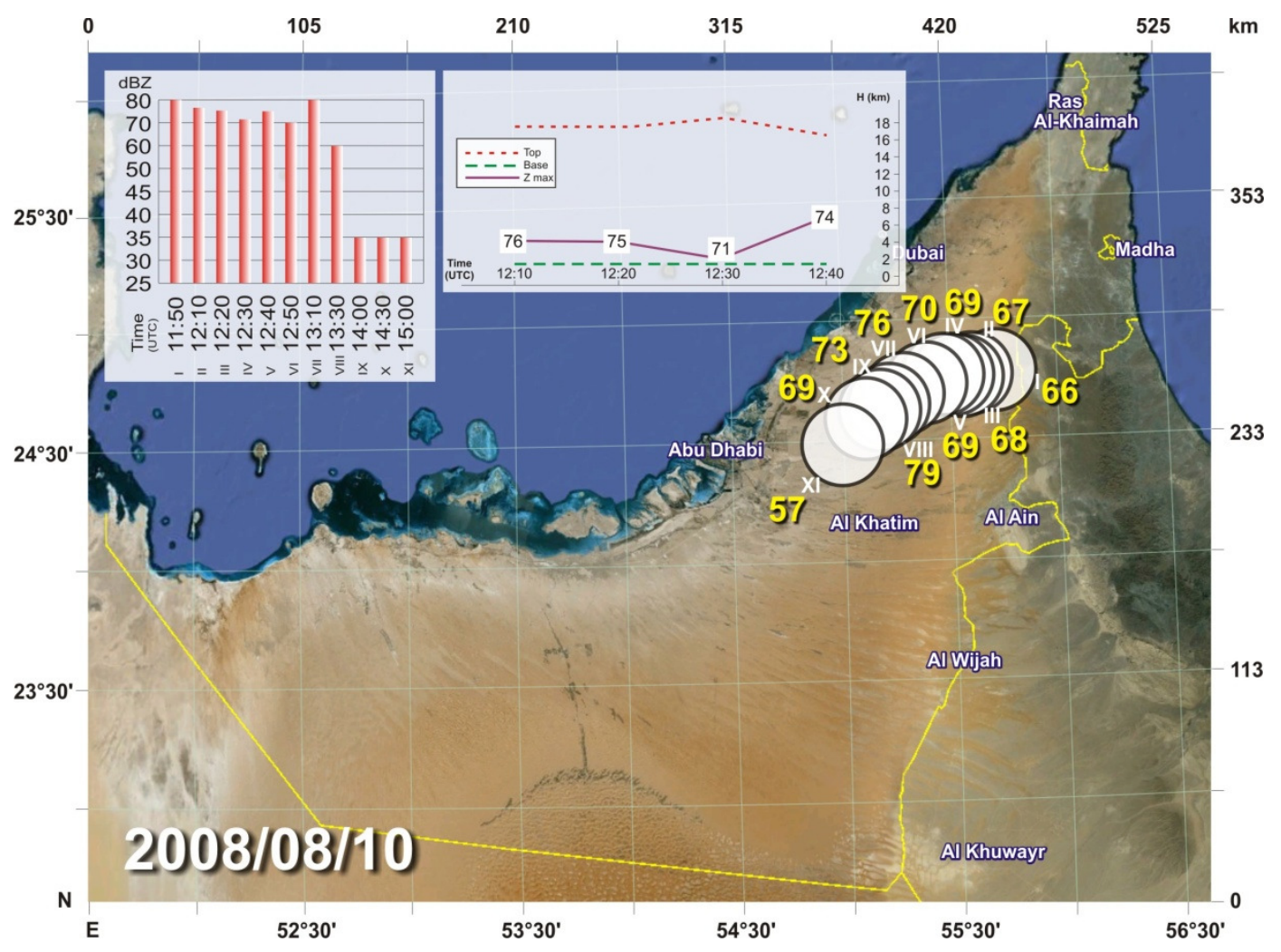

Fig. 7.20. Radar characteristics of cloud 2 from Fig. 7. 18a. The meanings are the same as in the Fig. 7. 10. 
The time evolution, displacement and main radar characteristics of selected cells 1 and 2 (shown in Fig. 7. 18b) are presented in Figs. 7. 19 and 7. 20. The cell 1 is relatively short lived cell, practically without displacement, but with very vigorous development in the vertical direction. Cloud top height attains $18 \mathrm{~km}$ and maximum reflectivity was $78 \mathrm{dBZ}$.

The cell 2 is long lived. In Fig. 7.20 the first part of its life is not shown because it did not make any significant displacement. This cell is very developed in vertical and horizontal directions. Cloud top height attains $18.2 \mathrm{~km}$ and maximum reflectivity was $80 \mathrm{dBZ}$. Regeneration of strong new cells predominantly occurred on the right flank of the cluster, so that the resulting displacement was right of the NE of the environmental wind. Cell moved along path toward right for average deviation of $35^{\circ}$ of the mean wind at the level of the $500 \mathrm{hPa}$. The deviation is smaller during final part of the life.

\section{Case study 3: 31 July 2010}

Clouds that occurred on 31 July 2010 are developed under the influence of a wide spread ridge of height pressure with axes along the Red sea and a low pressure over the Arabian Sea. At 1200 UTC over territory of UAE this system is characterized by $\mathrm{N}$ flow at $500 \mathrm{hPa}\left(\mathrm{AT}_{500}\right)$ with velocity smaller than $25 \mathrm{~km} / \mathrm{h}$. Bellow this level the northern flow was very slow (less than $15 \mathrm{~km} / \mathrm{h}$ ). An subsidence inversion is situated between levels of $500-400 \mathrm{hPa}$ and can be seen from the Abu Dhabi sounding. The total CAPE was only $98 \mathrm{~J} / \mathrm{kg}$ and LCL (Lifting Condensation Level) was very height, about $4.5 \mathrm{~km}$. The atmosphere below the level of $5 \mathrm{~km}$ was very dry.

Obviously, the general weather conditions where not favorable for development of strong convection. But, even such conditions, weak convective clouds are developed, mainly along the coast line and some on the western slopes of Oman mountain (Fig, 7. 21). The two main convective clouds which came under the radar surveillance at 1140 UTC are located near Al Ain and Madiant- Zayid. They are marked as 1 and 2 respectively (Fig. 7. 21a). The cloud 1 is developed under the most favorable local conditions on the sunlight side of Oman mountain. The cloud life is practically finished at 1300 UTC. The radar cloud characteristics are shown in Fig. 7. 22. ). During a life the maximum of radar intensity was low, less than $45 \mathrm{dBZ}$ and was not deep, below $9 \mathrm{~km}$. It moved slowly southward, in the direction of the prevailing wind on the $\mathrm{AT}_{500} \mathrm{hPa}$. The deviation of storm movement was not found.

The storm 2 is consisted of cluster of clouds. They are developed on the front side of the sea-breeze circulation. The sea-breeze circulation was the trigger mechanism of the convection. This storm is developed and moved just parallel with the red line shown in Fig. 5. 11. Obviously, the progress of the sea-breeze front inland was most remarkable in this area where the cost is orthogonal on the northern upper level flow (Read,.. Al Mandoos et al., 2008a).

During travelling toward the south the new cells are formed on left front side and amalgamated into large echoes within which the cells could still be recognized (Fig.7. 21d,e). This left hand side regeneration of storm is under the influence of the differential heating (Ćurć and Janc, 2011a,b). These echoes persisted up to 1640 UTC (Fig. 7. 21f). During a lifetime which lasted about 5 hours the fused cells into one storm was not never very intense (maximum reflectivity less than 45dBZ) and was nor deep (below $8.5 \mathrm{~km}$, Fig. 7. 23). This system moved southward by mean velocity abut $45 \mathrm{~km} / \mathrm{h}$. It is greater than the velocity of the environmental wind at the $\mathrm{AT}_{500} \mathrm{hPa}(25 \mathrm{~km} / \mathrm{h})$. This faster movement of storm than environment is involved by the sea-breeze front forcing and regeneration of storm on the left front side. Due to this factors it was found that the deviation of storm movement was to the left for about $20^{\circ}$. 

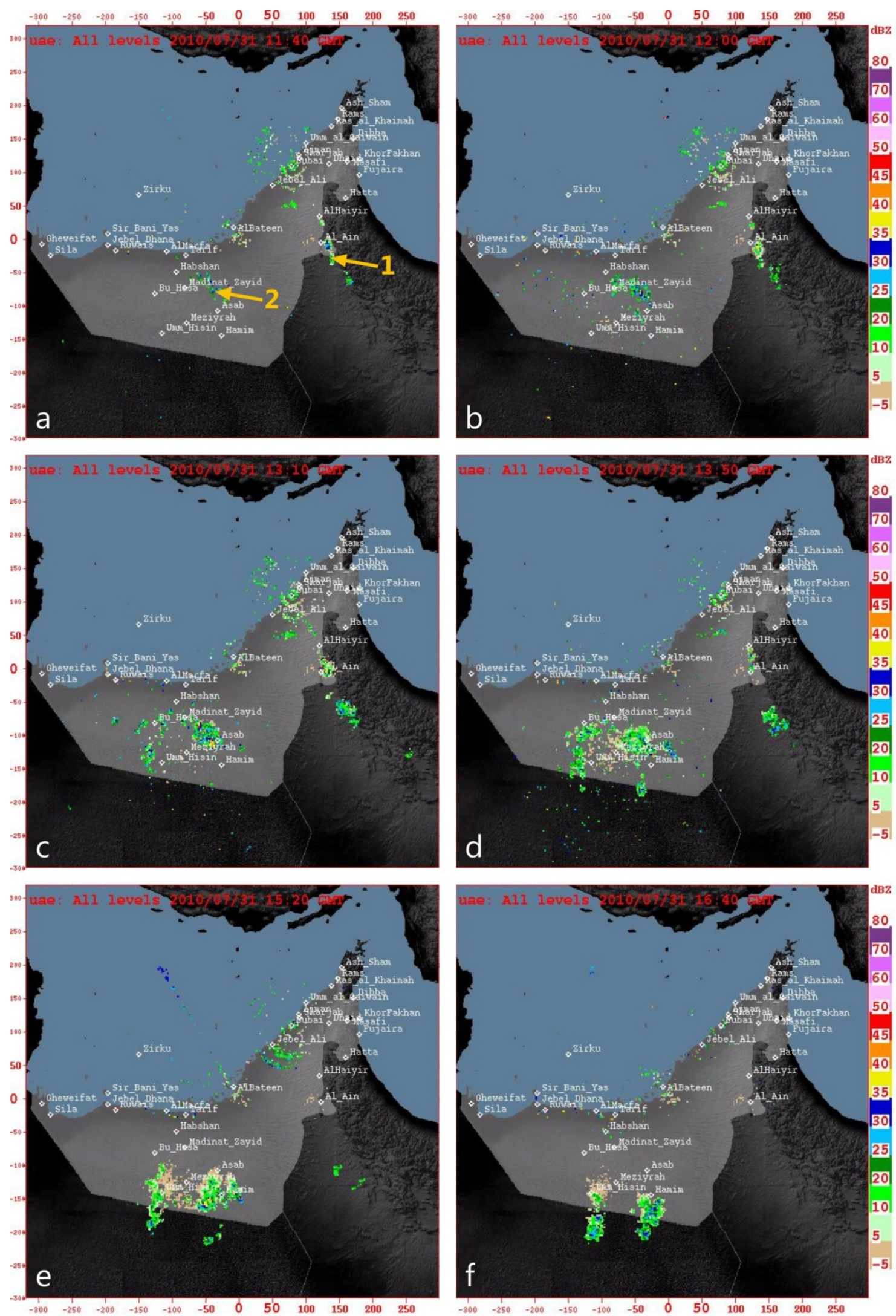

Fig. 7.21. Six consecutive positions of storms on the PPI radar display, 31 July 2010. 


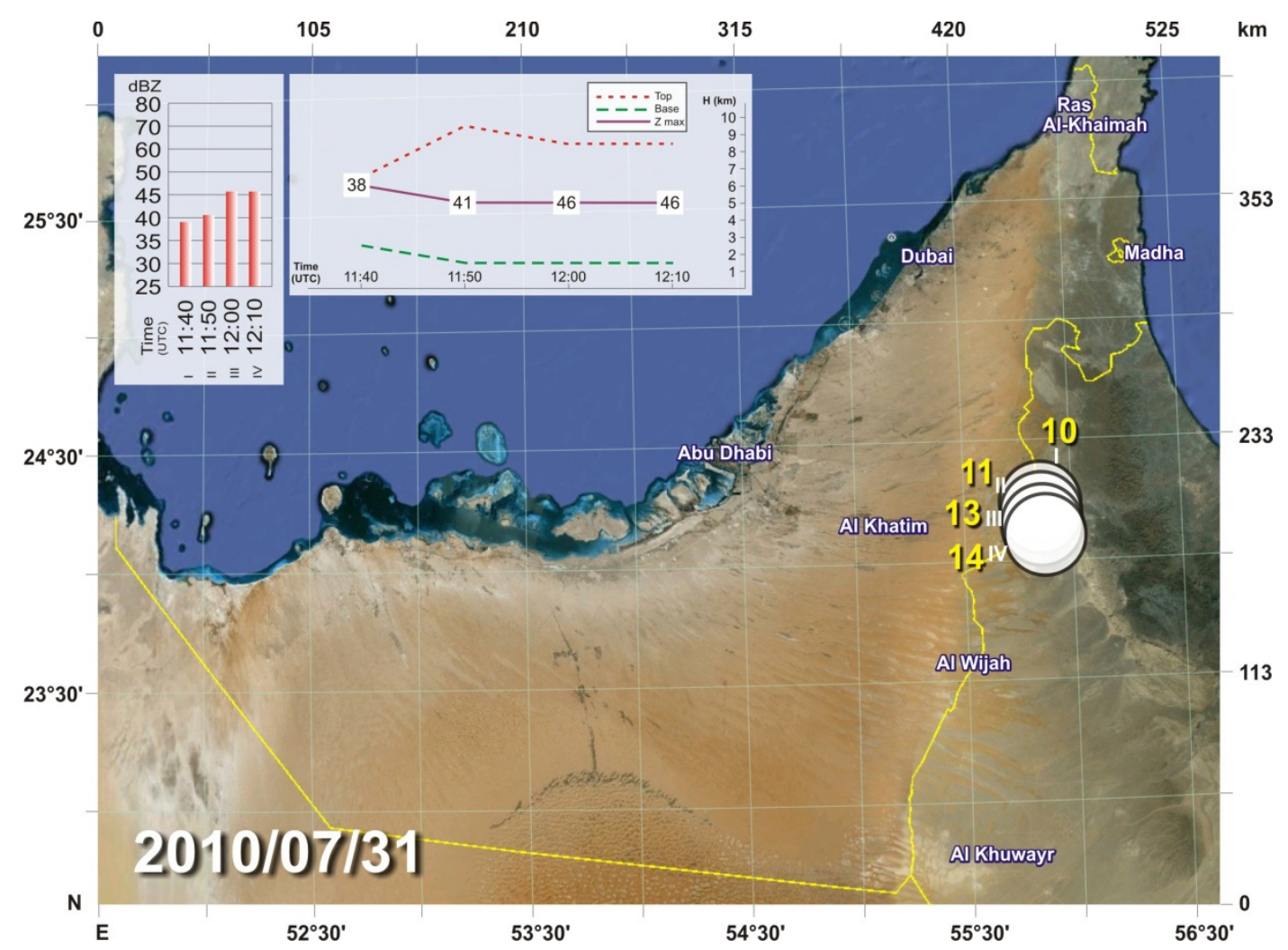

Fig. 7.22. Radar characteristics of cloud 1 from Fig. 7. 21a. The meanings are the same as in the Fig. 7. 10 .

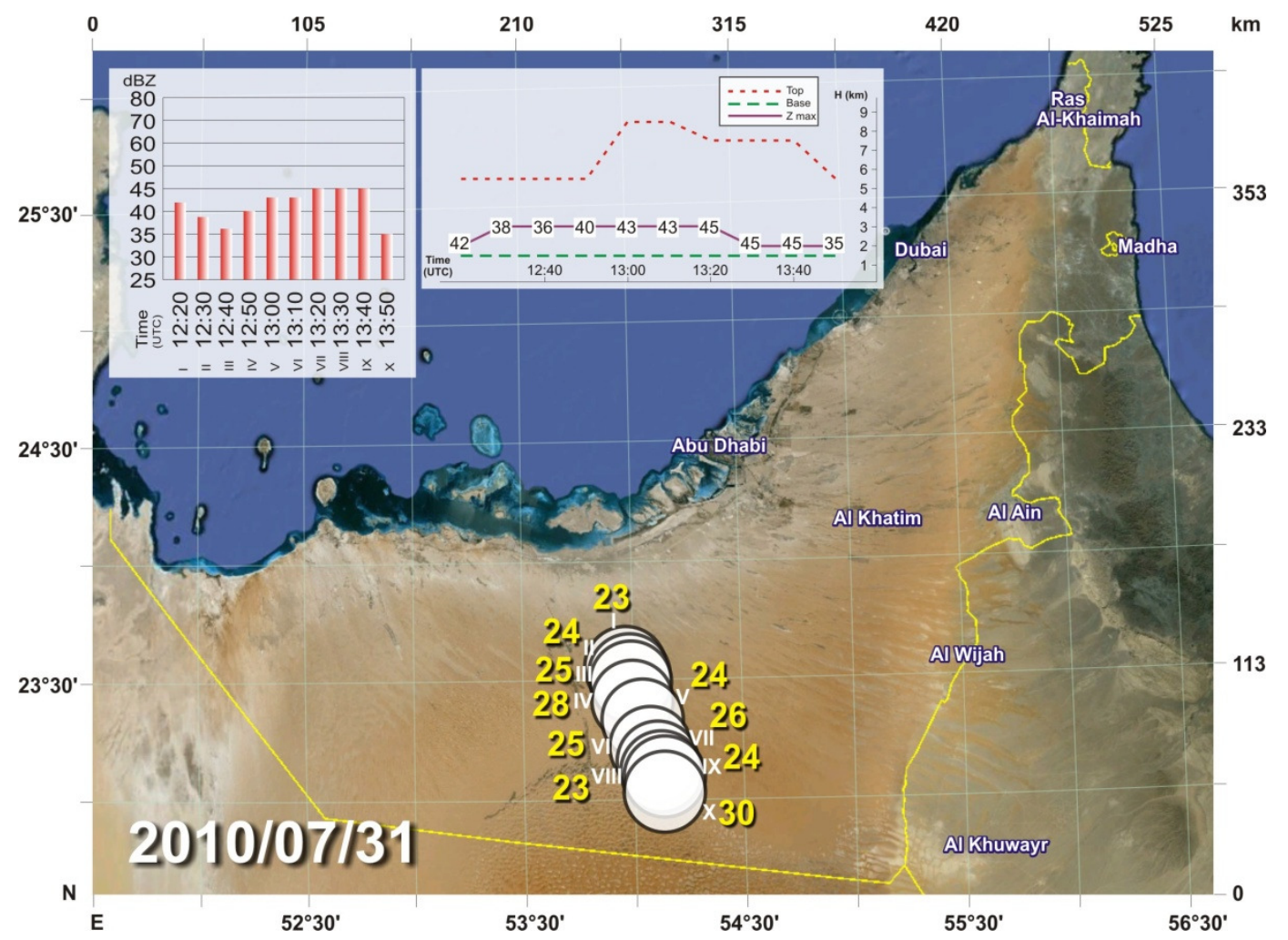

Fig. 7.23. Radar characteristics of cloud 2 from Fig. 7. 21a. The meanings are the same as in the Fig. 7. 10. 


\section{Case study 4: 10 August 2007}

Two main thunderstorms that occurred on 10 August 2007 are different mainly regarding to their different paths even they are developed under the same larger scale of environmental flow. At 1200 UTC a center of height pressure was located over the central part of the Red Sea with very extended ridge of height pressure in NE direction, northern of UAE. At the same time a deep low pressure was over the Arabian Sea with through of low pressure extended in the direction SE-NW, southerly of the territory of UAE. So, the isohypses were zonal over area of UAE. This system is characterized by E flow at $500 \mathrm{hPa}\left(\mathrm{AT}_{500}\right)$ with velocity smaller than 30 $\mathrm{km} / \mathrm{h}$. Below this level the easterly flow was very slow (less than $20 \mathrm{~km} / \mathrm{h}$ ).

At 0950 UTC there are many different $\mathrm{Cb}$ clouds developed at the ridge of the Oman mountain (Fig. 7.24a. They were at the different stage of the development. Some one merged with neighbor cloud by the bridging process, some one, on the other side, are split and dissipated. At 1130 two which are located in the northern and southern side are especially well developed. It is easy to see at 1219 UTC in Fig. 7.24b. They are marked as 1 and 2. The first one is located NW from Al Haiyir. Until the 1300, both storms grow and first continue movement toward the SW (Fig. 7. 25) while second very slowly travel toward the west (Figs. 7. 24c and 7. 26).

At 1350 the first has very widespreaded part on the NW side from the core of main cell (Fig. 7. 24d) with relative low reflectivity (about $25 \mathrm{dBZ}$ ). The second merges with the new cells situated on NE side (Fig. 7. 24d). At 1410 UTC storm 1 starts dissipation while the storm 2 rapidly grows on the NE side until the 1530 UTC. At 1530 storm 1 totally dissipates (Figs. 7. 24e and 7. 25) while the storm 2 starts slowly dissipation until the 1620. At 1640 it dissipated totally (Figs. 7. 24f and 7.26).

Storm 1during travelling toward the southwest the new cells are formed on the left front side (Fig.7. 24c,d). This left hand side regeneration of storm is under the influence of the differential heating and sea-breeze (Ćurć and Janc, 2011a,b,c; Reid,...Al Mandoos et al., 2008a,b; Eager,...Al Mandoos et al., 2008). Due to this factors it was found that the deviation of storm 1 movement was to the left for about $45^{\circ}$. During a lifetime which lasted about 6 hours the fused cells into one storm was very intense (maximum reflectivity $75 \mathrm{dBZ}$ ) and was very deep (up to $20 \mathrm{~km}$, Fig. 7. 26).

The storm 2 system moved very irregular in respect to the mean environmental flow. First it moves toward the SW, after that toward the NE, than NW and finally toward SW. It is some kind of the semicircle unticlockwice displacement. This traveling is not result of the real displacement of some selected core of the cloud. It is mainly result of the storm growing due to the merging or the new cell generation, so that the storm as all system has such irregular positions in the consecutive time intervals. During a lifetime which lasted about 7 hours the storm was not very intense (maximum reflectivity mainly less than $60 \mathrm{dBZ}$ ) and was not very deep (cloud top heights below 10 km, Fig. 7. 26). 

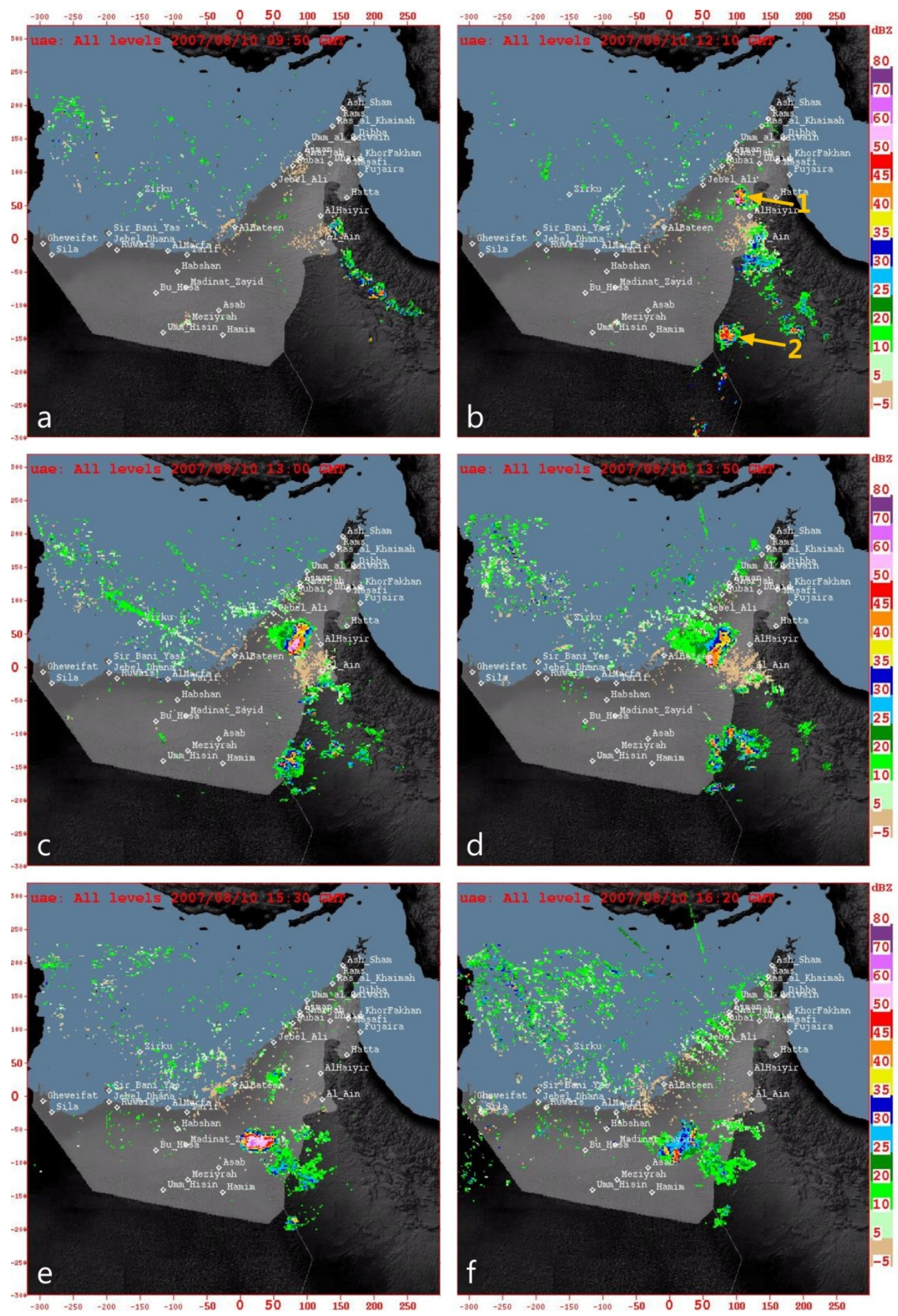

Fig. 7.24. Six consecutive positions of storms on the PPI radar display, 10 August 2007. 


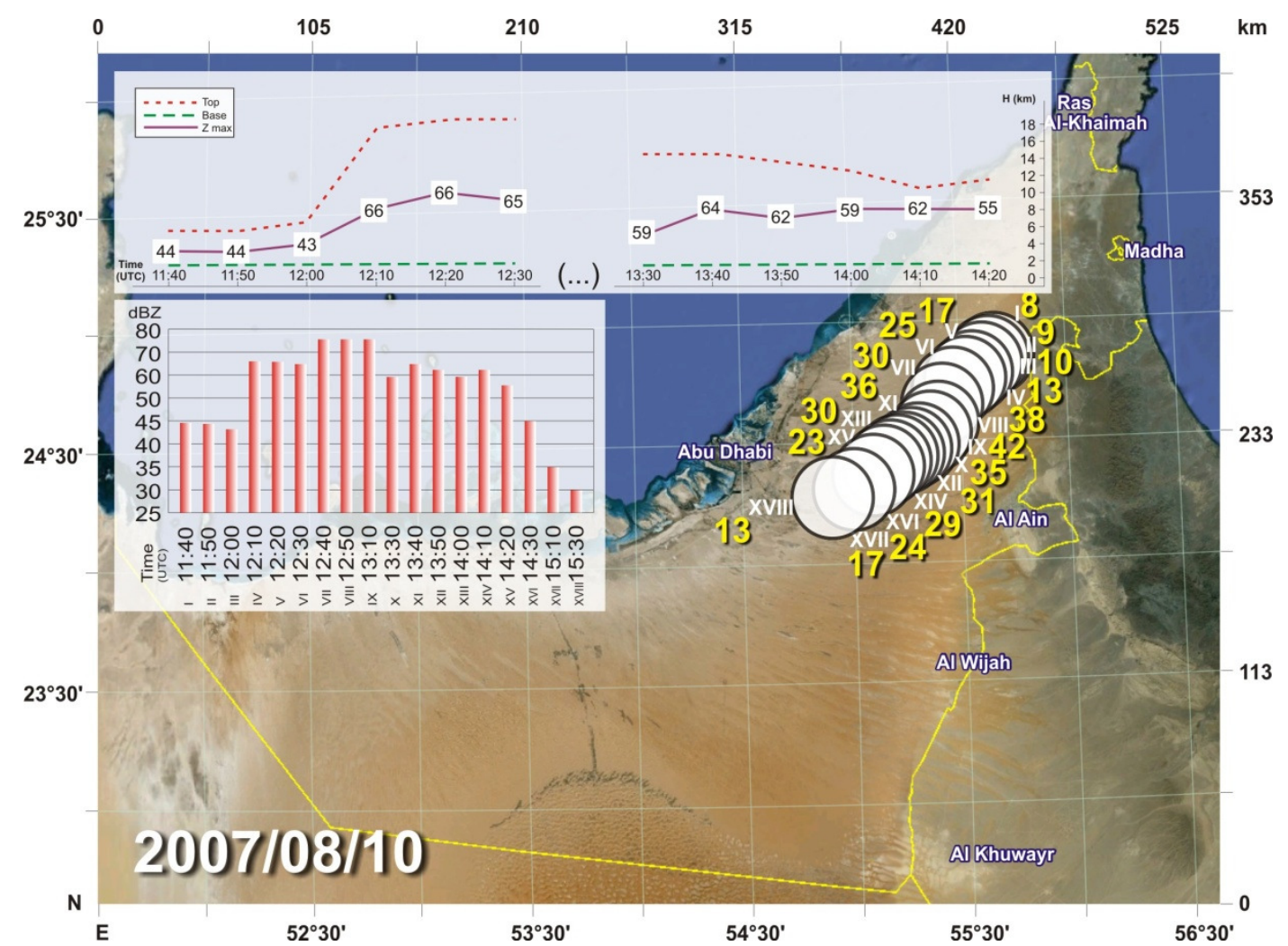

Fig. 7.25. Radar characteristics of cloud 1 from Fig. 7. 24b. The meanings are the same as in the Fig. 7. 10.

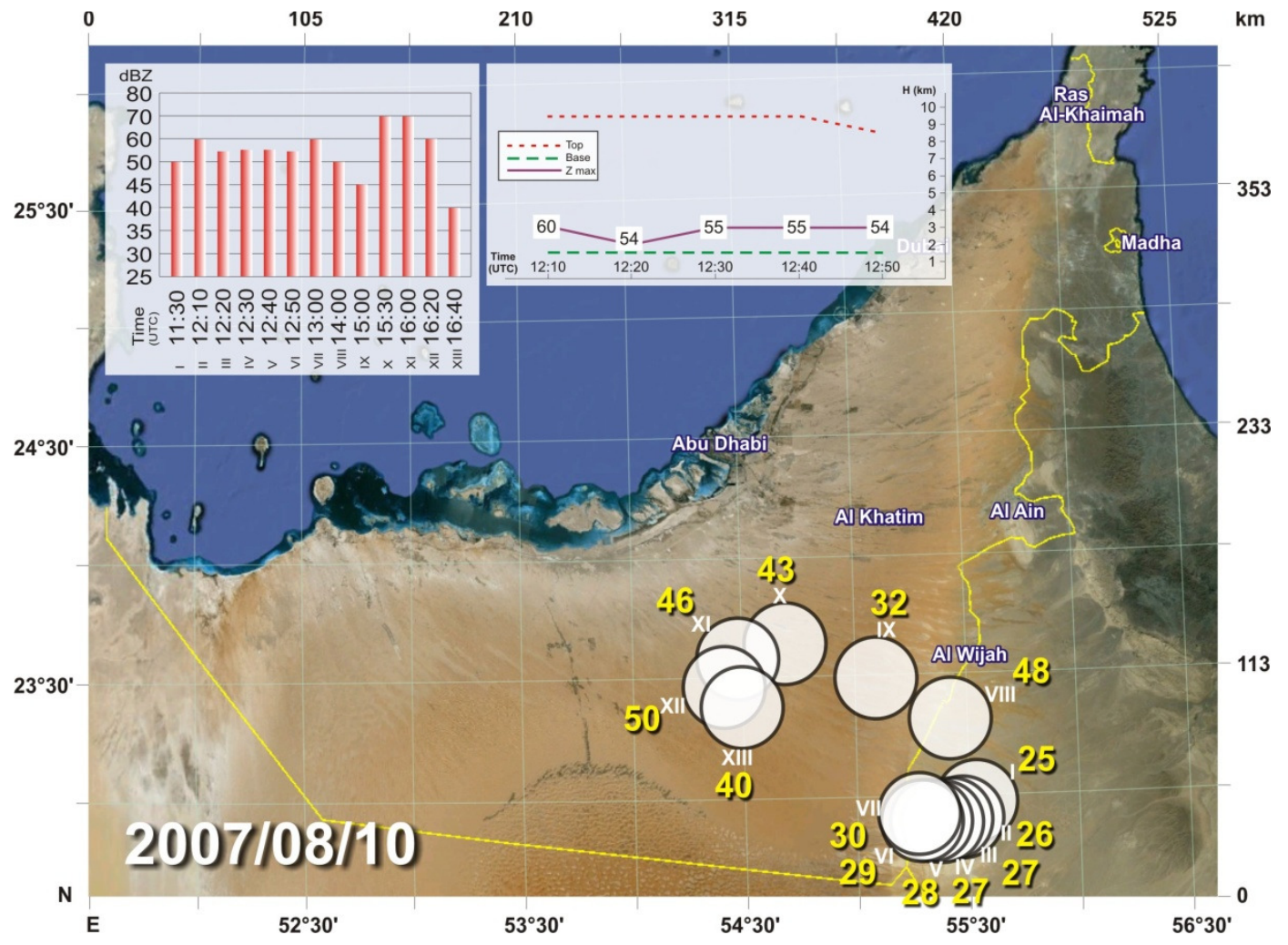

Fig. 7.26. Radar characteristics of cloud 2 from Fig. 7. 24b. The meanings are the same as in the Fig. 7. 10. 


\subsection{Accumulated precipitation from $\mathrm{Cb}$ clouds}

As we already shown the severity of thunderstorm can be judged in many ways. What we are concerned with here is its precipitation production. The development of precipitation has a major effect on the general dynamics of thunderstorms. Both fallspeed differences of different precipitation particles and terminal fallspeed changes of a given population of particles can lead to accumulation of precipitation in certain parts of a storm (Ćurć et al.,2009a,b). Although precipitation amount as high as $20-30 \mathrm{~g} \mathrm{~m}^{-3}$ do not occur extensively, larges with concentrations of up to $10 \mathrm{~g} \mathrm{~m}^{-3}$ may be common. Drag produced by $4 \mathrm{~g} \mathrm{~m}^{-3}$ of precipitation would have an effect equivalent to the negative buoyancy associated with the virtual temperature deficit of $1^{\circ} \mathrm{C}$. Thus water loading effects can significantly impede an updraft or to help sustain a downdraft. Evaporation of the precipitation will further intensify a downdraft by chilling it.

From many studies it appears that ordinary $\mathrm{Cb}$ produces rain at the ground during the period of about $30 \mathrm{~min}$. The average area instantaneously occupied by rain at the ground is about an order of magnitude greater than corresponding width of the updraft near the level of cloud base (Ludlam, 1980; Cotton et al., 2007). The precipitation from a severe storm reaches the ground instantaneously over an area as much as $10^{3} \mathrm{~km}^{2}$ or even more (Ćurć and Janc, $2011 \mathrm{a}, \mathrm{b}, \mathrm{c})$.

The knowledge of the spatial and temporal distribution of convective precipitation is important for the purpose of various predictions and analysis. The precipitation data are usually taken from rain gauge networks. Convective precipitation is poorly depicted due to the limited resolution and spot-like coverage of the observational network (Lovejoy et al. 2006). The situation is still more complicated in complex terrain (Prudhomme et al. 1999). Meteorological radars are an improvement since they provide widespread spatial coverage at high spatial and temporal resolution and produce spatially continuous values. However, meteorological radars have important disadvantages due to the calibration of the Z-R (Reflectivity-Rain amount) relationship and their positioning in a complex topography (Young et al. 1999). Recently, the meteorological satellite has become an important tool to provide indirect rainfall estimation, mostly the capability of monitoring widespread areas, independent of orography with a good spatial resolution and a regular sampling time (Scofield and Kuligowski 2003). Thus, remotesensing observations still give a very rough estimation of convective precipitation at the surface.

In reality it is difficult to find out the exact relation between the precipitation and dynamical characteristics. Here we wish to first show that any methodologies used for precipitation measurement give very different results. In Figs. 7. 27 and 7. 28 are shown the accumulated precipitation over the 10 August 2007 measured by classical rain gauge and radar methodology, respectively. It is easy to see that there are the high discrepancies. 


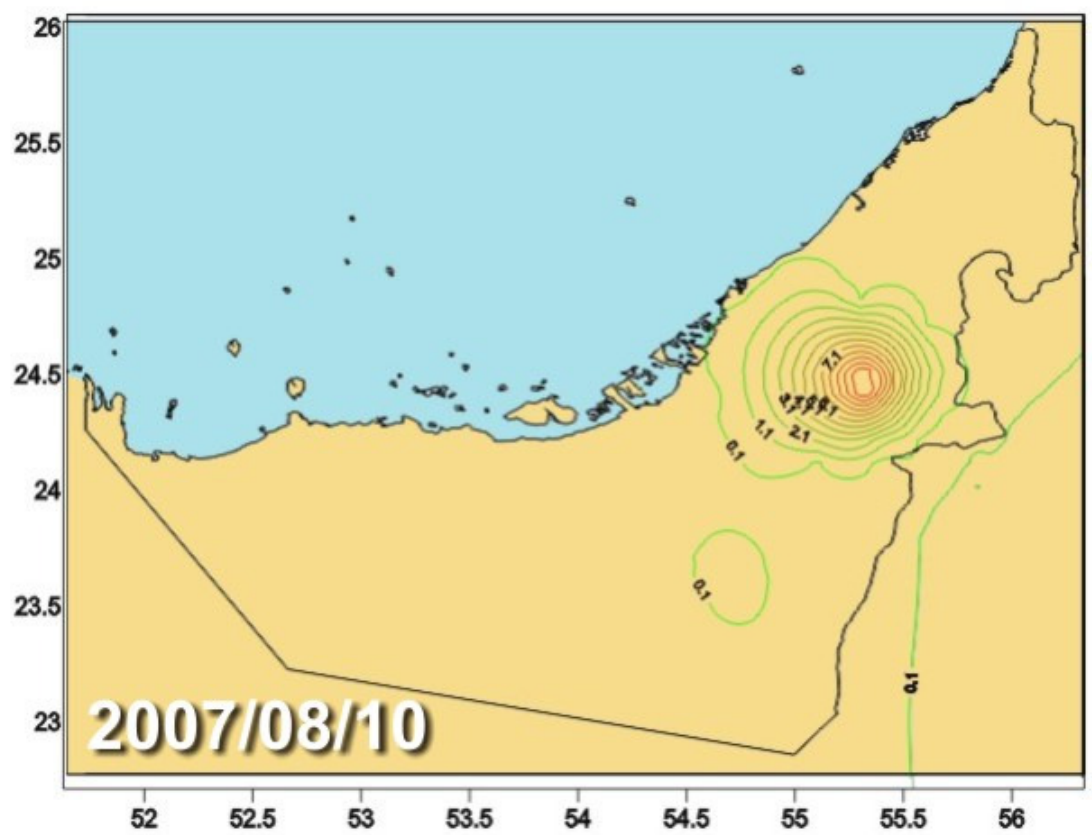

Fig. 7.27. Isohyetal map of 24 hours accumulated actual precipitation (mm) for 10 August 2007.

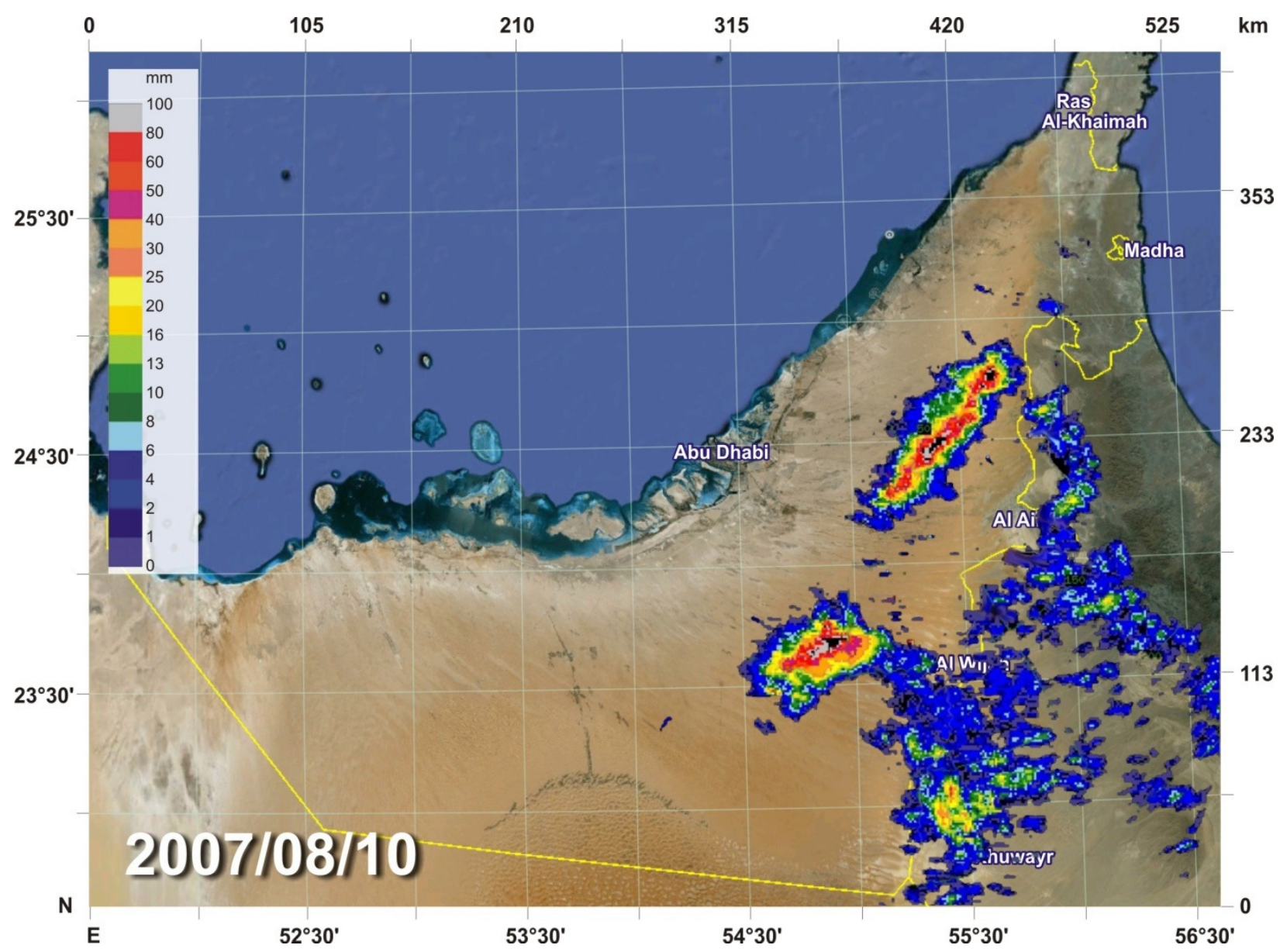

Fig. 7.28. Radar accumulated precipitation (mm) for 10 August 2007. 
The high discrepancies in the precipitation amount shown In Figs. 7.27 and 7. 28 arise from the following reasons. The precipitation data taken from rain gauge network is poorly depicted due to the limited resolution and spot-like coverage of the observational network. Meteorological radars have important disadvantages due to the calibration of the Z-R. In addition, the radar measurements highly overestimate the rain gauge data due to evaporation of precipitation from the level of radar measurement to the ground. Due to the evaporation many rain drops released from cloud base never reach the ground. This evaporation is especially prominent in the arid area as UAE. Nevertheless, meteorological radars are an improvement since they provide widespread spatial coverage at high spatial and temporal resolution and produce spatially continuous values. This is easy to see by comparing the Figs. 7.25,26,27, 28. From radar precipitation pattern it is easy to deduce very well the cloud path (see Figs. 7. 25 and 7. 28). It is much more obvious in the more complicated travelling of storms as it is presented in Fig. 7. 26. Radar precipitation pattern from the storm 2 (Fig. 7. 24b) very well correspond to the path shown in Fig. 7. 26.

The results of analysis of precipitation from two methodology of measurement give us sufficient confidence to conclude that both, rain gauge and radar data are needed for better reproduction of the areal accumulated convective precipitation over a small area during convective precipitation events. This is important for different climatological and hydrological analysis and predictions as well as for the activities related to the precipitation enhancement. 


\section{8}

\section{RELATION OF NATURAL AEROSOLS AND PRECIPITATION DEVELOPMENT: IMPLICATIONS FOR CLOUD SEEDING}

\subsection{Summarized data}

A total of 200 flights of the research aircraft were made equally split between summer and winter. About half of the flights collected microphysical data in clouds and precipitation, with seeding trials having been performed on about half of those flights. Microphysical observations of cloud droplets and aerosols show continental conditions during the summer. More varying conditions exist during the winter, mostly due to weaker cloud conditions (higher clouds and lower updraft speeds). During the 2001 and 2002 winter seasons, radar summaries showed that no significant rainfall events occurred over the UAE. For the 2001 and 2002 summer seasons, radar studies show that the vast majority of convective storms occurred over the Oman Mountains, southeast of Al Ain and northward.

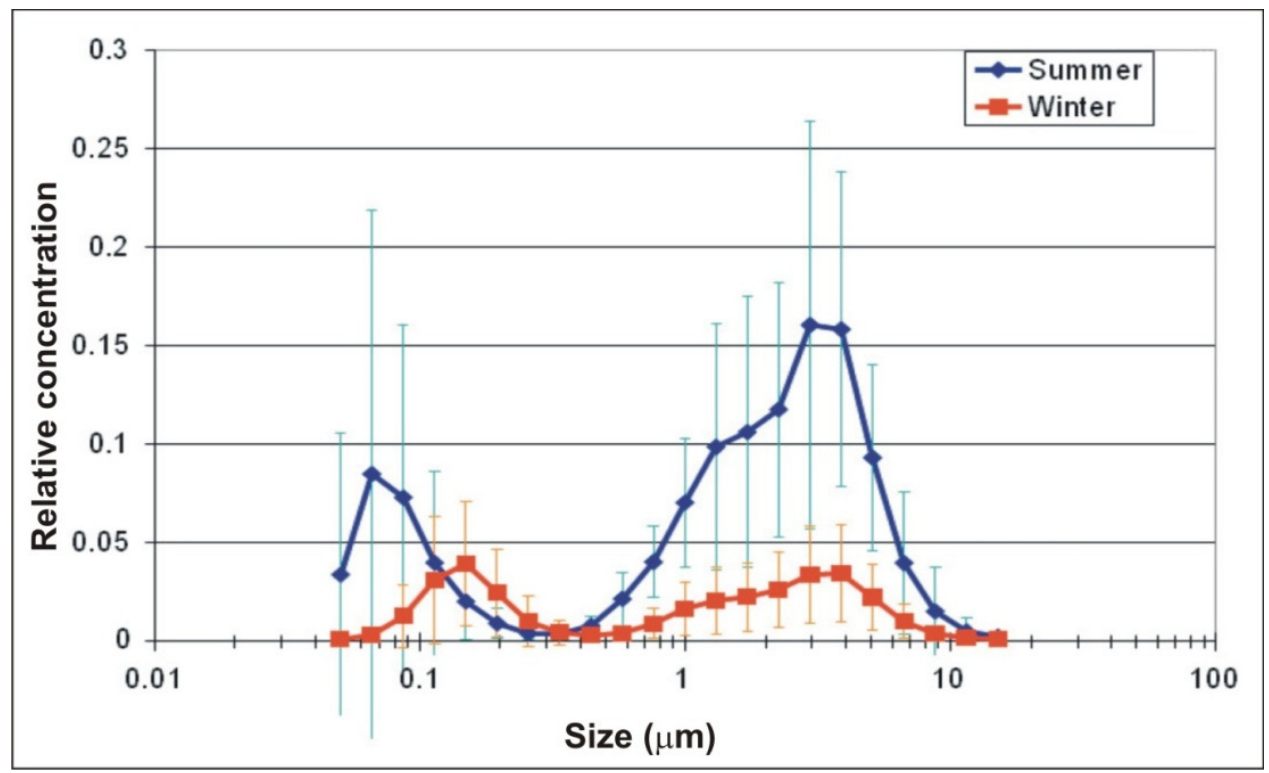

Fig.8.1. Average aerosol size distributions derived from the multiple wavelength sun photometry data set at Al Dhafra for winter and summer 2001. The error bars represent one standard deviation from the mean (After Al Mandoos et al.,2006). 
The accumulation modes aerosol data recorded over Al Dhafra have been summarized to evaluate a shift in this size distribution (Fig.8.1). The analysis does show that during the winter, aerosols numbers were slightly enhanced between 0.2 and $0.3 \mu \mathrm{m}$, especially below half a kilometer. Distinct inflections in the contoured data indicate distinct layering in the atmosphere of the aerosols. These data also do not show distinctly different number of airborne aerosols between the two seasons. The marked increase in the number of aerosols during the summer was noted in the size range $0.6 \mu \mathrm{m}-10 \mu \mathrm{m}$, with the vast majority of the increase been on the coarse mode $(>2.5 \mu \mathrm{m})$ The overlap with the PCASP instrument is between $0.6 \mu \mathrm{m}$ and $3 \mu \mathrm{m}$, probably explaining most of the conflict between the two data sets. A vertical profile of average aerosol concentrations over Al Dhafra shows the overall differences between the two seasons were fairly small with respect to the PCASP instrument (Fig.8.2). Future analysis should include direct comparisons between the PCASP data and the ground base sun photometer. It is also possible to conclude that at least during the winter campaign most of the aerosol mass observed by the sun photometer at least in the accumulation mode occurred below $1 \mathrm{~km}$.

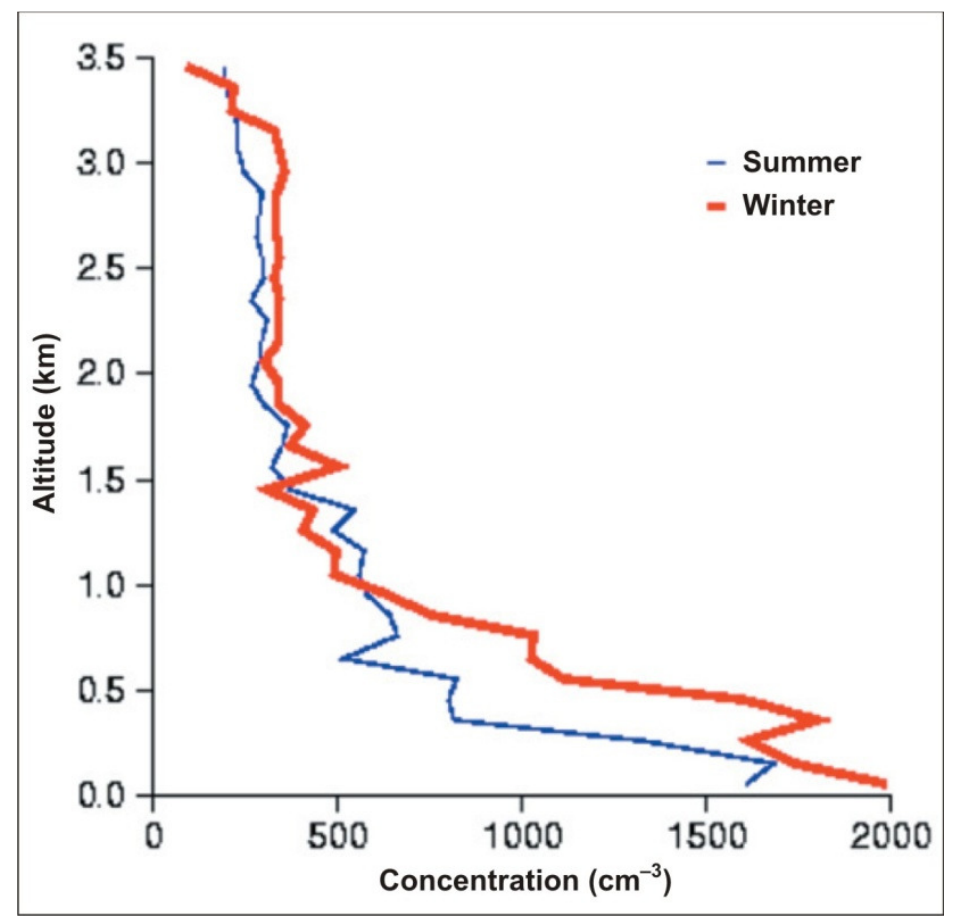

Fig.8.2. Aerosol concentrations of accumulation mode aerosols over AL Dhafra as measured by the PCASP 100x during winter and summer (After Al Mandoos et al.,2006).

Vertical profiles of the aerosols show that the top of the boundary layer was at about $1500 \mathrm{~m}$ for the experimental periods in the winter and much higher (to $3500 \mathrm{~m}$ or more) in the summer. This is the layer that is influenced by surface sources and processes. Concentrations of aerosols in all size ranges as well as most trace gases decreased rapidly above the boundary layer. The large difference between the $\mathrm{CN}$ and aerosol (PCASP) concentrations indicates that the $U A E$ region is a large source of nucleation mode aerosols. This is most obvious near specific source regions within the UAE. The aerosol measurements above the boundary layer also suggest that nucleation mode aerosols are as important a source of CCN as the accumulation mode aerosols. 
Instruments were flown that measured cloud microphysical parameters, aerosol characteristics, and trace gas concentrations. This suite of instruments combined to provide information about natural conditions important to cloud and precipitation development. For example, emissions of $\mathrm{SO}_{2}$ into the atmosphere result in the production of aerosols through oxidation. Highest concentrations of these particles were expected to occur in the vicinity of the highest emissions of $\mathrm{SO}_{2}$ in the UAE region (Figs. 8.3 and 8.4). This is due to the fact that the synoptic conditions over the UAE are dominated by anticyclonic circulations, with low wind speeds and stagnant air. In addition, the afternoon and evening sea breeze could bring many of these pollutants onshore from oil-related industries in the Gulf. $\mathrm{CN}$ aerosol concentrations were indeed found to be highest at identified $\mathrm{SO}_{2}$ sources. These aerosols can be very effective $\mathrm{CCN}$ and therefore have the potential to influence cloud microphysical processes and rainfall production efficiencies.

Measurements of $\mathrm{CCN}$ showed that background levels were enhanced due to local pollution sources in the region, which resulted in higher cloud droplet concentrations in clouds, making them more continental in nature. These are conditions generally thought to be more amenable to seeding with hygroscopic flares to enhance rainfall, since the polluted background particles generally work to suppress precipitation development. When mineral (desert) dust exists in conjunction with sulfates (and possibly other pollutants), the dust particles can become coated with sulfate, making them more active as cloud condensation nuclei. This is especially important in the UAE region where both sources exist and likely have an impact on the precipitation processes in clouds.

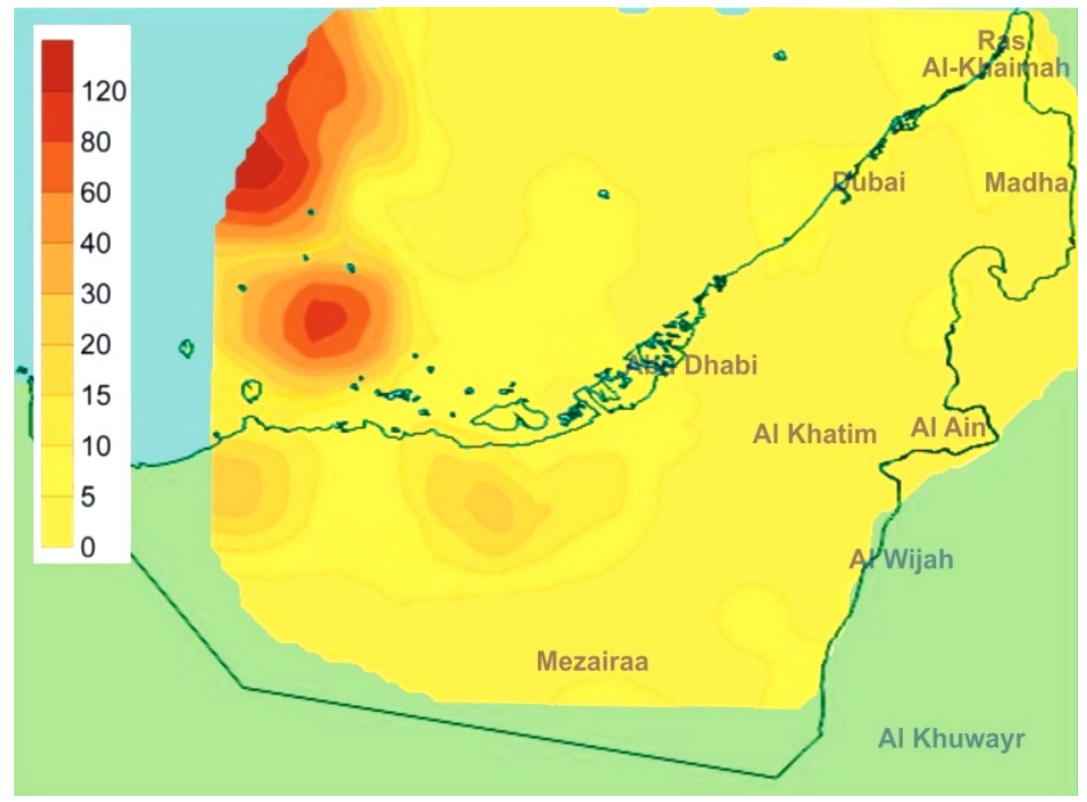

Fig.8.3. Average sulphur dioxide concentrations $\left(\mathrm{cm}^{-3}\right)$ between 50 and $3000(\mathrm{~m})$ during winter 2001.

In 2002, filters for detailed examination under electron microscopes were collected to determine the composition of the aerosols and assess whether sulfate coating of dust particles occurred and was significant. Preliminary analysis suggests that sulfate coating is not very significant process and therefore may not be a complicating mechanism in determining the natural variability of $\mathrm{CCN}$. 
Microphysical measurements collected in the UAE showed that cloud droplet effective radii were typically less than $10 \mu \mathrm{m}$ indicating that clouds are continental in nature. Although low droplet concentrations were evident when high cloud bases occurred in the winter, the available water vapor at higher levels in the atmosphere is also less and the depth of the cloud between the base and the $0^{\circ} \mathrm{C}$ level is minimal or non-existent, inhibiting the growth of droplets to larger sizes. Clouds with bases much warmer than $0^{\circ} \mathrm{C}$ are more amenable to the hygroscopic seeding method. In the winter, favorable conditions seem to occur when the cloud base is lower than about $3000 \mathrm{~m}$ MSL. However, as stated above, these conditions for convective clouds occurred infrequently. During the summer, bases as high as $4500 \mathrm{~m}$ were still warm enough to provide sufficient depth and time for coalescence to begin. One area needing more data analysis is determining the existence and extent of drizzle sized drops and conditions in which they occur. Drizzle drops were occasionally measured in some clouds, which has implications on the effectiveness of seeding in those cases.

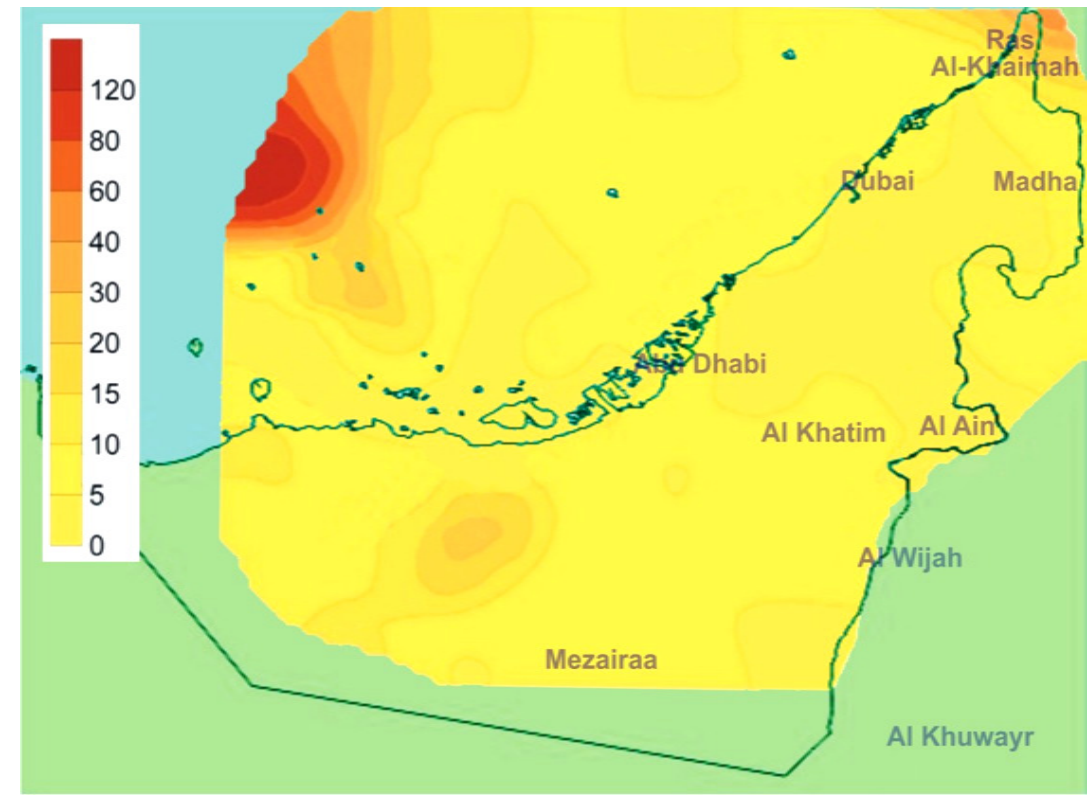

Fig.8.4. Average sulphur dioxide concentrations $\left(\mathrm{cm}^{-3}\right)$ between 50 and $3000(\mathrm{~m})$ during summer 2001.

\subsection{Case studies}

In August through September 2004 the United Arab Emirates Unified Aerosol Experiment (UAE2) was conducted in the southern Arabian Gulf region. It will be presented some more interesting atmospheric thermodynamic and aerosol data collected on 18 flights.

In the first few kilometers, we observed high concentrations of both regional dust (from 100 to $300 \mathrm{mg} \mathrm{m}^{-3}$ in background) and ubiquitous sulfate based pollution from the Gulf's prevalent petroleum industry $\left(10-100 \mathrm{mg} \mathrm{m}^{-3}\right)$. Smoke and pollution from Europe and possibly Africa were found at levels between 1.5 and $5 \mathrm{~km}$. Inland, classic deep over desert boundary 
layer characteristics were found. Over the Arabian Gulf, dust and pollution were most often either trapped below or sequestered above a strong stable boundary. However, there were cases where a well-distributed aerosol layer crossed the inversion uniformly. Data suggest that the observed vertical profiles can be explained by the rapid formation of stable marine boundary layers as air moves offshore. This can decouple aerosol layers from within the boundary layer to those aloft in regions of vertical wind shear. In the case of pollution, the ability of flaring plumes to penetrate the inversion may also in part determine layering. In coastal regions without vertical wind shear, uniform concentrations with height across the inversion are a result of internal boundary layer development.

It is concluded that the bulk of the observed variability in particle vertical distribution appear to be controlled by mesoscale and microscale processes, such as the sea/land breeze.

UAE belongs to the world's third largest dust source region and one of the largest aerosol burdens in the world (Prospero et al., 2002). With large dust events, emissions from the petrochemical industry, and transport into the region, seasonal aerosol optical thickness (AOT) is near 0.5 (Smirnov et al., 2002). Further, the Arabian Gulf exhibits complicated meteorology, with variable sea surface temperatures (SSTs), large sensible and latent heat fluxes, and abrupt topography. However, there are very few measurements reported in the literature. Previous studies on the more typical conditions have either focused on large synoptic patterns in the deep desert (Alpert et al., 2004), or on isolated observations of marine boundary layer (MBL) in the middle of the Gulf (Atkinson et al., 2001). Despite its clear importance, to our knowledge there are limited publications of combined regional aerosol and thermodynamic data.

Now, these data are used to give an overview of the observed atmospheric state during the UAE2 mission, including a study of how thermodynamic and aerosol features relate to the major synoptic and mesoscale flow patterns.

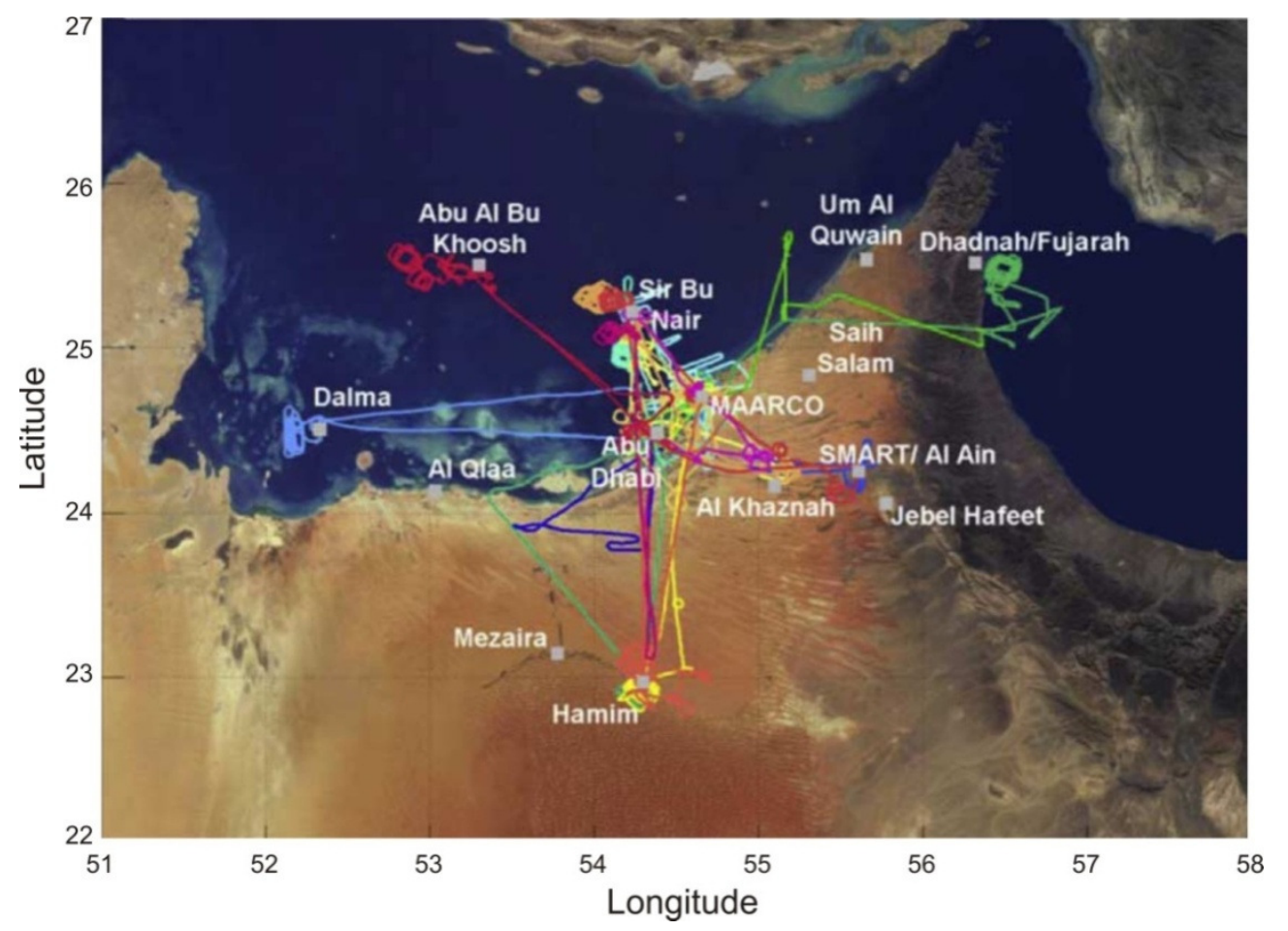

Fig. 8.5. Flight tracks of the aircraft during UAE2 ( Adapted from Reid,.. Al Mandoos et al., 2008). 
The UAE2 tracks are presented in Fig. 8.5. Most aircraft flights were performed during the morning hours to support Terra and occasionally SeaWiFS. Special flights to Delma Island and Dhadnah were conducted to support MISR. To study mesoscale phenomena, the 690A aeroplain flew transects exploring the coastal transition of the sea and land breeze circulations including vertical profiles up to the $700 \mathrm{hPa}$ level. The operations area was impacted by aerosol particles from at least four diverse source regions: (1) pollution from coastal band offshore oil processing facilities and dust from the northern Gulf region, such as the Tigris-Euphrates basin in Iraq; (2) dust transported from Oman/Yemen as well as UAE coastal carbonate deposits; (3) regional dust from sources within the UAE; and (4) dust from the northern UAE and southern Iran.

The profiles of aerosol and thermodynamic properties conducted during the mission can be broadly placed into three main categories: inland desert; over water southern Arabian Gulf with large-scale southwesterly offshore flow and over water with strong northwesterly flow over wider Gulf region.

\section{Case study 1: Inland Desert Profiles}

Four full profiles were performed at inland desert sites: Once at the SMART site in the mid afternoon (1500 LST on 28 August), and three at the Hamim site at midmorning (1000 LT on 10 and 28 September and on 1 October). For comparison purposes, one afternoon (SMART, 28 August) and one morning (Hamim, 10 September) profile are presented in Fig.8.6. In these cases, background fine mode/pollution particle concentrations tend to be low $\left(<5 \mathrm{mg} \mathrm{m}^{-3}\right)$. An elevated pollution plume is present at $1600 \mathrm{~m}$ over Hamim. For the afternoon case dust concentrations increase and decrease $20-40 \mathrm{mg} \mathrm{m}^{-3}$ every $200 \mathrm{~m}$ through the depth of the profile.
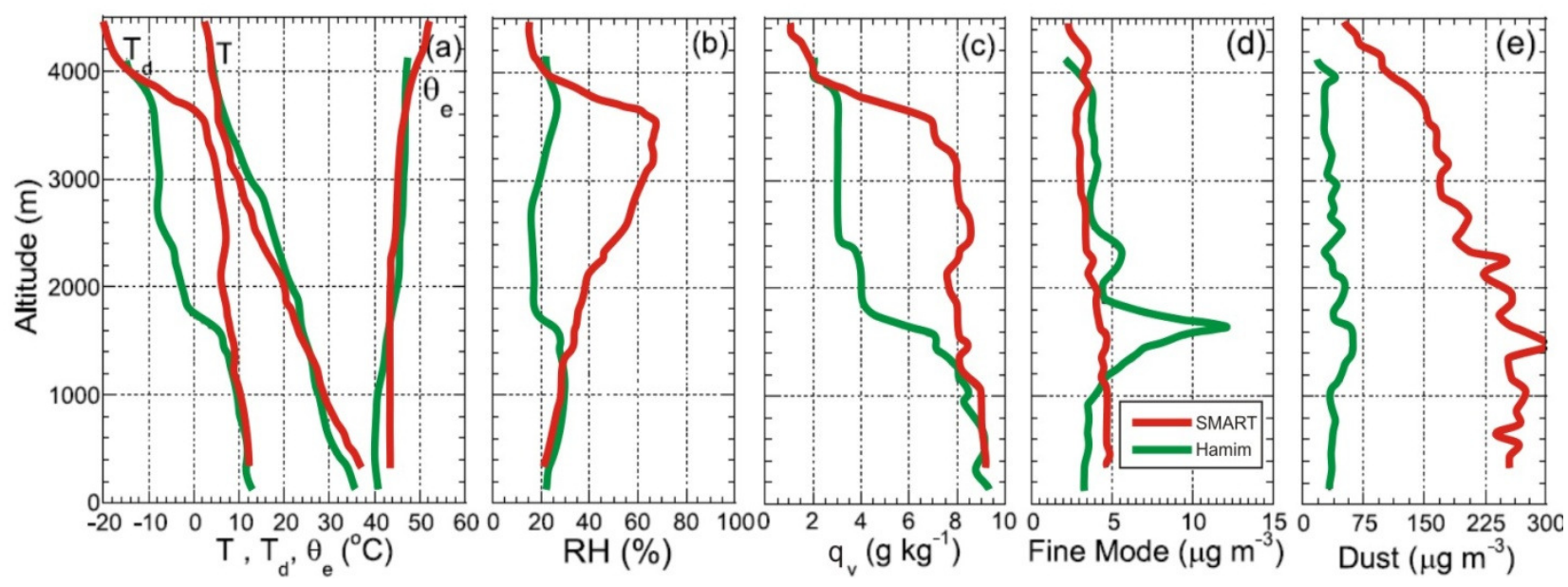

Fig. 8.6. Boundary layer profiles over the SMART site the afternoon of 28 August 2004 and Hamim for the morning of 10 September 2004 of following variables: (a) atmospheric state variables temperature $\left(\mathrm{T},{ }^{\circ} \mathrm{C}\right)$ dew point $\left(\mathrm{Td},{ }^{\circ} \mathrm{C}\right)$,

and equivalent potential temperature $\left(\theta \mathrm{e},{ }^{\circ} \mathrm{C}\right)$; (b) relative humidity; (c) water vapor mixing ratio $\left(\mathrm{g} \mathrm{kg}^{-1}\right)$; (d) estimated dry fine mode mass concentration $\left(\mathrm{mg} \mathrm{m}^{-1}\right) ;(\mathrm{e})$ estimated dust mass concentration, $\left(\mathrm{mg} \mathrm{m}^{-1}\right)$.

Profiles of the temperature exhibit classic over-desert boundary layers. The planetary boundary layer is well mixed from the surface to the base of the inversion at $1000 \mathrm{~m}$ for the morning case (typical for all three morning profiles), and higher at $2200 \mathrm{~m}$ in the afternoon 
profile (observable in both the $\theta_{\mathrm{e}}$ and $\mathrm{q}_{\mathrm{v}}$ profiles). Intermediate layers are present between the boundary layer inversion and the subtropical subsidence inversion, measured at 3800 to $5000 \mathrm{~m}$ during the mission.

Trajectory suggests the logical origin of the pollution plume to be the prevalent petrochemical industry in Abu Dhabi and the Gulf. As the builds during the day, this layer would likely be eroded into the main boundary layer.

Over the SMART site, the somewhat moister layer between 2000 and $3800 \mathrm{~m}$ (also identifiable in $\theta_{\mathrm{e}}$ and $\mathrm{q}_{\mathrm{v}}$ profiles) may be a remnant of a previous day's warmer and deeper boundary layer (in this case $>3 \mathrm{~km}$ in depth, which is not unreasonable (Warner, 2004). On the subsequent day, if the boundary layer height does not reach the same altitude, the top of the layer and inversion can persist.

\section{Case study 2: Southwesterly (SW) Offshore Flow Conditions}

At times the coupled high pressure to the north and Indian monsoonal trough near the Arabian Sea weaken, resulting in large-scale southwesterly flow, and offshore flow from the UAE into the Gulf. Four representative thermodynamic and aerosol particle soundings at or near the UAE coast, taken from three flights on 27 and 28 August and 8 September, are presented in Fig. 8.7.
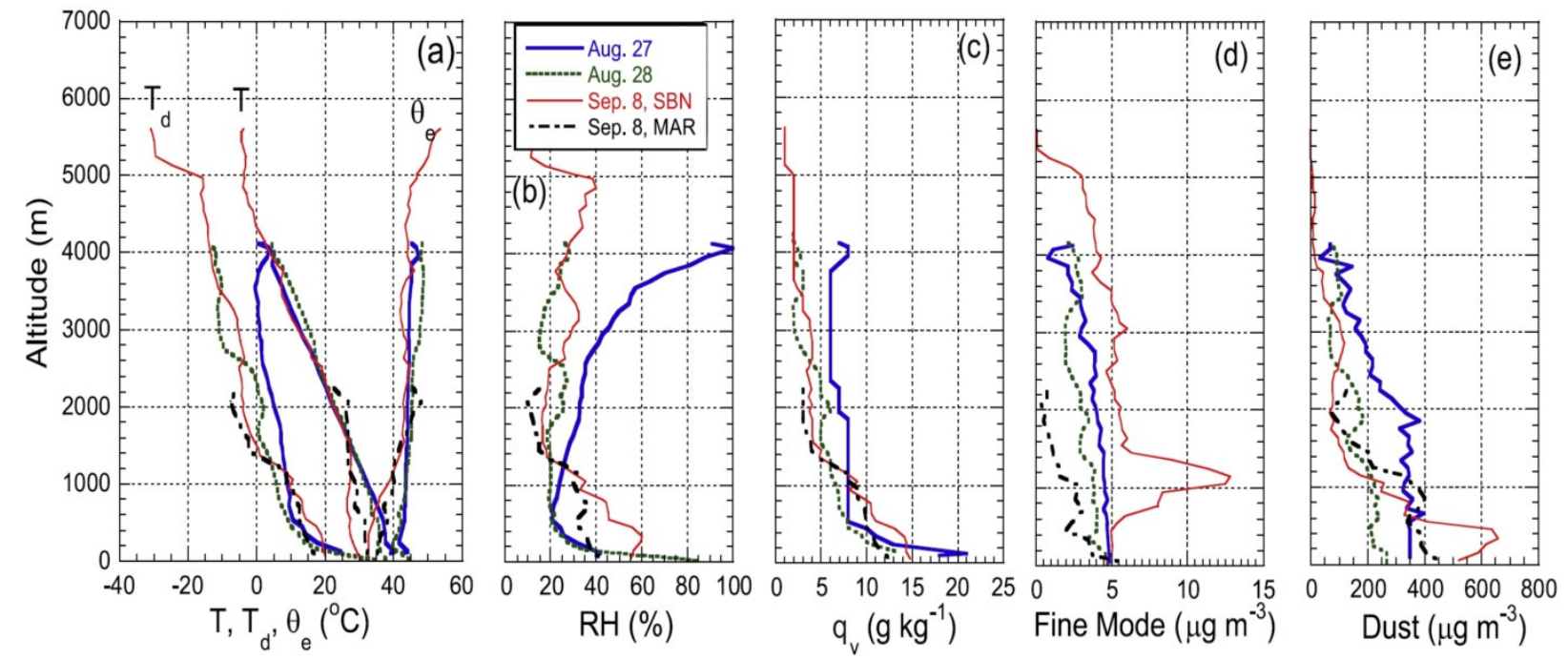

Fig. 8.7. Offshore or shoreline profiles for periods of SW synoptic forcing: (a) atmospheric state variables, (b) relative humidity, (c) water vapor mixing ratio, (d) estimated dry fine mode mass concentration, (e) estimated dust mass concentration.

For the SW wind flow regime: (1) Air masses move out of the UAE into the Gulf with a counterclockwise motion; (2) the air splits in the Gulf, with flow divergence into the central Gulf and Strait of Hormuz; and (3) the typical easterly winds in the Oman Gulf reverse and become westerlies or weaken and stagnate. The 27 and 28 August cases flights were conducted in midafternoon LT, just offshore the UAE coast. Profiles show typical afternoon soundings for subtropical or interior desert regions. The subtropical subsidence inversion capped the profiles (at 4,000 m, $650 \mathrm{hPa}$ ). On the basis of the $\theta_{\mathrm{e}}, \mathrm{q}_{\mathrm{v}}$ and particle profiles, however, we estimate the original boundary layer moving offshore was at $\sim 2 \mathrm{~km}$. On 27 August, midlevel moisture was 
advected from the east with a thin cloud deck at $4000 \mathrm{~m}$. Given that the profiles were taken just offshore over warm Gulf water $\left(>30^{\circ} \mathrm{C}\right)$, the influence of latent heat fluxes on the temperature and moisture variables is seen in Figs. $8.7 \mathrm{a}-\mathrm{c}$ resulting in an internal boundary layer in the lowest 100-200 m. For 27 and 28 August for both fine and coarse mode aerosol particles, concentrations varied by roughly a factor of two. Fine mode maximum concentrations of $5 \mathrm{mg}$ $\mathrm{m}^{-3}$ and 200-300 $\mathrm{mg} \mathrm{m}^{-3}$, for particles and dust, respectively.

Concentrations correlate with changes in $\mathrm{q}_{\mathrm{v}}$, indicating a change of air mass. Within the desert boundary layer $(2 \mathrm{~km})$, particles are clearly well mixed. In Fig. 8.7e an elevated dust layer is seen between 1600 and $2600 \mathrm{~m}$ for 28 August. As we would expect, the development of over water internal boundary layers as the parcel moves over the Gulf does not significantly impact near surface particle profiles in this case. As no significant aerosol particle sources or sinks exist over the water in this region, the afternoon internal boundary layer would develop without correlation to aerosol vertical profile.

The 8 September flights, demonstrate how profiles can change over relatively short distances in the littoral zone. These flights occurred during the late morning from 1022 to 1339 LT. One full profile was taken $80 \mathrm{~km}$ offshore near Sir bu Nair Island, and a partial profile was acquired over the coastal MAARCO site which initiated 20 min later (Figure 5g). As sampled over MAARCO, the boundary layer height was $1.2 \mathrm{~km}$ with low fine mode particle concentrations of 5 $\mathrm{mg} \mathrm{m}^{-3}$. Dust concentrations were high $\sim 400 \mathrm{mg} \mathrm{m}^{-3}$ and remained constant through the depth of the boundary layer. A rapid decrease in dust concentrations was seen above this layer. Such an aerosol profile reflects the desert origins of the air mass in a developing morning boundary layer. The big differences are evident when we compare the Sir bu Nair Island (SBN) and MAARCO (MAR) profiles for 8 September. The boundary layer is lower by $\sim 300 \mathrm{~m}$. In the lowest levels, $\mathrm{q}_{\mathrm{v}}$ values are double those at MAARCO. Dust concentrations are also higher in the marine boundary layer. A significant pollution layer with peak concentrations of $15 \mathrm{mg} \mathrm{m}^{-3}$ was observed just above the boundary layer.

Examination of the wind fields for 8 September (Reid et al. 2008), shows that although the distance along the flight path from MAARCO to Sir bu Nair Island is $80 \mathrm{~km}$, the sampled air mass has a substantial alongshore trajectory. Hence, even though the distance between the two sites is relatively short, the time spent over water for the two air masses is over $12 \mathrm{~h}$ different .

\section{Case study 3: The Shamal dust event}

During the UAE2 field campaign the most dramatic dust event was the 12 September 2004 (named Shamal) that originated in the Tigris-Euphrates basin of Iraq on 11 September. The combination of a mid latitude trough moving eastward over the Black Sea and an intensification of the Indian Monsoonal Trough resulted in strong northwesterly winds over the Tigris Euphrates valley mobilizing dust from this region. As a result on 12 September instantaneous dust concentrations of $1000 \mathrm{mg} \mathrm{m}^{-3}$ and $24 \mathrm{~h}$ average values of $300 \mathrm{mg} \mathrm{m}^{-3}$ were measured at MAARCO. Midvisible AOTs at MAARCO reached 0.9. Aircraft soundings along the UAE coast for this event are presented in Figs. 8.8 a-e. Fig. $8.8 \mathrm{f}$ give the regional satellite imagery, with surface wind fields on 12 September 2004. 

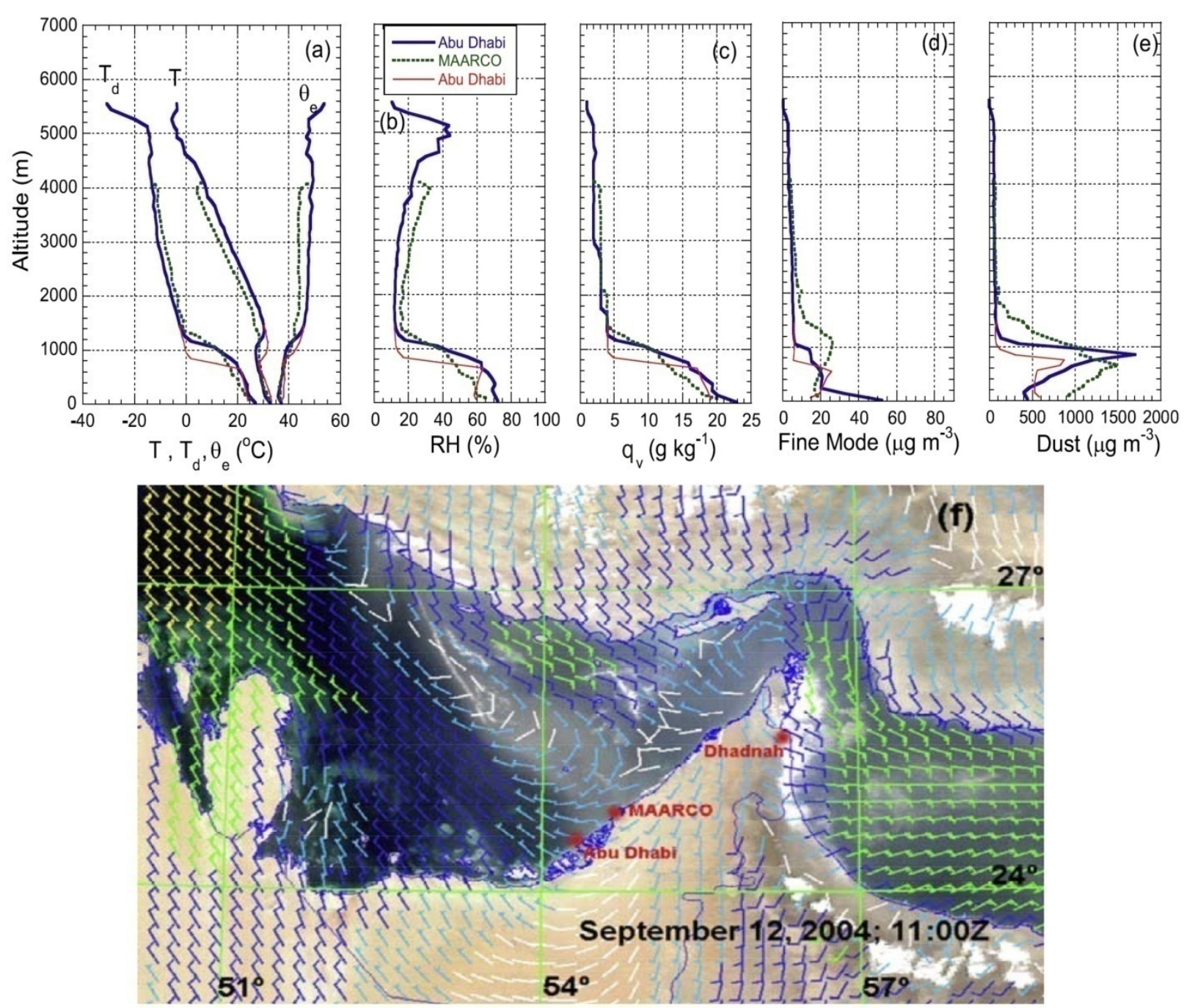

Fig. 8.8. Offshore or shoreline profiles for periods of strong NW synoptic forcing on 12 September 2004: (a) atmospheric state variables, (b) relative humidity, (c) water vapour mixing ratio, (d) estimated dry fine mode mass concentration, (e) estimated dust mass concentration, and (f) MODIS Terra satellite images with surface wind fields. Long barbs are $5 \mathrm{~m} \mathrm{~s}^{-1}$, and short barbs are $2.5 \mathrm{~m} \mathrm{~s}^{-1}$ (Adapted from Reid,.. Al andoos et al., 2008).

This flight originally targeted the Dhadnah AERONET site, to support a MISR overpass. As a result, only three vertical profiles in the vicinity of the dust plume were obtained: during morning take off ( $\sim 0400$ UTC); during the decent on the return flight over MAARCO ( 1000 UTC); and on a third partial climb just west of Abu Dhabi (1000 UTC).

The Shamal event shows clear dust stratification, with a maximum dust concentration right at the top of the boundary layer (deep1 $\mathrm{km}$ ). This appears to be consistent throughout this dust plume, as measurements were made at the leading edge in the morning (0400 UTC), and in the middle (MAARCO) and back (Abu Dhabi) edge in the early afternoon (1000 UTC). In all three profiles, very little dust was sampled above the boundary layer inversion. From Figure $7 \mathrm{~d}$ pollution concentrations are highest near the surface in the morning (likely from local sources) and $6 \mathrm{~h}$ later are found at the top of the inversion over MAARCO and Abu Dhabi. Dust concentrations decreased by half within the $6 \mathrm{~h}$ time frame of the two Abu Dhabi profiles. The satellite image in Fig. $8.8 \mathrm{f}$ taken $1 \mathrm{~h}$ after landing, shows that Abu Dhabi was situated on the 
back edge of the dust plume that covered the eastern half of the Gulf. This provides a pictorial explanation of the decreased dust concentrations between the two profiles.

\section{Case study 4: Land Breeze Event}

Coastal sea breeze phenomenon can be observed on most days of the year over the entire Gulf coastline (Eager et al. 2008; Zhu and Atkinson, 2004). The land/sea breeze adds significant complexity to the coastal flow patterns, which ultimately influence much of the aerosol vertical distribution. For the case of 29 September 2004, offshore flow developed at night in response to a pressure gradient between the cooler land surface $\left(26-29^{\circ} \mathrm{C}\right)$ and the warmer Gulf water $(\sim 30$ ${ }^{\circ} \mathrm{C}$ ). A weak line of convective clouds develops over a vertical circulation 20 to $100 \mathrm{~km}$ offshore, with return air above the boundary layer advected inland. This phenomenon can be observed on most days of the year over the entire Gulf coastline.

Offshore land breeze can impact the vertical distribution of thermodynamic and aerosol properties. In order to illustrate this the data from a land breeze flight conducted the morning of 29 September 2004 are presented. The first profile began at $0800 \mathrm{LT}$ over the Al Khaznah AERONET site roughly $50 \mathrm{~km}$ inland, and progressed out toward Sir bu Nair Island,80 km offshore. Longitudinal cross sections of potential temperature $(\theta)$, $\mathrm{q}_{\mathrm{v}}$, and inferred dust concentration $\left(\mathrm{cm}, \mathrm{mg} \mathrm{m}^{-3}\right.$ ) are shown in Figs. $8.9 \mathrm{a}, \mathrm{b}, \mathrm{c}$, respectively. The winds were southeasterly and generally along the flight track. At Al Khaznah it is observed the early morning, or nocturnal, $200 \mathrm{~m}$ deep stable boundary layer embedded in the previous day's 1200 $\mathrm{m}$ deep boundary layer. The stable surface layer was slightly enriched in water vapor and contained high concentrations of dust $\left(700 \mathrm{mg} \mathrm{m}^{-3}\right)$ trapped within the nocturnal boundary layer. As the flight moved toward the coast, a decrease in $\theta$ between Al Khaznah and the coast coincided with an increase in $\mathrm{q}_{\mathrm{v}}$ that was the likely remnants of the previous day's sea breeze.
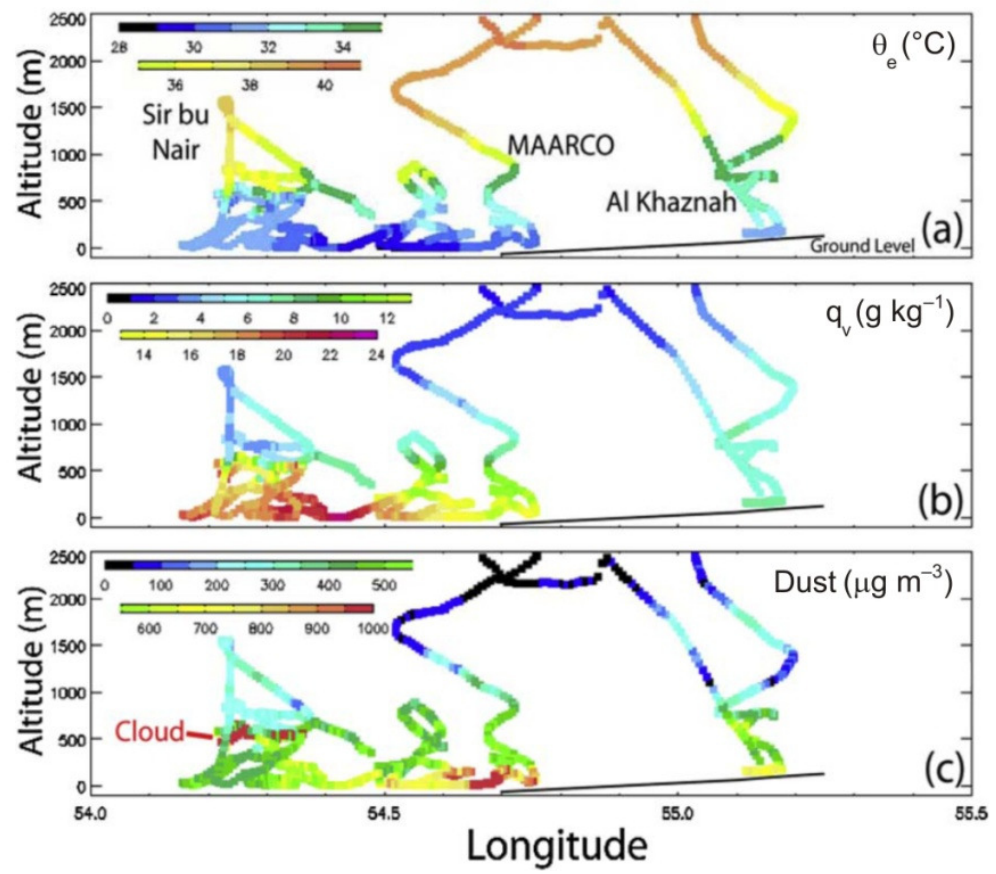

Fig. 8.9. Flight track longitudinal cross sections of (a) potential temperature, $\theta$, in ${ }^{\circ} \mathrm{C}$; (b) water vapour mixing ratio, $\mathrm{q}_{\mathrm{v}}$, in $\mathrm{g} \mathrm{kg}^{-1}$; and (c) estimated dust concentration in $\mu \mathrm{g} \mathrm{m}^{-3}$ (Adapted from Reid,.. Al Mandoos et al., 2008). 
Aircraft readings measured $7 \mathrm{~m} \mathrm{~s}^{-1}$ at the coast with dust concentrations of $1000 \mathrm{mg} \mathrm{m}^{-3}$. The surface layer was clearly visible over MAARCO as a peak in dust concentrations.

It can be seen a marked increase in $\mathrm{q}_{\mathrm{v}}$ in the lowest layers as the air mass moved from the shore out to sea, due to latent heat flux. For land breeze conditions, the air is slightly cooler than the water, so the atmosphere is weakly unstable. However, dust, water vapor, and temperature remain poorly mixed behind the land breeze front. In flight, we identified the front by thin band of clouds normal to the prevailing wind direction that formed a minor convergence zone at the land breeze front. These clouds appear in the "dust" concentration plot (Fig. $8.9 \mathrm{c}$ ) as red data points at $54.3 \mathrm{E}$ longitude and $500 \mathrm{~m}$ altitude. Such clouds were commonplace during the mission and were frequently used to determine the location of the land breeze front. At the vicinity of the front, the vertical gradients were eliminated by turbulent mixing (as detected on the aircraft) from both below (slightly unstable) and above (cloud convection), along with the large-scale lifting of $\sim 1 \mathrm{~m} \mathrm{~s}^{-1}$ (as estimated from aircraft winds). The mean flow was out and into the gulf. Due to these process the net impact of was to form low-level peaks in dust concentrations nearshore, and eventually move dust and moisture upward at the front. These mesoscale processes contributed to the complicated vertical distributions observed over the Gulf. 


\section{9}

\section{CONCLUSIONS}

A major effort during realization of this research was the development of an infrastructure, especially the network of 6 radars in the UAE, a network of 50 automatic weather stations, an instrumented aircraft with trace gas, aerosol and cloud microphysical instrumentation to determine the background aerosol characteristics of the region and their influence on cloud and precipitation processes. A significant part was intensive collection of observational data including aircraft, radar, surface measurements and satellite.

Microphysical measurements collected showed that cloud droplet effective radii were typically less than $10 \mu \mathrm{m}$ indicating that clouds are continental in nature. Although low droplet concentrations were evident when high cloud bases occurred in the winter, the available water vapor at higher levels in the atmosphere is also less and the depth of the cloud between the base and the $0^{\circ} \mathrm{C}$ level is minimal or non-existent, inhibiting the growth of droplets to larger sizes. Clouds with bases much warmer than $0^{\circ} \mathrm{C}$ are more amenable to the hygroscopic seeding method. During the summer, bases as high as $4500 \mathrm{~m}$ were still warm enough to provide sufficient depth and time for coalescence to begin.

Measurements of $\mathrm{CCN}$ showed that background levels were enhanced due to local pollution sources in the region, which resulted in higher cloud droplet concentrations in clouds, making them more continental in nature. These are conditions generally thought to be more amenable to seeding with hygroscopic flares to enhance rainfall, since the polluted background particles generally work to suppress precipitation development. When desert dust exists in conjunction with sulfates (and possibly other pollutants), the dust particles become coated with sulfate, making them more active as cloud condensation nuclei. This is especially important in the UAE region where both sources exist and have an impact on the precipitation processes in clouds.

When the general weather conditions where not favorable for development of strong convection the convective clouds are developed, mainly inland, along the coast line and some on the western slopes of Oman mountain. The most favorable local conditions for cloud development occur on the sunlight side of Oman mountain. Cb clouds also develop on the front side of the sea-breeze circulation. The sea-breeze circulation was the trigger mechanism for many $\mathrm{Cb}$ clouds. These storms moved inland orthogonal to the coast line, in the direction were the progress of the sea-breeze front was most remarkable. During travelling toward the south the new cells are formed on left front side and amalgamated into large echoes within which the cells could still be recognized These left hand side regeneration of storms is under influence of the differential heating. Some clouds were very deep, with cloud top heights up to $20 \mathrm{~km}$ and maximal radar reflectivity over $75 \mathrm{dBZ}$. 
Very often the path of cloud is not under the influence of the upper level environmental flow. Such clouds move very irregular in respect to the mean environmental flow. This traveling is not result of the real displacement of some selected core of the cloud. It is mainly result of the storm growing due to the merging or the new cell generation, so that the storm as all system has such irregular positions in the consecutive time intervals.

The accumulated precipitation of convective clouds are obtained by using two methods of measurements, with rain gauges and by radars. The high discrepancies in the precipitation amount are found. They arise from the following reasons. The precipitation data taken from rain gauge network is poorly depicted due to the limited resolution and spot-like coverage of the observational network. Meteorological radars have important disadvantages due to the calibration of the Z-R. In addition, the radar measurements highly overestimate the rain gauge data due to evaporation of precipitation from the level of radar measurement to the ground. Due to the evaporation many rain drops released from cloud base never reach the ground. This evaporation is especially prominent in the arid area as UAE. Nevertheless, meteorological radars are an improvement since they provide widespread spatial coverage at high spatial and temporal resolution and produce spatially continuous values. From radar precipitation pattern it is easy to deduce very well the cloud path. It is much more obvious in the more complicated travelling of storms

The results of analysis of precipitation from two methodology of measurement give us sufficient confidence to conclude that both, rain gauge and radar data are needed for better reproduction of the areal accumulated convective precipitation over a small area during convective precipitation events. This is important for different climatological and hydrological analysis and predictions as well as for the activities relation to the precipitation enhancement.

KEYWORDS: Storms; Cloud condensation nuclei; Accumulated convective precipitation; Microphysical instrumentation; Radar measurement; Cloud lifetime, Cloud displacement. 


\section{0}

\section{ZAKLJUČCI}

Tokom realizacije ovog istraživanja posebna pažnja je posvećena razvoju infrastrukture, naročito mreže od 6 radara, mreže od 50 automatskih meteoroloških stanica, opremanju aviona sa instrumentima za merenje gasova, aerosola i mikrofizičkih karakteristika oblaka i padavina. Značajan deo posla je bilo intenzivno prikupljanje podataka dobijenih letilicama, radarima, površinskih merenja i satelita.

Mikrofizička merenja pokazala su da oblačne kapljica imaju poluprečnik manji od $10 \mu \mathrm{m}$, što ukazuje da su oblaci po svojoj prirodi kontinentalni. Iako su niske koncentracije kapljica bile evidentne, kod zimskih oblaka visoke baze sadržaj vodene pare u atmosferi na višim nivoima je mali kao i dubina oblaka između baze i nivoa sa $0^{\circ} \mathrm{C}$ je mala, što sprečava rast kapljica većih dimenzija. Oblaci sa bazama mnogo toplijim od $0^{\circ} \mathrm{C}$ su pogodniji za higroskopno zasejavanje. Tokom leta, i u oblacima visoke baze, oko $4500 \mathrm{~m}$, oko baze je još uvek dovoljno toplo, sto daje dovoljnu dubinu oblacima i dovoljno vremena da počne proces sjedinjavanja kapi.

Merenja kondenzacionih čestica su pokazala da je osnovni nivo sadržaja povećan zbog lokalnih izvora zagađenja u regionu, što je rezultiralo većim koncentracijama oblačnih kapljica, što ih čini više kontinentalninim. Ovo su uslovi koji se smatraju pogodni da se obavlja zasejavanje oblaka sa higroskopnim česticama da bi se stimulisale padavine. Kada postoji pustinjska prašina i sulfati iz izvora zagađenja, tada se čestice peska oblažu sa slojem sulfata, tako da postaju aktivne čestice kondenzacije. Ovo je posebno važno u regionu UAE u kojem postoje oba izvora, koji imaju uticaj na procese stvaranja oblaka i padavina.

Kada opšti vremenski uslovi nisu povoljni za razvoj jake konvekcije konvektivni oblaci se razvijaju uglavnom u unutrašnjosti, duž obale, a neki na zapadnim padinama Omanskih planina. Najpovoljniji uslovi za lokalni razvoj oblaka su na sunčanoj strani Omanskih planina. $\mathrm{Cb}$ oblaci se takođe razvijaju na prednjoj strani fronta cirkulacije more-kopno. Ova cirkulacija je bila okidač za razvoj mnogih $\mathrm{Cb}$ oblaka. Ove oluje se premeštaju u unutrašnjost ortogonalno na pravac obale, u pravcu u kome se proširuje cirkulacija more-kopno. Tokom putovanja oblaka na jug formiraju se nove ćelije na levoj prednjoj strani i spajaju se sa matičnim oblakom. Ova regeneracija oblaka sa leve strane desava se pod uticajem diferencijalnog zagrevanja. Neki oblaci su bili veoma duboki, sa visinom vrha oblaka do $20 \mathrm{~km}$ i maksimalnom radarskom refleksivnosti preko $75 \mathrm{dBZ}$.

Veoma često putanja oblaka nije pod uticajem strujanja okoline $u$ sredini troposfere. Ovakvi oblaci se kreću veoma nepravilno u odnosu na taj vodeći vetar. Putanja ovih oblaka nije rezultat realnog premeštanja nekog izabranog jezgra oblaka. Ona je uglavnom 
rezultat rasta olujnog oblaka zbog spajanja sa drugim oblakom ili regeneracije sa novim ćelijama. Zbog toga oluja kao sistem ima takve neregularne pozicije u uzastopnih vremenskim intervalima.

Akumulirane padavina iz konvektivnih oblaka su dobijene korišćenjem dva metoda merenja, sa kišomerima i radarima. Uočavaju se velike razlike u količini padavina. One nastaju iz sledećih razloga. Padavine uzete iz mreže kišomernih stanica daju lošu sliku zbog ograničenog broja mernih mesta, zbog velikog međusobnog rastojanja i loše pokrivenosti osmatračkom mrežom. Meteorološki radari imaju značajne nedostatke zbog loše veze Z-R. Pored toga, radarska merenja mnogo precenjuju količine padavina usled isparavanja padavina od nivoa radarskog merenja do tla. Zbog isparavanja mnogo kapi kiše od baze oblaka nikada ne dođu do tla. Ovo isparavanje je posebno izraženo u suvom i toplom području kao je UAE. Ipak, meteorološki radari imaju prednost u korišćenju, jer oni pružaju potpunu prostornu pokrivenost, $\mathrm{i}$ daju podatke sa visokom prostornom i vremenskom rezolucijom. Iz radarske slike padavina može se vrlo precizno naći putanja oblaka. Ovo je naročito korisno u slučajevima sa komplikovanim premeštanjem oblaka.

Rezultati analize padavina dobijenih sa dve metodologije merenja daju nam mogućnost da se zaključi da su obe vrste podataka potrebne za što bolje saznanje o stvarno akumuliranim padavinama na tlu. Ovo je naročito potrebno za različite klimatološke i hidrološke analize i prognoze, kao i za aktivnosti vezane za veštačko povećanje padavina.

KLJUČNE REČI: Oluje; Kondenzaciona jezgra; Akumulirane konvektivne padavine; Mikrofizička merenja; Radarska merenja; Život oblakač; Premeštanje oblaka. 


\section{REFERENCES}

Al Mandoos, A. Al Mangoos, A. R. Bruintjes, S. Piketh, 2006: Rainfall enhancement and air chemistry studies in the United Arab Emirates. In: Achievement in weather modification, Ed. Bojkov, Abu Dhabi, 157-171.

Al Mandoos, A., 2005: Synoptic and atmospheric stability classification for the United Arab Emirates.Master Scince dissertation, Faculty of Science, University of the Witwatersrand, Johannesburg, 95 pp.

AMS, 1992: Planned and inadvertent weather modification. Bull. Amer. Meteor. Soc., 73, 33137.

Baddour, O., M. Benassi and A.A. Ouldbba, 1994: An evaluation trial of the Marocco's "Alghait" weather modification program. Sixth WMO SCWM, Paestum, Italy, 329-332.

Bailey, I.H., 1985: The feasibility of seeding clouds in Western Australia. Fourth WMO SCWM, Honolulu, 407-410.

Berjulev, G.P., L.P. Zatsepina, B.I. Zimin, Yu.. A, Seregin, A.A. Chernikov, and A.B. Shupiatsky, 1985: Methodology and some results of cloud seeding experiments at Penza meteorological experimental site. Fourth WMO SCWM, Honolulu, 529-534.

Berjulev, G.P., A.A. Chernikov, B.G. Danelian, V.I. Khvorostyanov, Yu. A, Seregin, G.R. Torozan, and M.P. Vlasiuk, 1989: An experimental investigation and numerical simulation of the natural and seeded orographic cloud system. Fifth WMO SCWM, Beijing, 243-246.

Bigg, E.K., 1985: Estimating cloud - seeding success in the presence of persistent effects of seeding. Fourth WMO SCWM, Honolulu, 467-472.

Biswas, K.R., and A.S. Dennis, 1972; J. Appl. Meteor., 11, 755.

Boev, P., R. Petrov, P. Konstantinov, and L. Boeva. 1994: An experiment for rainfall enhancement from convective clouds over Thracian Lowland. Sixth WMO SCWM, Paestum, 357-360.

Borland, S. W., 1977: A review of hail science and hail suppression. Meteor. Monogr., 16, AMS, Boston, 155-175.

Buikov, M.V., E.E. Kornienko, B.N. Leskov, S.V. Khusid and A.P. Chyorny, 1985: Results of field experiments on artificial enhancement of precipitation in the Ukraine. Fourth WMO SCWM, Honolulu, 519-524. 
Brown, K.J. and E.M. Tomlinson, 1994: Precipitation augmentation in Greece. Sixth WMO SCWM, Paestum, 387-390.

Bruitjes, R.T., and E.A. Betterton, 1994: The Arizona atmospheric modification program. Sixth WMO SCWM, Paestum, 267-270.

Bruintjes, R.T., R.M. Rasmussen, W. Sukarwanaset, P. Sudhikpses and N. Tantipubthong, 1999: Variations of cloud condensation nuclei $(\mathrm{CCN})$ and aerosol particles over Thailand and the possible impacts on precipitation formation in clouds. Seventh WMO SCWM, Thailand, 33-36.

Chai, Y., Y. Sun, R. Jin, and H. Fu, 1989: Study on moisture distribution in cloud and potential of artificial precipitation. Fifth WMO SCWM, Beijing, 81-84.

Chang-cheng, L., and G. Buyun, 1989: The macroscopic results of artificial rainfall estimated with the radar echo data. Fifth WMO SCWM, Beijing, 547-550.

Charak, MT., 1978: J. Weather Modification, 10, 165.

Chernikov, A., B. Koloskov, Yu. Seregin, and B. Zimin, 1994: Results of experiments on precipitation enhancement from convektive clouds in the Camaguey experimental area, Cuba. Sixth WMO SCWM, Paestum, 361-364.

Cotton, W. R., Brayan, G.A.and van der Hiven S.C., 2011: Storm and cloud dynamics. Academic press, Amsterdam, 809 pp.

Ćurić, M., 1980: Dynamics of cold air outflow from the base of the thunderstorm. J. Rech. Atmos. 14, 493-498.

Ćurić, M.,.and Janc, D. 1992: Mountain influence on the areal characteristics of types of convective precipitation, Theor. Appl. Climatol.,45, 71-76,.

Ćurić, M., D. Janc, 1993a: Dependence of the simulated seeding effects of Cb cloud on the types of the AgI agents. Meteorol. Atmos. Phys., 91-100.

Ćurić, M., D. Janc, 1993b: Predictive capabilities of a one-dimensional convective cloud model with forced lifting and a new entrainment. J. Appl. Meteor., 32, 1733- 1740.

Ćurić, M., D. Janc, 1990: Numerical study of the cloud seeding effects. Meteorol. Atmos. Phys., 145-164.

Ćurić, M., 1989: Numerical modeling of thunderstorm. Theor. Appl. Climatol.,40, 227-235.

Ćurić, M., Janc, D., and Vuckovic, V. 2008: Precipitation change from a Cumulonimbus cloud downwind of a seeded target area, J. Geophys. Res., 113, D11215, doi:10.1029/2007JD009483.

Ćurić, M., Janc, D., and Vuckovic, V. 2009: The influence of merging and individual storm splitting on mesoscale convective system formation. Atmospheric Research, 93, 21-29.

Ćurić, M. , D. Janc, D.Vujović, V. Vučković and N Kovacevic, 2009: The impact of the choice of the entire drop size distribution function on Cumulonimbus characteristics. Meteorologische Zeitschrift, 18, 207-222.

Ćurić, M., Janc, D., Vuckovic, V., 2009: The influence of merging and individual storm splitting on mesoscale convective system formation, Atmos. Res., 93, 21-29. 
Ćurić, M.,. Janc, D. and Veljovic K., 2010: Dependence of accumulated precipitation on cloud drop size distribution. Theor. Appl. Climatol., 102, 471-481.

Ćurić, M., and Jane D. $2011 \mathrm{a}$ : Differential heating influence on hailstorm vortex pair evolution. Q. J. R. Meteorol. Soc. 138: 72-80. DOI:10.1002/qj.918

Ćurić, M., and Janc, D., 2011b: Comparison of modeled and observed accumulated convective precipitation in mountainous and flat land areas, J. Hydrometeorol., 12, 245-261.

Ćurić, M.,and Janc, D., 2011c: Analysis of predicted and observed accumulated convective precipitation in the area with frequent split storms. Hydrol. Earth Syst. Sci., 15, 36513658.

Czys, R.R., S.A. Changnon, N.E. Westcott, M.S. Petersen, and W. Scott, 1993: Evaluation of echo core responses in the 1989 Illinois exploratory cloud seeding experiment using a seedability index. J. Wea. Mod., 25, 12-25.

Dalezios, N.R., S.I. Spanos, N. Papamanolis, and T.W. Krauss, 1996: Climatological and microphysical cloud features towards rain enhancement for agriculture in Greece. J. Wea. Mod., 28, 59-74.

Deshou, X., 1989: Some statistical characteristics of cumulus precipitation in the summer of eastern Hubei. Fifth WMO SCWM, Beijing, 711-716.

Dell'Angelo, A., F. Micale, and R. List, 1994: "Progetto Piogga", The Italian rain enhancement project. Sixth WMO SCWM, Paestum, 11-14.

Dennis, A.S., 1980: Weather modification by cloud seeding. Academic Press, New York, pp. 271

Dennis, A.S., and D.W. Reynolds, 1989: Seeding of shallow orographic clouds in the Sierra cooperative pilot project. Fifth WMO SCWM, Beijing, 155-158.

Deshou, X., and C. Keguang, 1989: Statistical evaluation of using 37 - type anti-aircraft on cumulus rain modification experiment in the mid-summer of southeast Hubei Province. Fifth WMO SCWM, Beijing, 703-710.

Eager, R. E., S. Raman, A. Wootten, D. L. Westphal, J. S. Reid, and A. Al Mandoos 2008: A climatological study of the sea and land breezes in the Arabian Gulf region, J. Geophys. Res., 113, D15106, doi:10.1029/2007JD009710.

Ekba, Ya.A., L.G. Kaplan, M.D. Atabiev, G.Kh. Badakhova, and R.G. Zakinyan, 1994: The artificial enhancement of the liquid precipitation on the North Caucasus. Sixth WMO SCWM, Paestum, 295-296.

Emanuel, K. A., 1994: Atmospheric Convection, Oxford University Press, Oxford, 580 pp.

Erickson, E.J. and L.E. Whitney, 1969:Gravity waves following severe thunderstorms, Mon. Wea. Rev. 101, 708-711.

Farhar, B.C., 1973: J. Weather Modification, 5, 261.

Farhar, B.C., 1975: J. Appl Meteor., 14, 694.

Farley, R.D., P. Nguyen, and H.D. Orville, 1994: Preliminary study of the numerical simulation of cloud seeding using a three-dimensional cloud model. Sixth WMP SCWM, Paestum, 
467-470.

Gagin, A., and J. Neumann, 1981: The second Israeli Randomized cloud seeding experiment: Evaluation of the results. J. Appl. Meteor., 20, 1301-1311.

Griffith, D.A., and M.E. Solak, 1999: A cloud seeding program to enhance hydroelectric power production from the El Cajon Drainage, Honduras. Seventh WMO SCWM, Thailand, 131-134.

Guili, F., 1999: The study of evaluation of cost-effectiveness for Shandong artificial precipitation with wheat yield. Seventh WMO SCWM, Thailand, 169-171.

Hassan, H., and S. Raman (2003), Numerical modeling of coastal circulations near complex topography, Proc. Indian Acad. Sci., 69, 615- 632.

Heimbach, J.A., 1990: Some characteristics of aerally-released AgJ plumes in Alberta. J. Wea. Mod., 22, 133-136,

Henderson, T.J., J.M. Wood, and D.L. Newsom, 1999: Preliminary results from the use of hygroscopic flares for precipitation enhancement in Indonesia during the period 22 April - 30 June 1998. Seventh WMO SCWM, Thailand, 49-52.

Hesheng, Z., 1989: Artificial stimulation of precipitation by anti-aircraft guns. Fifth WMO SCWM, Beijing, 579-582.

Humphreys, W.J., 1914: The thunderstorms and its phenomena, Mon. Wea. Rev.42, 348-380.

Isaac, G.A., 1986: Summer cumulus cloud lifetime- Importance to static mode seeding. AMS Met. Monog.,43, 25-28.

Jijia, Z., 1989: Weather modification in China: Its status quo and prospects. Fifth WMO SCWM, Beijing, 1-4.

Kamalov, B.A., 1999: The ancient methods of water enhancement from the atmosphere and their use. Seventh WMO SCWM, Thailand, 154-156.

Kochtubajda, B., 1989: Aircraft and radar observations of cumulus cloud base seeding experiments in Alberta. Fifth WMO SCWM, Beijing, 163-166.

Koloskov, B.P., Yu.V. Melnichuk, and A. Abbas, 1999: Statistical estimation of cloud seeding operations in Syria (1991-1996). Seventh WMO SCWM, Thailand, 161-164.

Koloskov, B.P. „Korneev V.P., Beryulev G.P, Danelyan B.G., Stasenko V.N., 2011: Cloud seeding activity to modify weather conditions in cities. WMO SCWM, Bali, Indonesia.

Langmuir, I.J., 1948: J. Meteorol., 5, 175.

Lease, J.C., 1985: Estimated effects from cloud seeding in the Colorado river basin. Fourth WMO SCWM, Honolulu, 463-466.

Levin, Z., 2000: Cloud modeling. Programme on physics and chemistry of clouds and weather modification research. WMO/TD- No. 1059.

List, R., 1985: The chances for rain enhancement. Fourth WMO SCWM, Honolulu, 455-460.

Long, A.B., 1989: The Melbourne winter storm cloud seeding experiment for urban water supply augmentation. Fifth WMO SCWM, Beijing, 73-76. 
Lovejoy, S., and D. Schertzer, 2006: Multifractals, cloud radiances and rain. Journal of Hydrology, 322, 59-88.

McCracken, J.G., and J. O'Laughlin, California cloud seeding and Idaho precipitatrion. J. Wea. Mod., 28, 39-49.

Martinez D., Perez C. A., Koloskov, B.P., Korneev V.P., Petrov V.V, Gamboa F. and Novo S., 2007: Randomized Convective Cold Cloud Seeding Experiment in Extended Areas in Cuba (EXPAREX).Ninth WMO SCWM Antalya, Turkey.

Mason, B.J., 1971: The physics of clouds, Oxford Univ. Press, 671 pp.

Meyers, M.P., P.J. DeMott, and W.R. Cotton, 1994: A comparison of seeded and non-seeded orographic cloud simulations with an explicit cloud model. Sixth WMO SCWM, Paestum, 519-522.

Nozyce, H., and D. Rosenfeld, 1994: Seeding effects in Israel stratified by cloud top temperature and by desert dust. Sixth WMO SCWM, Paestum, 577-580.

Orville, H.D., 1990: The uses of cloud models in weather modification. J. Wea. Mod., 22, 137142.

Petrov, R., Ch. Dimitrov, and K. Slavov, 1994: Automated radar system for a convective cloud seeding project. Sixt WMO SCWM, Paestum, 451-454.

Pflaum, J.C., H.L. Johnson, and M.R. Poellot, 1989: Preliminary investigations of a dynamic seeding strategy for Oklahoma convective clouds. J. Wea. Mod., 21, 54-61.

Pirnach, A., 1999: Numerical simulation of seeded and non-seeded convective cells embedded in frontal rainbands. Seventh WMO SCWM, Thailand, 287-291.

Prudhomme, C., and D.W. Reed, 1999: Mapping extreme rainfall in a mountainous region using geostatistical techniques: a case study in Scotland. International Journal of Climatology, 19(12), 1337-1356.

Reid, J. S... Al Mandoos, et al. 2008: An overview of UAE2 flight operations: Observations of summertime atmospheric thermodynamic and aerosol profiles of the southern Arabian Gulf, J. Geophys. Res., 113, D14213, doi:10.1029/2007JD009435.

Reid, J. S., E. A. Reid, A. Walker, S. Piketh, S. Cliff, A. Al Mandoos, S.-C. Tsay, and T. F. Eck 2008, Dynamics of southwest Asian dust particle size characteristics with implications for global dust research, J. Geophys. Res., 113, D14212,doi:10.1029/2007JD009752.

Scofield, R.A., and R.J. Kuligowski, 2003: Status and outlook of operational satellite precipitation algorithms for extreme-precipitation events. Weather and Forecasting,18, 1037-1051.

Silverman, B.A., D. Rosenfeld, W. Sukarwanaset, and R. Talumassawatdi, 1999: The Thailand warm cloud seeding experiment: 2. Results of the statistical evaluation. Seventh WMO SCWM, Thailand, 9-12.

Sinkevich A., W. Krauss, and S. Ghulam, 2011: Radar Investigation of AgI Seeding Efficiency in the Kingdom of Saudi Arabia, WMO SCWM, Bali, Indonesia.

Siriluk C. and W. Bunthai, 2011:Testing Efficacy of Rainmaking Activities in the Northeast of 
Thailand, WMO SCWM, Bali, Indonesia

Steiner, J.T., and D.E. Shaw, 1985: The possibility of rainfall modification in Canterbury, New Zealand. Fourth WMO SCWM, Honolulu, 411-414.

Super, A.B., and E.W. Holroyd, 1994: Estimation of effective AgI ice nuclei by two methods compared with measured ice particle concentrations in seeded orographic clouds. J. Wea. Mod., 26, 33-40.

Suracul, S., S. Warit, W. Khantiyanin, and B.A. Silverman, 1989: The Thailand applied atmospheric resources research program. Fifth WMO SCWM, Beijing, 567-570.

Svanidze, G.G., N.A. Begalishvili, M.P. Vatyan, A.A. Kusnetsov, V.P. Kurbatkin, G.Z. Rakhman-Zada, and V. Ph. Ushintseva, 1985: Results of experiments on precipitation artificial enhancement in mountain regions. Fourth WMO SCWM, Honolulu, 525-528.

Sukarwanaset, W., 1999: The applied atmospheric resources research program (AARRP) of Thailand. Seventh WMO SCWM, Thailand, 1-4.

Terblanshe, D.E., 1999: Rainfall enhancement research and operations in South Africa: Past, present and Future. Seventh WMO SCWM, Thailand, 37-40.

Tessendorf, S.A., et. al., 2010: Overview of the Queensland Cloud Seeding Research Program. J. Wea. Modification, 42, 33-48.

Vardiman, L., and J.A. Moore, 1977: Skywater Monograph, No. 1, Appendix, Bureau of Reclamation, Denver, 91 pp.

Vento, D., S. Esposito, and M.C. Serra, 1994: On the control of a rain enhancement experiment in southern Italy. Sixth WMO SCWM, Paestum, 35-38.

Vonnegut, B.J., 1947: J. Appl. Phys., 18, 593.

Warner, T. T., and R.-S. Sheu (2000), Multiscale local forcing of the Arabian

Desert daytime boundary layer, and implications for the dispersion of surface-released contaminants, J. Appl. Meteorol., 39, 686-707.

Woodly, W.L., D. Rosenfeld, W. Sukarwanaset, P. Sudhikoses, S. Ruangsuttinaruparp, and W. Khantiyanan, 1999:The Tailand cold-cloud seeding experiment. Seventh WMO SCWM, Thailand, 21-24.

Young, C.B., B.R. Nelson, A.A. Bradley, J.A. Smith, C.D.Peters-Lilard, A. Kruger, and M.L. Baeck, 1999: An evaluation of NEXRAD precipitation estimates in complex terrain. Journal of Geophysical Research, 104, 19691-19703.

Woodly, W.L., and M.E. Solak, 1990: Results of operational seeding over the watershed of San Angelo, Texas. J. Wea. Mod., 22, 30-42.

Zhaomao, J., and G. Ziyi, 1999: The statistical analysis of artificial snow augmentation effect on freeze injury on the winter wheat. Seventh WMO SCWM, Thailand, 176-178.

Zhu, M., and B. W. Atkinson 2004: Observed and modelled climatology of the land-sea breeze circulation over the Persian Gulf, Int. J. Climatol.,24, 883- 905. 


\section{BIOGRAPHY}

The name Abdulla Al Mandoos

Nationality United Arab Emirates

Birthday November $16^{\text {th }} 1966$

Education: $\quad$ Completed Secondary school in the UAE Rashid 1984

Graduated in Aeronautical Meteorology, St. Louis University, Missouri, USA 1989.

Advance forecasting at Meteorological service of Great Britain 1994.

Meteorology, level I, Meteorology Department in Cairo, 1997.

Master's degree at the University Witwaterstrand, Johannesburg, 2005. with the theme: Classification of types of stability and synoptic situation over

UAE.

Training \& courses Advanced training for officers in the Air Force, 1993.

Probing System, 1993.

Aeronautical meteorological stations, 1996.

Meteorological Satellite ground system, 1998.

Modern weather radars, 1998.

Software for weather radars, 1999.

Integrated Meteorological Systems, 1999.

Automatic weather station, 2001.

Course in computers, 2000.

Seminar in aeronautical meteorology and dangerous meteorological phenomena, 2001.

Weather stations and integrated system, 2001.

Professionally experience

Meteorologist forecaster, 1990-1998.

Senior meteorological forecaster 1998-2000.

Head of maintenance, meteorology and navigation systems, 1999-2000.

Head of the Meteorological Department at the Department of Water Studies, 2000-2005.

Director of the Department of Atmospheric Studies, since 2005.

Director of National Centre for Meteorology and Seismology.

Lider of project stimulation of precipitation in the UAE.

Participated in many international meteorological conference.

Author of several scientific papers in reviewed international journals, monographs and proceedings of international conferences. 


\section{BIOGRAFIJA}

Ime Abdula Almanduš (Abdulla Al Mandoos)

Nacionalnost Ujedinjenih Arapskih Emirata

Datum rođenja 16. novembar 1966.

Školovanje: Z Z Završio srednju školu Rashid u UAE 1984.

Diplomirao Vazduhoplovnu meteorologiju na St. Louis Univerzitetu, Misuri, SAD 1989.

Viši kurs za sinoptičara u Meteorološkoj službi Velike Britanije, 1994.

Meteorologija, nivo I, Meteorološki odsek u Kairu, 1997.

Magistrirao na Univerzitetu Witwaterstrand, Johanesburg, 2005. sa temom:

Klasifikacija tipova stabilnosti i sinoptičkih situacija iznad UAE.

Završeni kursevi Viši kurs za oficire u vazduhoplovstvu, 1993.

Sondažni sistem, 1993.

Vazduhoplovne meteorološke stanice, 1996.

Prijemni sistemi meteoroloških satelita, 1998.

Savremeni meteorološki radari, 1998.

Softver za meteorološke radare, 1999.

Integralni meteorološki sistemi, 1999.

Automatske meteorološke stanice, 2001.

Kurs iz računara, 2000.

Seminar iz vazduhoplovne meteorologije i opasnih meteoroloških fenomena, 2001.

Meteorološke stanice i integrisani sistem, 2001.

Profesionalno iskustvo

Meteorolog prognostičar, 1990-1998.

Stariji meteorolog prognostičar, 1998- 2000.

Šef održavanja, meteorologije i navigacionih sistema, 1999-2000.

Šef meteorološkog odeljenja pri Odeljenju za vodne studije, 2000-2005.

Direktor Odeljenja za atmosferske studije, od 2005.god.

Direktor Nacionalnog centra za meteorologiju i seizmologiju.

Rukovodi projektom Stimulisanja padavina u UAE.

Učesnik je velikog broja međunarodnih meteoroloških konferencija.

Autor je više naučnih radova u istaknutim medjunarodnim časopisima, monografijama i Zbornicima međunarodnih konferencija. 


\title{
Prilog 1.
}

\section{Izjava o autorstvu}

Potpisani Abdulla A.Y. Al Mandoos

broj upisa 24/V/2006

\author{
Izjavljujem
}

da je doktorska disertacija pod naslovom

ANALIZA KARAKTERISTIKA KUMULONIMBUSNIH OBLAKA I EFIKASNOSTI STIMULISANJA PADAVINA IZNAD ISTOČNIH OBLASTI UAE

- rezultat sopstvenog istraživačkog rada,

- da predložena disertacija u celini ni u delovima nije bila predložena za dobijanje bilo koje diplome prema studijskim programima drugih visokoškolskih ustanova,

- da su rezultati korektno navedeni i

- da nisam kršio/la autorska prava i koristio intelektualnu svojinu drugih lica.

\section{Potpis doktoranta}

U Beogradu, 23. V 2012.

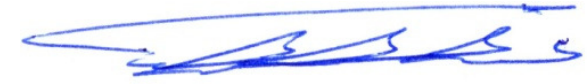




\section{Prilog 2.}

\section{Izjava o istovetnosti štampane i elektronske verzije doktorskog rada}

Ime i prezime autora Mr Abdulla A.Y. Al Mandoos

Broj upisa 24/V/2006

Studijski program Meteorologija

Naslov rada ANALIZA KARAKTERISTIKA KUMULONIMBUSNIH OBLAKA I EFIKASNOSTI STIMULISANJA PADAVINA IZNAD ISTOČNIH OBLASTI UAE

Mentor Prof. Mlađen Ćurić

Potpisani Abdulla A.Y. Al Mandoos

izjavljujem da je štampana verzija mog doktorskog rada istovetna elektronskoj verziji koju sam predao/la za objavljivanje na portalu Digitalnog repozitorijuma Univerziteta u Beogradu.

Dozvoljavam da se objave moji lični podaci vezani za dobijanje akademskog zvanja doktora nauka, kao što su ime i prezime, godina i mesto rođenja i datum odbrane rada.

Ovi lični podaci mogu se objaviti na mrežnim stranicama digitalne biblioteke, u elektronskom katalogu i u publikacijama Univerziteta u Beogradu.

U Beogradu, 23. V 2012.

\section{Potpis doktoranta}

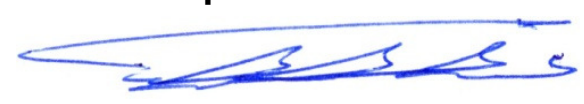




\section{Prilog 3.}

\section{Izjava o korišćenju}

Ovlašćujem Univerzitetsku biblioteku „Svetozar Marković“ da u Digitalni repozitorijum Univerziteta u Beogradu unese moju doktorsku disertaciju pod naslovom:

ANALIZA KARAKTERISTIKA KUMULONIMBUSNIH OBLAKA I EFIKASNOSTI STIMULISANJA PADAVINA IZNAD ISTOČNIH OBLASTI UAE

koja je moje autorsko delo.

Disertaciju sa svim prilozima predao/la sam u elektronskom formatu pogodnom za trajno arhiviranje.

Moju doktorsku disertaciju pohranjenu u Digitalni repozitorijum Univerziteta u Beogradu mogu da koriste svi koji poštuju odredbe sadržane u odabranom tipu licence Kreativne zajednice (Creative Commons) za koju sam se odlučio/la.

1. Autorstvo

2. Autorstvo - nekomercijalno

(3.) Autorstvo - nekomercijalno - bez prerade

4. Autorstvo - nekomercijalno - deliti pod istim uslovima

5. Autorstvo - bez prerade

6. Autorstvo - deliti pod istim uslovima

(Molimo da zaokružite samo jednu od šest ponuđenih licenci, kratak opis licenci dat je na poleđini lista).

U Beogradu, 23. V 2012.

\section{Potpis doktoranta}

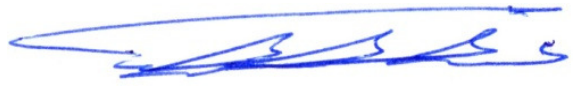

